\title{
MÉTODOS \\ CUALITATIVOS PARA \\ ESTUDIAR A LOS \\ USUARIOS DE LA \\ INFORMACIÓN
}

COORDINADORA

Patricia Hernández Salazar

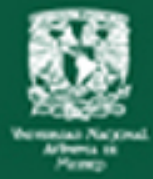

CUADERNOS DE INVESTIGACIÓN 5 
La presente obra está bajo una licencia de:

http://creativecommons.org/licenses/by-ncsa/3.0/deed.es MX

\section{(c) cointive}

Eres libre de:

(15)

copiar, distribuir y comunicar públicamente la obra

(D) hacer obras derivadas

Bajo las condiciones siguientes:

Atribución - Debes reconocer la autoría de la obra en los términos

especificados por el propio autor o licenciante.

No comercial - No puedes utilizar esta obra para fines comerciales.

Licenciamiento Reciproco - Si alteras, transformas o creas una obra a

partir de esta obra, solo podrás distribuir la obra resultante bajo una licencia igual a ésta.

Esto es un resumen fácilmente legible del: texto legal (de la licencia completa)

\section{En los casos que sea usada la presente obra, deben respetarse los términos especificados en esta licencia.}
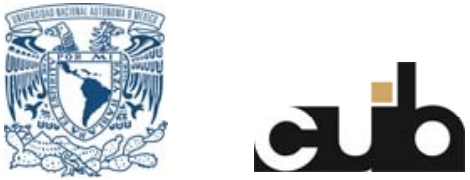
Métodos cualitativos para estudiar a los usuarios de la información 
COLECCIÓN

Cuadernos de Investigación 5

Centro Universitario de Investigaciones Bibliotecológicas 


\title{
Métodos cualitativos para estudiar a los usuarios de la información
}

\author{
Coordinadora \\ Patricia Hernández Salazar \\ Participantes \\ Carlos Fernando Cortés Gómez \\ Ana Cecilia Balboa \\ Ricardo Montes Gómez \\ Blanca Estela Solís Valdespino
}

Universidad Nacional Autónoma de México 2008 
Z678.88

H4 Hernández Salazar, Patricia

Métodos cualitativos para estudiar a los usuarios de la información / Patricia Hernández Salazar. - México : UNAM, Centro Universitario de Investigaciones Bibliotecológicas, 2008.

xvii, 212 p. - (Cuadernos de Investigación)

ISBN: 978-607-02-0768-6

1.Métodos cualitativos. 2. Estudios de usuarios 3. Usuarios de la información I. t. II. ser.

\section{Diseño de portada: Mario Ocampo Chávez}

Primera Edición, 2008

DR (C) UnIVERsidad NACIONAL AUtónOMa DE MÉXICO

Ciudad Universitaria, 04510, México, D.F.

Impreso y hecho en México

ISBN: 978-607-02-0768-6 


\section{Contenido}

INTRODUCCIÓN . . . . . . . . . . . . . . . . . . . . ix

UTILIZACIÓN DE MÉTODOS CUALITATIVOS PARA REALIZAR ESTUDIOS DE USUARIOS

Patricia Hernández Salazar

Estudios de usuarios. . . . . . . . . . . . . 1

Objetivos •................

Panorama sobre los métodos y las técnicas utilizadas para realizar estudios de usuarios . . . . . . 6

Análisis comparativo. . . . . . . . . . . . 13

Métodos cualitativos . . . . . . . . . . 17

LA TÉCNICA DEL FOCUS GROUP PARA DETERMINAR EL DISEÑO DE EXPERIENCIAS DE FORMACIÓN

DE USUARIOS

Carlos Fernando Cortés Gómez

Introducción . . . . . . . . . . . . 33

Focus group . . . . . . . . . . . . • 36

Descripción del proceso. . . . . . . . . . 37

Desarrollo del estudio . . . . . . . . . . . . 41

Resultados y conclusiones $\cdot \cdots \cdot \cdots 56$ 
EL INCIDENTE CRÍTICO COMO TÉCNICA PARA

RECOLECTAR DATOS

Ana Cecilia Balboa

Introducción . . . . . . . . . . . . 61

Definición del incidente crítico. . . . . . . . 63

Antecedentes . . . . . . . . . . . 66

Proceso para obtener incidentes críticos $\cdot \cdot \cdot \cdot 69$

El procedimiento de la entrevista y la

recolección de datos.$\cdots \cdot \ldots 72$

Análisis y validación de los datos • • . . . . • 76

Aplicaciones . . . . . . . . . . . 77

El uso de la técnica del incidente crítico

en bibliotecas . . . . . . . . . . . . . . 80

Descripción de la aplicación . . . . . . . . 84

Interpretación de reportes o resultados • . • • • 99

\section{LA BIBLIOTECA COMO SISTEMA AUTORREFERENTE \\ Ricardo Montes Gómez}

Introducción . . . . . . . . . . . . 113

Identificación del sistema y su función

en el entorno. $\cdot \cdots \cdot \ldots 19$

Autorreferencia del sistema $\cdot \cdots \cdot \cdots$

Modelación sistémica . . . . . . . . . • 143

Conclusión.. . . . . . . . . . . . 163 
LA TÉCNICA DEL ANÁLISIS DE CONTENIDO Y SU APLICACIÓN EN LOS PLANES DE ESTUdIO DE BIBLIOTECOLOGía EN MÉXICO, PARA

DETERMINAR LA PRESENCIA DE LA FORMACIÓN DE USUARIOS

Blanca Estela Solís Valdespino

Introducción . . . . . . . . . . . . 167

La técnica del análisis de contenido $\cdots 169$

El concepto del análisis de contenido $\cdot . \cdot \cdots 170$

Etapas para realizar un análisis de contenido $\cdot \cdots 175$

Aplicación de la técnica análisis de contenido

en los planes de estudio de bibliotecología

en México. . . . . . . . . . . . . . . . . . . . 185

Proyecto . . . . . . . . . . . . . 185

Ejecución. . . . . . . . . . . . . . 192

Informe de resultados . . . . . . . . . . 194

Análisis comparativo entre las categorías $\cdot \cdots 200$

Inferencias . . . . . . . . . . . . 201

Escuela Nacional de Biblioteconomía y

Archivonomía . . . . . . . . . . . • 201

Colegio de Bibliotecología $\cdots 205$

Escuela de Bibliotecología e Información • • • • 207

Perfiles de egreso versus valores obtenidos • • • 209 



\section{Introducción}

Ta producción y el uso intensivo de las tecnologías de información y comunicación (TIC) a nivel mundial, han llevado a las disciplinas bibliotecológicas y de la información a redirigir su investigación hacia el usuario. Si bien el tema de usuarios siempre ha formado parte del discurso bibliotecológico, por considerarlo el principio y fin del ciclo de la producción de la información, no es sino hasta la década de los ochenta del siglo pasado cuando se empieza a abordar este fenómeno de manera sistemática y consistente.

Los acercamientos al tema han generado diversos subcampos: usuarios (definición, tipología); comunidades de usuarios; necesidades de información; comportamiento durante la búsqueda; satisfacción; actitud; formación de usuarios; y estudios de usuarios, entre otros. 
La técnica del análisis de contenido y su aplicación en los ...

En las décadas de los años ochenta, noventa y lo que va de la presente, la formación de usuarios ha sido retomada con mucho interés debido a la creciente preocupación de que los nuevos recursos tecnológicos sean explotados adecuadamente.

Sin embargo cabe preguntarse ¿es necesario identificar las características sobre los usuarios antes de diseñar experiencias de formación, o sobre cualquier otro servicio que se desee ofrecer? La respuesta definitiva es sí, lo que nos remite a retomar el subcampo de estudios sobre usuarios, ya que se convierte en el paso previo y en un requisito indispensable para diseñar, planear o mejorar cualquier servicio (incluidos los programas de formación de usuarios), herramienta o unidad de información.

Los estudios de usuarios han interesado a la comunidad bibliotecológica desde principios del siglo $\mathrm{XX}$, sin embargo, su desarrollo no ha sido el esperado, lo que se sustenta con los siguientes ejemplos:

- La producción sobre el tema es escasa.

- Existen estudios que identifican las necesidades de información sobre los usuarios y su comportamiento para cubrir esas necesidades, pero que no llegan a medir su satisfacción y su actitud.

- La metodología usada ha sido la que siguen las ciencias naturales, básicamente la tendencia cuantitativa, pero no se ha comprobado la viabilidad de ésta. Se deja de lado el hecho de que 
nuestro objeto de estudio es un sujeto, y de que sus características pueden variar de acuerdo con el momento y el contexto en el que se hagan los estudios.

- La utilización de métodos cualitativos para realizar estudios de usuarios es pobre.

Para hacer aportes al desarrollo del fenómeno estudios de usuarios, la presente obra Métodos cualitativos para estudiar a los usuarios de la información, incluye los trabajos de investigación que llevan a cabo los alumnos de maestría del Programa de Posgrado en Bibliotecología y Estudios de la Información, del cual es corresponsable el Centro Universitario de Investigaciones Bibliotecológicas. En esta se abordan los aspectos arriba listados poniendo especial énfasis en el uso de métodos cualitativos. $\mathrm{La}$ intención es probar tres ideas principales: 1) que la tendencia cualitativa permite acercarse a grupos de usuarios y describir sus características en un contexto real; 2) que los resultados que se obtienen permiten resolver problemas de actitud; y 3) que los resultados permiten diseñar y planear los servicios de acuerdo con los rasgos particulares de cada grupo.

En el primer capítulo "Utilización de métodos cualitativos para realizar estudios de usuarios”, $\mathrm{Pa}$ tricia Hernández Salazar presenta un marco conceptual de los términos y frases que aparecerán en todo el libro: definición y objetivos de los estudios 
La técnica del análisis de contenido y su aplicación en los ...

de usuarios; características de la metodología cualitativa; descripción de algunos métodos o técnicas cualitativas; y definición y formas de obtener validez y fiabilidad en los estudios sobre usuarios.

Asimismo ofrece un panorama sobre los métodos y las técnicas utilizadas para realizar estudios de usuarios, mediante la obtención y el análisis de los registros que sobre el tema incluyen cuatro herramientas de recuperación de información: dos índices internacionales, Library Literature y Library and Information Science Abstract (LISA); uno regional, Información Bibliográfica y Latinoamericana (INFOBILA); y un catálogo del acervo más importante que existe en el área bibliotecológica y de ciencias de la información en América Latina, el del Centro Universitario de Investigaciones Bibliotecológicas perteneciente a la Universidad Nacional Autónoma de México. Se revisaron en total 231 registros, y los datos que se examinaron fueron: el método o técnica utilizados, el objetivo del estudio y el año de publicación agrupado por décadas.

Los tres capítulos que siguen representan estudios de usuarios en los que se aplicó una técnica o método cualitativo. Cada capítulo cubre cuatro puntos principales, la definición del método o técnica; la descripción del proceso; el desarrollo del estudio y los resultados y conclusiones. 
El segundo capítulo "La técnica del Focus Group para determinar el diseño de experiencias de formación de usuarios" fue escrito por Carlos Fernando Cortés Gómez. En él se describe un estudio de la comunidad de alumnos de la Universidad de Tarapacá en Chile cuyo objetivo primordial fue vincular la formación de usuarios con el paradigma educativo de la institución. Para ello se aplicó la técnica del focus group, con el fin de conocer las actitudes, experiencias y sentimientos de los alumnos en relación con el modo en que la biblioteca de la Universidad debe formar a sus estudiantes en lo que toca al fomento y desarrollo de habilidades informativas. Este estudio representa un ejemplo de cómo lograr el adecuado diseño de un programa de formación para alumnos de instituciones de educación superior.

Ana Cecilia Balboa desarrolla el capítulo 3 "El incidente crítico como técnica para recolectar datos". Balboa define la técnica, y presenta sus antecedentes y sus aplicaciones en bibliotecas. Incluye varios apartados en los que describe paso a paso el proceso para realizar incidentes críticos, dándole especial énfasis a la sección "El procedimiento de la entrevista y la recolección de datos", ya que el instrumento que se utilizó para recolectar los datos fue precisamente la entrevista. 
La técnica del análisis de contenido y su aplicación en los ...

El objetivo de la aplicación de esta técnica fue evaluar la comunicación interpersonal que se da entre el bibliotecario y el usuario durante la entrevista de referencia. La población de estudio fue la comunidad de estudiantes de bibliotecas académicas y la muestra estuvo representada por las bibliotecas de cinco instituciones de educación superior privadas: tres universidades, la Iberoamericana, la Anáhuac y la Salle; y dos institutos, el Instituto Tecnológico Autónomo de México (ITAM), y el Tecnológico de Monterrey, campus Estado de México. Este estudio permitió determinar la actitud del usuario hacia los especialistas de información, aspecto que ha sido poco tratado en la literatura bibliotecológica.

En el capítulo 4 "La biblioteca como sistema autorreferente", Ricardo Montes Gómez elabora un modelo teórico sobre la previsión de las necesidades de información de comunidades de bibliotecas parlamentarias, para lo cual emplea un método de tendencia sistémica poco utilizado en bibliotecología, la teoría de sistemas autorreferentes de Luhman (1991). Esta teoría considera a la biblioteca como un sistema social autorreferente; es decir, que se refiere a sí mismo al construir sus elementos y operaciones elementales, y que posee dos características fundamentales: la autoorganización (construcción de estructuras propias dentro del sistema) 
y la autopoiésis (determinación del estado siguiente del sistema).

A partir de esta teoría, el autor genera el Modelo genérico de previsión de información, cuyo objetivo es adelantarse a la formulación de las necesidades de los usuarios (parlamentarios) y poder así proveer la información y los servicios que éstos requieran. Montes aporta la definición de varios términos: biblioteca parlamentaria; autorreferencia; modelo; y necesidades de información. Este capítulo cubre la prevención de las necesidades de información y la planificación de los servicios de información prospectivos.

El último capítulo, "La técnica del análisis de contenido y su aplicación en los planes de estudio de bibliotecología en México, para determinar la presencia de la formación de usuarios", cuya autoría es de Blanca Estela Solís Valdespino, no es un estudio de usuarios propiamente dicho, su inclusión aquí se justifica porque esta investigación utilizó la técnica cualitativa de análisis de contenido para analizar los planes de estudio de algunas escuelas que imparten las licenciaturas de bibliotecología a nivel nacional, y para encontrar aprendizajes relacionados con la formación de usuarios. Esta técnica es una de las más usadas en varias disciplinas y por ello se consideró relevante tener un acercamiento a ella con esta aplicación. 
La técnica del análisis de contenido y su aplicación en los ...

Se delimita el concepto de análisis de contenido y se describe el proceso para realizarlo según su creador Klaus Krippendorff (1990). Dentro de este proceso resaltan las etapas de generación de categorías y de inferencias, aspectos que son ampliamente explicados.

Para la aplicación de la técnica, Solís Valdespino tomó como universo de análisis los planes de estudio de las licenciaturas de tres escuelas mexicanas: el Colegio de Bibliotecología de la Facultad de Filosofía y Letras de la Universidad Nacional Autónoma de México; la Escuela Nacional de Biblioteconomía y Archivonomía y la Escuela de Bibliotecología e Información de la Universidad Autónoma de San Luis Potosí. Las unidades de análisis fueron los programas de 12 asignaturas relacionadas con servicios al público, y de cada asignatura se analizaron varios elementos: el objetivo de la asignatura; los contenidos programáticos; las estrategias de aprendizaje; y las bibliografía básica y complementaria. Los resultados apuntaron a que existe la necesidad de incluir mayor cantidad de contenidos en la elaboración de programas de formación de usuarios.

El desarrollo de estos cinco capítulos permitió lograr los tres objetivos planteados al principio, y nos ayuda a percibir la posibilidad de seguir la metodología cualitativa en la bibliotecología, particular- 
Introducción

mente para investigar sobre el fenómeno denominado estudios de usuarios.

Va el agradecimiento a los autores de cada capítulo por sus contribuciones al presente trabajo, y la esperanza de que esta obra promueva el uso de métodos de investigación cualitativa para mejorar los estudios de usuarios.

Patricia Hernández Salazar 


\title{
Utilización de métodos cualitativos para realizar estudios de usuarios
}

\author{
PATRICIA HERNÁNDEZ SALAZAR
}

\begin{abstract}
G 1 interés por el área de estudios de usuarios ha Cido en aumento en las últimas décadas y cada vez encontramos más recursos que hablan sobre este tema en la literatura bibliotecológica, desafortunadamente la mayoría de estos documentos no incluyen definiciones que permitan responder a preguntas tales como: ¿qué son los estudios de usuarios? ¿cuáles son sus objetivos? ¿qué métodos y técnicas son los más utilizados? ¿se han seguido métodos y/o técnicas cualitativas? ¿qué son los métodos cualitativos?

Este documento pretende dar respuestas a los cuestionamientos arriba planteados.
\end{abstract}

\section{Estudios de usuarios}

El significado de ciertas frases es tan claro que suponemos que no es necesario dar una definición puntual, tal es el caso con los estudios de usuarios; sin 
Métodos cualitativos para estudiar a los usuarios de ...

embargo, la consolidación de una disciplina y su ejercicio profesional generan estructuras conceptuales que permiten conformar comunidades epistémicas que se expresan, en la medida de lo posible, con un lenguaje unívoco. Por eso se hace necesario delimitar el significado de los estudios de usuarios.

Empecemos por definir la palabra estudios, cuyo singular estudio significa según el diccionario, la "Acción de estudiar", lo cual no resulta muy esclarecedor por lo que ofrecemos esta acepción:

Aplicar la inteligencia a aprender o comprender algo [...] Pensar insistentemente sobre un asunto para resolver sobre él [...] Buscar la solución de algo. (Moliner, 1998, p. 1236).

De acuerdo con esta definición nosotros deberemos comprender a los usuarios para poder resolverles sus requerimientos, o solucionarles los problemas que tengan con la información.

Ahora bien, ¿cómo los comprendemos? pues percibiendo e identificando sus características, lo cual nos lleva a decir que los estudios de usuarios son un área multidisciplinaria que analiza fenómenos referidos a la relación información-usuario. (Hernández, 2006, p. 215) Esta comprensión derivará de examinar todas las cuestiones relacionadas con la unión de dos fenómenos básicos de las disciplinas bibliotecológica y de ciencias de la información: el usuario y la información. No es el usuario 
Utilización de métodos cualitativos para realizar estudios ...

por un lado y la información por el otro, resalta el hecho que deben ir unidos (en el caso de la definición con un guión).

\section{Objetivos}

Ya tenemos lo que es la esencia de los estudios de usuarios, lo que éstos son; ahora debemos precisar su función, su "para qué". Su objetivo general es:

[...] determinar la posición del usuario con respecto al flujo de información, desde su creación hasta que la incorpora a su acervo cognoscitivo. (Hernảndez, 2006, p. 215).

Este objetivo nos ubica en el ciclo de producción de conocimiento desde el momento en el que el usuario identifica una brecha o carencia en su acervo de conocimientos y quiere cubrirla, hasta que la cubre y crea o recrea nuevo conocimiento. Durante este ciclo el usuario se hace ciertas preguntas, las cuales deben ser respondidas por los especialistas de la información a partir de realizar estudios de usuarios; las preguntas que se hace son:

\begin{tabular}{||l|l||}
\hline \multicolumn{1}{|c|}{ Usuario } & \multicolumn{1}{c|}{ Estudios } \\
\hline ¿Qué necesito? & Necesidades de información \\
\hline ¿Cómo obtengo lo que necesito? & $\begin{array}{l}\text { Comportamiento durante la } \\
\text { búsqueda de información }\end{array}$ \\
\hline ¿Qué recursos debo usar? & Necesidades de información \\
\hline
\end{tabular}


Métodos cualitativos para estudiar a los usuarios de ...

\begin{tabular}{||l|l||}
\hline ¿Cómo debo usar los recursos? & $\begin{array}{l}\text { Comportamiento en la búsque- } \\
\text { da de información }\end{array}$ \\
\hline $\begin{array}{l}\text { ¿Obtuve la información que ne- } \\
\text { cesitaba? }\end{array}$ & Satisfacción del usuario \\
\hline $\begin{array}{l}\text { ¿Cómo me siento ante los biblio- } \\
\text { tecarios y las unidades de infor- } \\
\text { mación? }\end{array}$ & Actitud \\
\hline
\end{tabular}

De la respuesta a las preguntas del usuario podremos derivar los objetivos específicos de los estudios de usuarios:

1. Detectar las necesidades de información. Entendiendo que una necesidad de información es una condición de carencia en la cual un sujeto requiere cierta información para cubrir esa carencia y lograr un propósito de uso genuino o verdadero. Así, este tipo de estudios establece, entre otros datos, las características de las fuentes primarias a las que recurre una comunidad de usuarios (Hernández, 2006).

2. Identificar el comportamiento del usuario durante la búsqueda de información. El comportamiento en la búsqueda es la actividad o conjunto de actividades que realiza un sujeto para obtener la fuente que satisfaga su necesidad de información. De este tipo de estudio se derivan las necesidades de formación, las cuales proveen los datos para elaborar programas de formación de usuarios, los datos que se detectan están relacio- 
Utilización de métodos cualitativos para realizar estudios ...

nados con el uso de las fuentes secundarias y terciarias, es decir, herramientas de recuperación de información (Hernández, 2006).

3. Evaluar la satisfacción del usuario. Para medir la satisfacción es imprescindible haber realizado estudios sobre las necesidades de información y de comportamiento durante la búsqueda, de tal manera que si hacemos una comparación entre las colecciones que poseemos y los servicios que ofrecemos, y lo que requiere y hace el usuario, tendremos una primera evaluación de su satisfacción. Se recaba información sobre las colecciones; los servicios; las instalaciones; el equipo, y el mobiliario.

4. Determinar la actitud del usuario hacia la unidad o especialista de la información. Las colecciones, el servicio y en general el trato que les hemos dado a nuestras comunidades de usuarios crean una forma de respondernos, un comportamiento y una opinión; precisar lo que piensan acerca de las unidades, los servicios y los especialistas de la información nos llevará a comprenderlos mejor. Los estudios de actitud tienen una relación estrecha con los de satisfacción, un usuario satisfecho tendrá una actitud positiva. 
Métodos cualitativos para estudiar a los usuarios de ...

\section{Panorama sobre los métodos y las técnicas utilizadas para realizar estudios de usuarios}

Existe la idea generalizada de que la mayoría de estudios de usuarios efectuados han utilizado métodos y técnicas cuantitativas, idea que nosotros compartimos.

Para sostener esta afirmación se hicieron búsquedas en varias herramientas de recuperación y se consultaron tres bases de datos y un catálogo. Las bases de datos fueron los siguientes índices y resúmenes: Library Literature; Library and Information Science Abstract (LISA); y la Base de datos Información Bibliográfica y Latinoamericana (INFOBILA). El catálogo fue el del Centro Universitario de Investigaciones Bibliotecológicas (CUIB), de la Universidad Nacional Autónoma de México.

Library Literature, y LISA tienen una cobertura internacional, mientras que INFOBILA cubre la producción de América Latina. En cuanto al catálogo del CUIB, es ésta una herramienta nacional; sin embargo, es importante mencionar que el Centro posee el acervo más completo que existe en América Latina, y que sus líneas de investigación abordan en forma exhaustiva casi la totalidad de los campos fenoménicos de la bibliotecología, las ciencias de la información, y disciplinas afines. 
Utilización de métodos cualitativos para realizar estudios ...

Los descriptores utilizados para diseñar las estrategias de búsqueda fueron: estudios de usuarios y estudios de usuarios / métodos y/o técnicas, con sus respectivas traducciones al inglés. Se intentó hacer una búsqueda bajo los términos estudios de usuarios I métodos y/o técnicas cualitativos, sin embargo este último descriptor no existe en las fuentes consultadas. Cabe aclarar que se hicieron búsquedas en la base de datos Library, Information Science \& Technology Abstracts (LISTA), pero los resultados fueron tan escasos que fue preferible no considerarlos en el presente análisis.

Por cada registro recuperado se analizaron tres aspectos: el método y/o técnica utilizados; los objetivos que perseguían; y la fecha de publicación por décadas. A continuación se presentan los resultados obtenidos por cada herramienta, y luego en forma comparativa.

\section{Library Literature}

La búsqueda en esta base nos arrojó que sólo 63 registros tenían como descriptor user studies, la estrategia con user studies y methods no se hizo porque el término methods no estaba considerado por la base.

En relación al tipo de método que se siguió, casi la tercera parte $(27 \%)$ fue cuantitativa; en tanto que 
Métodos cualitativos para estudiar a los usuarios de ...

la cantidad de trabajos teóricos ${ }^{1}$ fue considerable porque representaba una cuarta parte (25\%); los métodos cualitativos sólo aparecieron en el 7\% de los registros. En esta recuperación el número de registros no considerados fue muy alto (41\%) debido a que estaban escritos en lenguas como el alemán, el holandés y el ruso.

Los objetivos perseguidos fueron: casi la mitad de corte teórico (general) (43\%); mientras que aquellos que estudiaban las necesidades de información y el comportamiento en la búsqueda de información se encontraron en (22\%); cifra que disminuye a $13 \%$ cuando evalúa la satisfacción del usuario.

Al precisar la década en la que más se escribieron estudios de usuarios, tenemos registros casi en la misma proporción que se encontraron en las décadas de los ochenta (32\%) y de los noventa, esta última década con un ligero aumento (38\%); del año 2000 hasta ahora se registró el $27 \%$ y en los años setenta sólo el $3 \%$.

De los datos anteriormente expuestos se puede determinar que los métodos cuantitativos aparecen como los más usados en estudios de usuarios que detectaron tanto las necesidades de información como el comportamiento durante la búsqueda, en un periodo que abarca de 1980 al 2000.

1 Se consideraron como trabajos teóricos aquellos que trataban aspectos generales sobre los estudios de usuarios. 
Utilización de métodos cualitativos para realizar estudios ...

\section{Library and Information Science Abstracts (LISA)}

Esta base no considera el descriptor user studies, sino user surveys, la búsqueda bajo este descriptor arrojó 3391 registros mientras que el número total de registros fue de 298,776; es decir que sólo un $1.13 \%$ abordaban el tema de estudios de usuarios. Para fines de análisis el resultado fue muy grande, por lo que se restringió la búsqueda y se agregaron las truncaciones ¿metho? or ¿techn?; la nueva búsqueda dio un total de 65 registros. El examen de ellos permitió obtener los siguientes datos.

En casi la mitad de los registros (48\%) se usaron métodos cuantitativos, sólo un 17\% correspondió a los cualitativos y existió un caso que siguió tanto la tendencia cuantitativa como la cualitativa. Un poco más de la décima parte $(11 \%)$ fue de corte teórico y hubo un buen porcentaje $(23 \%)$ que no fue considerado. Esto se debió a que el descriptor user surveys es muy genérico y a que las referencias correspondían a otros campos disciplinarios; otra causa fue que se trataba de estudios bibliométricos o cienciométricos, los que, de acuerdo con la definición que se dio de estudios de usuarios (relación información-usuario) no estaban considerados como estudios de usuarios.

En relación con el objetivo que perseguían los estudios, aparecieron casi en igual proporción los de comportamiento durante la búsqueda de informa- 
Métodos cualitativos para estudiar a los usuarios de ...

ción (36\%) y los teóricos (30\%); y también tanto los de necesidades de información (16\%) como los de satisfacción (14\%) fueron coincidentes. Aparece en esta herramienta un pequeño porcentaje $(4 \%)$ de estudios relacionados con la actitud.

Los años de publicación de los documentos fueron casi iguales en número a los de las décadas de los noventa (38\%) y los del 2000 (36\%); cantidad que decrece a $18 \%$ para los años 80 y a $8 \%$ en los setenta.

De estos datos se desprende que los estudios indizados en LISA se hicieron para identificar principalmente el comportamiento durante la búsqueda de información, que siguieron una tendencia cuantitativa desde los noventa y hasta lo que va de la década del 2000.

\section{Base de datos Información Bibliográfica Latinoame- ricana (INFOBILA)}

La búsqueda bajo estudios de usuarios arrojó 125 referencias a partir de 17,650 registros que contiene la base; es decir, menos de un $1 \%(0.70 \%)$, de las cuales se descartaron las que coincidían con el catálogo del CUIB, por lo que quedaron sólo 65 .

Mediante el análisis de las referencias se precisó que en más de la mitad de ellas (51\%) se siguieron métodos cuantitativos; mientras que un poco más de la décima parte (12\%) utilizó los cualitativos; la 
Utilización de métodos cualitativos para realizar estudios ...

cantidad de métodos teóricos corresponde a más de una décima parte (15\%), y no se consideró el $22 \%$ porque trataban sobre evaluación de programas de formación de usuarios o sobre capacitación profesional.

Casi la mitad de los estudios (41\%) se hicieron para determinar las necesidades de información; pero los de comportamiento variaron por unas cuantas décimas (29\%) y los de tipo teórico $(24 \%)$; aquellos que evaluaron la satisfacción fueron sólo el $6 \%$.

En el dato de "año", apareció que más de una tercera parte de los documentos (35\%) fueron publicados en 1980, y otros (32\%) entre 1990 y 1999; en la década del 2000 apareció un $27 \%$ y sólo un $6 \%$ lo hizo en los años setenta.

De lo anterior se concluye que en América Latina se ha estudiado al usuario desde una perspectiva cuantitativa que buscaba determinar sus necesidades de información entre 1980 y 1999.

Catálogo del Centro Universitario de Investigaciones Bibliotecológicas (CUIB)

De un total de 20,296 registros que tiene este catálogo, la búsqueda bajo los términos estudios de usuarios arrojó sólo 38 registros, cantidad que corresponde a un pequeño porcentaje de $0.18 \%$ de todo el acervo. La estrategia estudios de usuarios / 
Métodos cualitativos para estudiar a los usuarios de ...

métodos y/o técnicas no se hizo porque no existe este último descriptor. Como se trata de un catálogo general, los registros recuperados se analizaron con base en el título.

La tendencia cuantitativa fue la que más se manifestó, ya que es la que siguió más de la mitad (58\%) y únicamente el $8 \%$ fueron estudios cualitativos. El $13 \%$ se refirió a contenidos teóricos generales y el $21 \%$ no fue considerado porque se trataba de estudios bibliométricos o sobre aspectos de formación de usuarios.

En cuanto al objetivo que buscaban cubrir los estudios de usuarios se obtuvo lo siguiente. Más de la mitad de ellos (60\%) identificaron el comportamiento durante la búsqueda; el $20 \%$ determinó las necesidades de información; y el (10\%) evaluó la satisfacción y tocó temas teóricos.

La distribución por años fue de la manera que sigue: casi la mitad (43\%) se escribió en la década del 2000 ; y en el (20\%) se produjeron trabajos en las décadas de los años setenta y noventa; un $14 \%$ aparece en la de los 80 ; y un registro (3\%) no incluía el dato de año.

Estos datos nos llevan a inferir que la mayoría de los estudios de usuarios contenidos en el catálogo del CUIB fueron realizados en la década del 2000, que siguieron un método cuantitativo, y que deter- 
Utilización de métodos cualitativos para realizar estudios ...

minaron el comportamiento durante la búsqueda de información.

\section{Análisis comparativo}

En este apartado se hará una comparación de los porcentajes obtenidos en las búsquedas de las cuatro herramientas, con el fin de obtener una visión global de la situación. Los datos sobre los métodos utilizados de cada fuente se comportaron así (ver Cuadro 1):

\begin{tabular}{|c|c|c|c|c|}
\hline \multicolumn{5}{|c|}{$\begin{array}{c}\text { Cuadro } 1 \\
\text { Tendencia metodológica }\end{array}$} \\
\hline $\begin{array}{l}\text { Fuente } \\
\text { Métodos }\end{array}$ & $\begin{array}{l}\text { Lib. Lit. } \\
(\%)\end{array}$ & $\begin{array}{c}\text { LISA } \\
(\%)\end{array}$ & $\begin{array}{c}\text { Catálogo } \\
\text { CUIB } \\
(\%)\end{array}$ & $\begin{array}{c}\text { INFOBILA } \\
(\%)\end{array}$ \\
\hline Cuantitativos & 27 & 48 & 58 & 51 \\
\hline Cualitativos & 7 & 17 & 8 & 12 \\
\hline $\begin{array}{l}\text { Cuantitativo - } \\
\text { cualitativo }\end{array}$ & - & 1 & - & - \\
\hline Teóricos (generales) & 25 & 11 & 13 & 15 \\
\hline No considerados & 41 & 23 & 21 & 22 \\
\hline
\end{tabular}

Sobresalen significativamente los estudios cuantitativos sobre los cualitativos. Las cuatro herramientas empleadas tuvieron un muy alto porcentaje de registros no considerados, lo que se debió al 
Métodos cualitativos para estudiar a los usuarios de ...

carácter genérico de los descriptores (user surveys, user studies, estudios de usuarios), situación que hizo que la relevancia fuera alta; sin embargo al momento de analizar los trabajos, éstos no correspondieron a estudios de usuarios propiamente dichos. Más aún, tres de las fuentes no permitieron restringir la búsqueda con los términos métodos y técnicas.

Un hallazgo interesante fue que en varios países europeos, tales como Holanda, Suiza, Alemania y Rusia se están escribiendo documentos relacionados con los estudios de usuarios, y también en algunos asiáticos como Japón, China, India y Taiwán.

Las referencias consideradas como teóricas ofrecían información general sobre algunos métodos y técnicas que se podían utilizar para estudiar al usuario, en tanto que abundaban los trabajos sobre la encuesta y algunos sobre técnicas estadísticas para analizar los resultados obtenidos.

Los métodos y/o técnicas cualitativos seguidos fueron:

- Análisis de contenido

- Análisis de zonas de intervención

- Dinámica de grupos

- Estudio de caso

- Focus group

- Incidente crítico

- Materialismo dialéctico

- Observación participante 
Utilización de métodos cualitativos para realizar estudios ...

- Sense Making

La tendencia cualitativa se empieza a utilizar desde comienzos de la década de los años ochenta (1981); sin embargo, como se puede apreciar en el Cuadro 1, aún son muy pocos los estudios que siguen esta tendencia.

En el Cuadro 2 se aprecian los objetivos de los estudios de usuarios que más han interesado.

\begin{tabular}{||l|c|c|c|c||}
\hline \multicolumn{5}{|c|}{ Cuadro 2 } \\
Objetivos de los estudios de usuarios \\
\hline Fuente & $\begin{array}{c}\text { Lib. Lit. } \\
(\%)\end{array}$ & $\begin{array}{c}\text { LISA } \\
(\%)\end{array}$ & $\begin{array}{c}\text { Catálogo } \\
\text { CUIB } \\
(\%)\end{array}$ & $\begin{array}{c}\text { INFOBILA } \\
(\%)\end{array}$ \\
\hline Nec. de Información & 22 & 16 & 20 & 41 \\
\hline $\begin{array}{l}\text { Comportamiento du- } \\
\text { rante la búsqueda }\end{array}$ & 22 & 36 & 60 & 29 \\
\hline Satisfacción & 13 & 14 & 10 & 6 \\
\hline Actitud & - & 4 & - & - \\
\hline Teóricos & 43 & 30 & 10 & 24 \\
\hline
\end{tabular}

Este cuadro muestra que no existe consistencia en cuanto a los objetivos que cubrieron los estudios de usuarios. En las herramientas internacionales abundaron los aspectos teóricos. Por otra parte, en algunas regiones interesa más determinar las actividades que realizan los sujetos para cubrir una necesidad de información (comportamiento en la búsqueda) mientras que en otras se busca identificar las 
Métodos cualitativos para estudiar a los usuarios de ...

necesidades de información; e incluso existe el mismo interés por abordar ambos objetivos.

Los únicos resultados consistentes son los relacionados con medir la satisfacción, lo cual es poco realizado; asimismo, la actitud no fue un aspecto considerado en tres de las cuatro herramientas. Esto nos muestra que a pesar de que la fecha de los primeros estudios registrados en las herramientas examinadas corresponde a la década de los años setenta, se siguen identificando las necesidades de información y el comportamiento de los usuarios, pero no se evalúan ni su satisfacción ni su actitud. Los trabajos teóricos siguen el mismo patrón que en la característica metodológica.

Precisamos ahora lo tocante a los años de publicación; los datos aparecen en el Cuadro 3.

\begin{tabular}{||c|c|c|c|c||}
\hline \multicolumn{5}{|c|}{$\begin{array}{c}\text { Cuadro 3 } \\
\text { Años de publicación }\end{array}$} \\
\hline $\begin{array}{c}\text { Fuente } \\
\text { Década }\end{array}$ & $\begin{array}{c}\text { Lib. Lit. } \\
(\%)\end{array}$ & $\begin{array}{c}\text { LISA } \\
(\%)\end{array}$ & $\begin{array}{c}\text { Catálogo } \\
\text { CUIB } \\
(\%)\end{array}$ & $\begin{array}{c}\text { INFOBILA } \\
(\%)\end{array}$ \\
\hline $1970-1979$ & 3 & 8 & 20 & 6 \\
\hline $1980-1989$ & 32 & 18 & 14 & 35 \\
\hline $1990-1999$ & 38 & 38 & 20 & 32 \\
\hline $2000-$ & 27 & 36 & 43 & 27 \\
\hline No tenía año & - & - & 3 & - \\
\hline
\end{tabular}


Utilización de métodos cualitativos para realizar estudios ...

El Cuadro 3 nos permite observar que en términos generales ha ido en aumento la producción de trabajos relacionados con los estudios de usuarios. En la década de los ochenta se produjeron hasta diez veces más documentos con respecto al período anterior; entre los años 80 y 90 se estabiliza la cantidad, y para este siglo (2000) se han hecho estudios que, siguiendo una proyección lineal, rebasarán los de la década de los noventa; de hecho en el Catálogo del CUIB ya aparece el doble de la cantidad de trabajos.

Este análisis somero de los trabajos registrados por las cuatro herramientas secundarias analizadas nos permite comprobar que se sigue utilizando la metodología cuantitativa para estudiar a los usuarios de la información, la cual no siempre refleja las características verdaderas de las comunidades de usuarios estudiadas, de aquí que se sugiera el uso de métodos cualitativos que permitan obtener resultados más cercanos a sus condiciones reales.

\section{Métodos cualitativos}

El seguimiento de métodos cualitativos para realizar investigaciones nos permite abordar fenómenos reales de la vida humana tal y como éstos se desarrollan cotidianamente; es decir, dentro de su contexto natural. Estos métodos se enfocan a des- 
Métodos cualitativos para estudiar a los usuarios de ...

cribir la esencia de alguna situación dada entre sujetos, como actores de procesos sociales.

La metodología cualitativa concibe a la vida humana como un proceso de transformación permanente, de tal manera que una situación actual puede cambiar en el futuro por la propia injerencia de los sujetos. Se percibe entonces al ser humano como una síntesis de los elementos que conforman a la sociedad: tradiciones, valores, papeles y normas. Estos elementos son acomodados en su estructura interna y los manifiesta en su comportamiento ( $\mathrm{Fe}$ rrarotti, 1983). Es decir, que interesa lo que la gente realmente hace y no lo que dice que hace.

La realidad es entendida como un cúmulo de significados, símbolos e interpretaciones, como algo holístico, global y polifacético, que se construye socialmente. De aquí que tanto la comprensión como la interpretación de los fenómenos sea holística y estudie progresivamente grupos humanos específicos mediante acciones tanto individuales como colectivas, lo que lleva a comprenderlos profundamente y a poder interpretar los significados que los sujetos les dan a los procesos sociales.

Siguiendo una tendencia cualitativa la forma de construcción del conocimiento es inductiva, va de lo particular (datos) a lo general (teoría). Y los datos pueden ser de diversos tipos: palabras, imáge- 
Utilización de métodos cualitativos para realizar estudios ...

nes, impresiones, gestos y sonidos, y representan los eventos reales simbólicos.

La investigación cualitativa responde a preguntas:

[...] sobre tópicos analíticos [que] implican el "cómo" y el "por qué" de unos fenómenos. Para tratar estos problemas el investigador recopila detalles descriptivos sobre el "quién", "qué, "dónde" y "cuándo" de los fenómenos. (McMillan y Schumacher, 2005, p. 4022).

Los métodos cualitativos persiguen varios objetivos:

- Comprender las complejas relaciones que se dan dentro de una sociedad.

- Entender problemas prácticos.

- Generar diagnósticos de situaciones específicas.

- Proponer acciones para mejorar las relaciones entre los sujetos y entre grupos de sujetos.

- Sugerir cambios sociales, modelos de organización y acción social.

- Desarrollar estrategias para solucionar problemas sociales.

- Establecer las causas de cada situación y de cada proceso (Pérez, 1994).

Aquellos que emplean métodos cualitativos pretenden interpretar los fenómenos que investigan, que en nuestro caso son los usuarios, y tal interpretación permite profundizar en rasgos que a simple 
Métodos cualitativos para estudiar a los usuarios de ...

vista podrían pasar inadvertidos como son los actitudinales, los relacionados con la comunicación corporal, o con las emociones que se generan en un sujeto cuando está buscando información. Para lograr una interpretación adecuada, el sujeto que estudia (investigador) se relaciona de alguna manera con el sujeto estudiado, lo que le da un carácter humanista a la investigación, lo cual también busca patrones de intercambio con el fin de compartir significados e interpretaciones.

Entre los métodos y/o técnicas cualitativas más utilizados en disciplinas como Pedagogía, Antropología, Sociología y Comunicación están: la observación; las historias de vida; el estudio de caso; el focus group; el incidente crítico; la teoría de sistemas autorreferentes; y el análisis de contenido. A continuación se describen los tres primeros, los cuatro siguientes se explican ampliamente en los subsecuentes capítulos.

\section{Observación}

Este método es uno de los más antiguos e importantes que existen para realizar una investigación, y ha sido definido por filósofos como Aristóteles y John Stuart Mill (A system of logic frames). En su acepción etimológica observar significa vigilar, prestar atención, mirar atentamente y con ciertos fines: "En rigor, la noción filosófica de 'observa- 
Utilización de métodos cualitativos para realizar estudios ...

ción' conlleva, ya desde Aristóteles, la idea de un control y dirección" (Ferrater, 2001, p. 2610).

Como método, la observación es un proceso que se dirige a fenómenos o a complejos fenoménicos denominados hechos, ${ }^{2}$ de tal manera que el tal método puede seguirse tanto en investigaciones cualitativas (estudio de fenómenos) como cuantitativas (estudio de hechos), y aplicarse en las ciencias naturales, sociales y en las humanidades.

La observación puede ser participante o no participante; en la participante el investigador se integra a la vida cotidiana de los sujetos que van a ser estudiados y coexiste con ellos para tener una visión directa de las situaciones que le interesan. Mientras que en la no participante el observador no interviene en la vida de la comunidad que va a estudiar.

El proceso de observación consta de las siguientes fases generales:

1. Definir los objetivos. Estos corresponderán al problema detectado.

2 Para un mayor entendimiento, cabe delimitar los conceptos de fenómeno y hecho. El primero es aquello que aparece ante nosotros y se nos revela tal como se manifiesta mediante la intuición; es decir, mediante la comprensión o visión directa de la realidad por medio del pensamiento (por sí mismo y desde sí mismo). En cuanto al hecho es el resultado de algo, por ejemplo, un proceso que se ha llevado a cabo, que ya está cumplido y cuya realidad no puede negarse. 
Métodos cualitativos para estudiar a los usuarios de ...

2. Crear las categorías y criterios de análisis.

3. Seleccionar los grupos de sujetos (unidades de observación) y situaciones a ser observadas.

4. Mirar el fenómeno. Esto requiere ubicarse en el lugar, el tiempo y la situación planeadas.

5. Registrar los datos. Lo cual debe hacerse en forma sistematizada e inmediata. En esta fase también se crean los códigos de registro y se interpretan.

6. Analizar los datos. Identificar patrones de comportamiento, compararlos, valorarlos e interpretarlos.

7. Generar conclusiones. Y contrastarlas con los objetivos de la investigación.

De acuerdo con Pérez (1994, pp. 23-24) una observación se desarrollará adecuadamente siempre que se:

- Oriente a un objetivo de investigación formulado previamente.

- Planifique sistemáticamente en fases, aspectos, lugares y personas.

- Controle y relacione con proposiciones generales en vez de ser presentada como una serie de curiosidades interesantes.

- Someta a comprobaciones de fiabilidad y validez.

Entre los instrumentos que se utilizan para registrar los datos están: los diarios; los cuadernos de notas; las fotografías; las grabaciones en audio y en vi- 
Utilización de métodos cualitativos para realizar estudios ...

deo; los mapas; las listas de control; la documentación personal, y las escalas de estimación.

\section{Historia de vida}

Es la aproximación longitudinal a la vida de una persona para obtener su imagen total; comprende el relato de una persona y toda la información que sobre ella se pueda recoger. Mediante este método "[...]el sentido de la experiencia humana se revela en relatos personales, de modo que da prioridad a las explicaciones individuales" (P'érez, 1994, p. 34). $\mathrm{Su}$ objetivo general es captar los procesos sociales básicos de la interacción cotidiana.

Representa un núcleo de aproximaciones interdisciplinarias, y es usada como fuente primaria en investigaciones históricas, sociales y culturales; busca elucidar las relaciones: entre individuos y sociedad; entre aspectos locales, nacionales y regionales; entre el pasado y el presente; y entre experiencias públicas y privadas de los sujetos. Este método se vale de la memoria, el lenguaje y la autorrepresentación de los sujetos.

Como objetivos específicos la historia de vida pretende:

- Comprender las distintas etapas y periodos en la existencia de un individuo, y en su proceso de desarrollo. 
Métodos cualitativos para estudiar a los usuarios de ...

- Captar los procesos y los modos como los individuos perciben el significado de la vida.

- Identificar la forma en la que los individuos crean y reflejan el contexto social en el que están insertos.

El único riesgo que existe al utilizar la historia de vida es que el sujeto no narre su verdadera historia, para evitar esto se sugiere considerar los criterios que se expresan a continuación:

- La persona a estudiar forma parte de una cultura.

- Tomar en cuenta a los integrantes de los contextos familiar y social del sujeto.

- Identificar las acciones sociales en las que se basa la realidad social del sujeto: valores centrales; códigos de conducta, mitos y ritos.

- Reconstruir la secuencia temporal de las experiencias de la persona.

- Recrear continua y simultáneamente la conducta de la persona como parte de un contexto social, en conexión con un momento histórico.

Es decir; se deben entrelazar los escenarios que producen la biografía, la historia y la sociedad.

Las etapas que se deben seguir para realizar una historia de vida son:

1. Formular las preguntas o el problema de investigación.

2. Establecer los objetivos de la investigación.

3. Determinar los temas o tópicos a tratar. 
Utilización de métodos cualitativos para realizar estudios ...

4. Definir a los sujetos de estudio.

5. Recolectar los datos necesarios.

- Diseñar y realizar la(s) entrevista(s). Listar los temas de interés; seleccionar un lugar tranquilo y silencioso para hacer la(s) entrevista(s).

- Registrar la información. Se sugiere que sea a través de grabaciones de audio y/o video.

- Hacer notas acerca de la(s) entrevista(s) inmediatamente después de haber sido hechas.

- Recuperar los documentos que completen la información de la(s) entrevista(s).

6. Analizar los datos recolectados.

7. Organizar y presentar los resultados.

En las historias de vida la entrevista representa el medio más importante para obtener información, de aquí que su registro deba ser muy exhaustivo y sistematizado, para lograr esto, Pérez (1994) sugiere realizar cuatro tipos de registros:

1. Básico. Está representado por el conjunto de notas y grabaciones (transcritas literalmente) hechas durante la(s) entrevista(s).

2. Temático. Son los apuntes, descripciones, reflexiones y ensayos que se deben hacer de acuerdo con los temas o tópicos determinados. Cabe aclarar que pueden surgir nuevos temas que también se deberán considerar. 
Métodos cualitativos para estudiar a los usuarios de ...

3. Logístico. Anotaciones que se hacen sobre: los sucesos que pudieran enriquecer el estudio; los problemas que se hayan manifestado; y los pensamientos que surjan.

4. Complementario. Es el resultado del análisis de los documentos que aporten datos a la investigación.

\section{Estudio de caso}

Puede ser utilizado como método o como forma de selección de una población determinada de estudio, aquí se considerará como método. El estudio de caso examina longitudinalmente y a profundidad un caso o suceso. El caso se entiende como un sistema definido de acciones referidas a un conjunto de actividades interrelacionadas en las que participan varios actores en una situación social (Tellis, W. Introduction to case study. Disponible en: http://www.nova.edu/ssss/QR/QR3-2/tellis1. html Consulta: 10 de julio del 2007), se considera pues, la interacción entre los sujetos y su entorno. El fin último de este método es describir y entender situaciones de la vida real contemporánea.

El interés por estudiar un caso surge de varias circunstancias: por ser representativo; por ser particular; o por ilustrar un tema. El caso puede ser un programa, un acontecimiento, una actividad, una 
Utilización de métodos cualitativos para realizar estudios ...

institución o una comunidad específica de individuos.

Como características generales de este método tenemos que:

- Puede incluir evidencia tanto cuantitativa como cualitativa.

- Utiliza más de una técnica.

- Analiza los casos desde varias perspectivas.

Realizar un estudio de usuarios siguiendo el estudio de caso implica:

1. Establecer las preguntas de investigación.

2. Determinar el caso.

3. Seleccionar las situaciones y los individuos que integran los casos.

4. Establecer categorías de análisis.

5. Definir las técnicas e instrumentos para recolectar los datos.

6. Recoger y registrar los datos.

7. Analizar y evaluar la información.

8. Elaborar conclusiones.

9. Preparar el reporte de la investigación.

Este método es muy utilizado en disciplinas como la Pedagogía, la Sociología y la Antropología. Desafortunadamente en bibliotecología se ha usado más como una forma para seleccionar la población de estudio y no como un método para abordar todo un caso. 
Métodos cualitativos para estudiar a los usuarios de ...

\section{Validez y fiabilidad}

Toda investigación que se realice, ya sea de carácter cuantitativo o cualitativo, debe poseer dos cualidades esenciales, ser válida y fiable. Estas cualidades le imprimen mayor credibilidad a los resultados, se relacionan básicamente con los instrumentos de recolección de datos, y se evidencian en las explicaciones de los fenómenos estudiados.

La validez se refiere a la exactitud de los estudios:

[...] es el grado en el que las interpretaciones y los conceptos poseen significados recíprocos entre los participantes y el investigador. El investigador y los participantes están de acuerdo en la descripción o la constitución de los acontecimientos, especialmente en los significados de estos acontecimientos. (McMillan y Schumacher, 2005, p. 414).

Según Pérez (1994) la validez estima la medida en que los resultados representan la realidad estudiada y si son categorías reales de la experiencia humana.

Para lograr la validez en un estudio existen varias estrategias, en el Cuadro 4 se presentan algunas de ellas. 
Utilización de métodos cualitativos para realizar estudios ...

\begin{tabular}{||l|l||}
\hline \multicolumn{1}{||c|}{$\begin{array}{c}\text { Cuadro 4 } \\
\text { Estrategias para lograr validez en los } \\
\text { estudios de usuarios }\end{array}$} \\
\hline Estrategia & \multicolumn{1}{|c|}{ Descripción } \\
\hline Temporal & $\begin{array}{l}\text { Diseño longitudinal que considera diferentes mo- } \\
\text { mentos: antes, inicio y diseño del estudio; durante, } \\
\text { se escalonan temporalmente diferentes fases de la } \\
\text { acción; y después, efectos y repercusiones produci- } \\
\text { das en los sujetos y los ambientes. }\end{array}$ \\
\hline $\begin{array}{l}\text { Campo de tra- } \\
\text { bajo prolonga- } \\
\text { do y continuo }\end{array}$ & $\begin{array}{l}\text { Permite el análisis interno de los datos y la corrobo- } \\
\text { ración para asegurar la concordancia entre la infor- } \\
\text { mación y la realidad del participante. }\end{array}$ \\
\hline Metodológica & $\begin{array}{l}\text { Utiliza el mismo método y/o técnica en diferentes } \\
\text { ocasiones o diferentes métodos y/o técnicas sobre } \\
\text { un mismo fenómeno de investigación. Permite la } \\
\text { triangulación en la recopilación y el análisis de da- } \\
\text { tos. }\end{array}$ \\
\hline $\begin{array}{l}\text { Investigadores } \\
\text { múltiples }\end{array}$ & $\begin{array}{l}\text { Varios investigadores realizan la misma investiga- } \\
\text { ción. Se contrasta la información del grupo de in- } \\
\text { vestigación mediante el análisis, contraste, discu- } \\
\text { sión y debate sobre los datos. }\end{array}$ \\
\hline $\begin{array}{l}\text { Registro de } \\
\text { datos de ma- } \\
\text { nera mecánica }\end{array}$ & $\begin{array}{l}\text { Utilización de grabadoras, cámaras fotográficas y } \\
\text { videograbadoras. }\end{array}$ \\
\hline Saturación & $\begin{array}{l}\text { Reunir pruebas y evidencias suficientes. } \\
\text { Revisar el proceso. } \\
\text { Reproducir el estudio para comprobar si los resulta- } \\
\text { dos se mantienen. }\end{array}$ \\
\hline \hline
\end{tabular}


Métodos cualitativos para estudiar a los usuarios de ...

\begin{tabular}{||l|l||}
\hline $\begin{array}{l}\text { Revisión de } \\
\text { participantes }\end{array}$ & $\begin{array}{l}\text { Validar los resultados e informes de la investiga- } \\
\text { ción, mediante la contrastación de los mismos con } \\
\text { otros compañeros, observadores, informadores y } \\
\text { personas implicadas. }\end{array}$ \\
\hline $\begin{array}{l}\text { Fuente: McMillan, James H. y Sally Schumacher (2005), Investigación educati- } \\
\text { va, Madrid : Pearson Addison Wesley, p. 415; }\end{array}$ \\
$\begin{array}{l}\text { Pérez Serrano, Gloria (1994), Investigación cualitativa: retos e interrogantes. } \\
\text { Madrid : La Muralla, pp. 82-85. }\end{array}$ \\
\hline
\end{tabular}

En cuanto a la fiabilidad, ésta se entiende como "[...]el grado en que las respuestas son independientes de las circunstancias accidentales de la investigación”. Pérez (1994, p. 77). El logro de esta cualidad permite que la investigación efectuada pueda ser replicada por otros investigadores, ya sea que sigan los métodos y técnicas utilizadas en el primer estudio o que empleen con otros y obtengan resultados iguales; es decir, que reconstruyan las estrategias analíticas originales.

El principio fundamental para lograr la fiabilidad es normalizar el proceso de recolección de datos (instrumentos, registros) tomando como base las categorías establecidas por el marco teórico.

Algunas formas para lograr la fiabilidad son:

- Hacer registros descriptivos.

- Contrastar los registros de la información recogida por los diferentes colectores de información 
Utilización de métodos cualitativos para realizar estudios ...

o con algún agente externo durante el curso de la investigación.

- Utilizar diferentes métodos para la recolección de datos.

- Seleccionar adecuadamente tanto a los informantes como a las situaciones.

Si se siguen las estrategias aquí presentadas, tanto de validez como de fiabilidad, tendremos la certeza de que nuestro estudio será replicable, estará bien interpretado y reflejará la realidad humana estudiada.

\section{Obras consultadas}

Ferrater Mora, J. (2001), Diccionario de filosofía, Barcelona, Editorial Ariel, 4 t.

Ferrarotti, F. (1983), "Sobre la autonomía del método biográfico”, 3n: Marinas M. y C. Santamaría, La historia oral : métodos y experiencias, Madrid, Ed. Debate.

García Morente, M. (1979), Lecciones preliminares de filosofía, México, Ed. Época.

Glazier, J. D. y R.R. Powell (1992), Qualitative research in information management, Englewood, Libraries Unlimited. 
Métodos cualitativos para estudiar a los usuarios de ...

Hernández Salazar, P., "El usuario de la información”, en H. A. Figueroa Alcántara y C.A. Ramírez Velázquez (Coord.), Servicios bibliotecarios (pp. 209-227), México: Facultad de Filosofía y Letras, Dirección General del Personal Académico, 2006.

McMillan, J. H. y S. Schumacher (2005), Investigación educativa, Madrid, Pearson Addison Wesley.

Moliner, M. (2001), Diccionario de uso del español, Madrid, Gredos.

Tellis, W. Introduction to case study, disponible en http://www.nova.edu/ssss/QR/QR3-2/tellis1 .html, consulta: 10 de julio del 2007.

Pérez Serrano, G. (1994), Investigación cualitativa: retos e interrogantes, Madrid, La Muralla, 2 vol. 


\title{
La técnica del Focus Group para determinar el diseño de experiencias de formación de usuarios
}

\author{
CARLOS FERNANDO CORTÉS GÓMEZ
}

\section{Introducción}

G1 ser humano es un individuo por naturaleza curioso y en ocasiones desea investigar o seguirle la huella a algo para conocer una novedad, detectar algún problema, saber de qué se trata alguna situación, etcétera.

El hecho de poder cuestionarse sobre algún problema que ocurre en nuestro alrededor es un camino que lleva a entender un fenómeno, su problemática y una posible solución que pueda resolver una determinada situación o hecho.

Como en las otras disciplinas la bibliotecología también puede proponerse el hecho de investigar o descubrir la verdad o solución sobre una determinada situación. Para ello, la investigación cualitativa es una gran ayuda en nuestra área, sobre todo 
Métodos cualitativos para estudiar a los usuarios de ...

para el campo fenoménico denominado usuarios de la información, que se plantea que observadores competentes y cualificados pueden informar con objetividad, claridad y precisión acerca de sus propias observaciones del mundo social, así como de las experiencias de los demás. Por otra parte estos investigadores se aproximan a un sujeto real, un individuo que está presente en el mundo y que puede, en cierta medida, ofrecernos información acerca de sus propias experiencias, opiniones, valores, etcétera (Rodríguez, Gil y Flores, 1999, p. 62).

La investigación cualitativa ayudará a que los sujetos, en este caso nuestros usuarios de información, ofrezcan, desde sus propios puntos de vista, respuestas que serán registradas por el investigador para que pueda después adentrarse en cada sujeto o individuo para esclarecer un hecho o situación.

La investigación cualitativa incluye diferentes fases algunas de las más importantes son las siguientes:

- Identificación del problema.

- Establecimiento de las preguntas que se van a investigar.

- Formulación de objetivos generales y específicos.

- Selección de casos.

- Selección de una estrategia metodológica.

- Preparación de casos. 
La técnica del Focus Group para determinar el diseño de ...

- Obtención de datos.

- Análisis preliminar.

- Análisis final.

- Presentación del informe final.

Valles (1997) señala que en la investigación cualitativa el investigador debe tener cierta preparación y cubrir varios requisitos entre los que se encuentran:

- Ser paciente, saber ganarse la confianza de aquellos a quienes estudia.

- Utilizar una gran variedad de métodos de investigación social.

- Ser meticuloso con la documentación (archivar metódicamente y a diario).

- Tener confianza en sus interpretaciones.

- Verificar y contrastar constantemente la información.

- No descansar hasta que el estudio se publique.

Como se mencionó anteriormente, la investigación cualitativa debe seleccionar un método para realizar el estudio, citamos algunos a continuación:

- Estudio de caso.

- Observación.

- Entrevista en profundidad.

- Grupos de discusión.

- Análisis de contenido.

- Incidente crítico.

- Historia de vida e historia oral. 
Métodos cualitativos para estudiar a los usuarios de ...

- Focus group.

- Sistemas anterreferentes.

En este capítulo se aborda un estudio realizado siguiendo la técnica del Focus Group o grupo focal.

\section{Focus Group}

El Focus Group (grupo focal) es una técnica que centra su atención en la pluralidad de respuestas obtenidas de un grupo de personas, y es definida como una técnica de la investigación cualitativa cuyo objetivo es la obtención de datos por medio de la percepción, los sentimientos, las actitudes y las opiniones de grupos de personas.

Matus y Molina (2005) señalan que esta técnica cualitativa pretende aprehender los significados que los sujetos comparten y que se expresan mediante el lenguaje.

Por otro lado, Romo y Castillo (2007) señalan que el grupo focal tiene predominantemente una finalidad práctica que busca recopilar la mayor cantidad de información posible sobre un tema definido. Además, mencionan que se estimula la creatividad de los participantes y se crea un sentimiento de co-participación por parte de los entrevistados. Por medio de esta técnica los entrevistados hablan en su propio lenguaje, desde su propia estructura y empleando sus propios conceptos, y 
La técnica del Focus Group para determinar el diseño de ...

son animados para seguir sus prioridades en términos propios.

\section{Descripción del proceso}

A continuación se señalan los pasos principales para aplicar la técnica del Focus Group:

1. Plantear o definir los objetivos de la investigación

La persona que aplicará en el grupo focal debe tener presente el propósito de la investigación, para lo cual deberá hacer una serie de reflexiones sobre el tema desde el examen, la exploración y la comprensión del asunto.

2. Realizar y planificar las preguntas sobre el tema de investigación

Se debe preparar un guión con preguntas abiertas de tipo general y también específico para que el entrevistado pueda responder ya sea de modo general o profundamente, y obtener la información necesaria para nuestra investigación. Las preguntas deben formularse en una secuencia lógica con el fin de guardar concordancia con los objetivos de nuestra investigación.

3. Seleccionar la audiencia y establecer el número de participantes

La selección de los integrantes del grupo focal no es una tarea simple, pues implica que se elijan personas adecuadas; es decir, deben ser indivi- 
Métodos cualitativos para estudiar a los usuarios de ...

duos que poseen ciertas características, ya que ellos aportarán la información requerida.

Las experiencias y visiones de cada individuo son imprescindibles y de ellas dependerá la compresión del problema. Los resultados de nuestra investigación dependerán de nuestras fuentes de información que en este caso son los entrevistados.

4 Establecer el número de personas que integrará el grupo focal

El número de integrantes debe ser limitado a entre 4 y 12 personas. Algunos autores como Young y Harmony (1998) señalan que los participantes pueden ser entre 7 y 10 personas. Matus y Molina (2005), por otro lado, mencionan entre 5 y 10 integrantes; la mayoría coincide en señalar que más de 10 personas pueden entorpecer el grupo focal.

5. Seleccionar al moderador y al ayudante u observador

El moderador debe mantener un perfil bajo y evitar realizar comentarios personales para no interferir o inhibir las respuestas de los entrevistados; su función es dirigir las preguntas, para lo cual debe ser un buen comunicador.

Una característica muy importante del moderador es la de ser amistoso con el fin de lograr que los entrevistados se entusiasmen, se relajen y respondan de manera adecuada las preguntas. Se re- 
La técnica del Focus Group para determinar el diseño de ...

comienda que el moderador tenga cierta experiencia en dinámica de grupos grandes o con pequeños grupos de interacción.

También es necesario elegir un ayudante $\mathrm{u}$ observador del Focus Group, quien tendrá la misión de tomar nota de las respuestas de los entrevistados. El ayudante del moderador debe ubicarse en un lugar poco visible para no molestar a los participantes y no debe intervenir en la sesión.

Es importante que tanto el moderador como el ayudante no hagan gesticulaciones que puedan interferir en las respuestas de los entrevistados.

6. Seleccionar el lugar

La elección del lugar también es importante: debe ser un espacio alejado de ruidos para que los integrantes no pierdan la concentración y entiendan las preguntas que realiza el moderador. El lugar debe ser conocido por los integrantes y estar equipado con el mobiliario adecuado.

7. Realizar una breve introducción sobre el tema a discutir

$\mathrm{Al}$ iniciar la sesión de entrevista será imprescindible que el moderador realice una breve introducción sobre el tema que se va a discutir, por lo que será importante que mencione los objetivos del estudio. Esta breve charla sobre el tema a discutir motivará a los participantes a la reflexión y a que expresen sus respuestas. 
Métodos cualitativos para estudiar a los usuarios de ...

8. Escuchar a los entrevistados

El moderador no debe hacer ninguna objeción ni censura a las respuestas de los entrevistados porque esto disminuiría la fluidez de sus comentarios. Debe también ser imparcial y escuchar a todos los entrevistados por igual; de las respuestas de sus entrevistados depende todo el estudio.

9. Tomar notas

El ayudante u observador del grupo focal debe estar capacitado para observar todos los gestos de los integrantes con el fin de registrar estas impresiones y anotar todas las respuestas de los participantes. Se recomienda la utilización de equipos de grabación sonora y/o filmadoras para registrar la sesión. Es importante que el ayudante también tome notas después que el moderador haya concluido la sesión.

10. Concluir la sesión

Una vez terminada la serie de preguntas el moderador concluirá la sesión y agradecerá la participación y asistencia de los integrantes, señalándoles la importancia de sus valiosos comentarios y respuestas.

11. Analizar los resultados

El análisis del material debe ser muy especializado. El investigador hará una revisión exhaustiva de toda la sesión desde su inicio hasta su finalización. 
La técnica del Focus Group para determinar el diseño de ...

12. Realización del Informe Final

Una vez analizados los resultados es necesario realizar un reporte final sobre el caso. Se recomienda que éste sea elaborado en forma inmediata para no olvidar ningún detalle. El reporte deberá registrar cómo se llevó a cabo la investigación, quiénes fueron los participantes, y cuáles fueron los resultados, las conclusiones y las recomendaciones de la investigación.

13. Compartir los resultados: retroalimentar a los participantes

El último paso, será comunicarles los resultados de la investigación a los participantes. Compartir las conclusiones con ellos afianzará estos contactos y quizá permita o ayude a realizar otros grupos.

\section{Desarrollo del estudio}

El objetivo del estudio de usuarios fue conocer las actitudes, experiencias y sentimientos de los alumnos en relación con el modo en que la biblioteca de la Universidad de Tarapacá (UTA) ${ }^{1}$ debe formar a sus estudiantes en lo que se refiere al fomento y desarrollo de las habilidades informativas.

1 La Universidad de Tarapacá, es un institución de educación superior de carácter público que se ubica en Arica (Ciudad de la Eterna Primavera), región no 15 de Chile. 
Métodos cualitativos para estudiar a los usuarios de ...

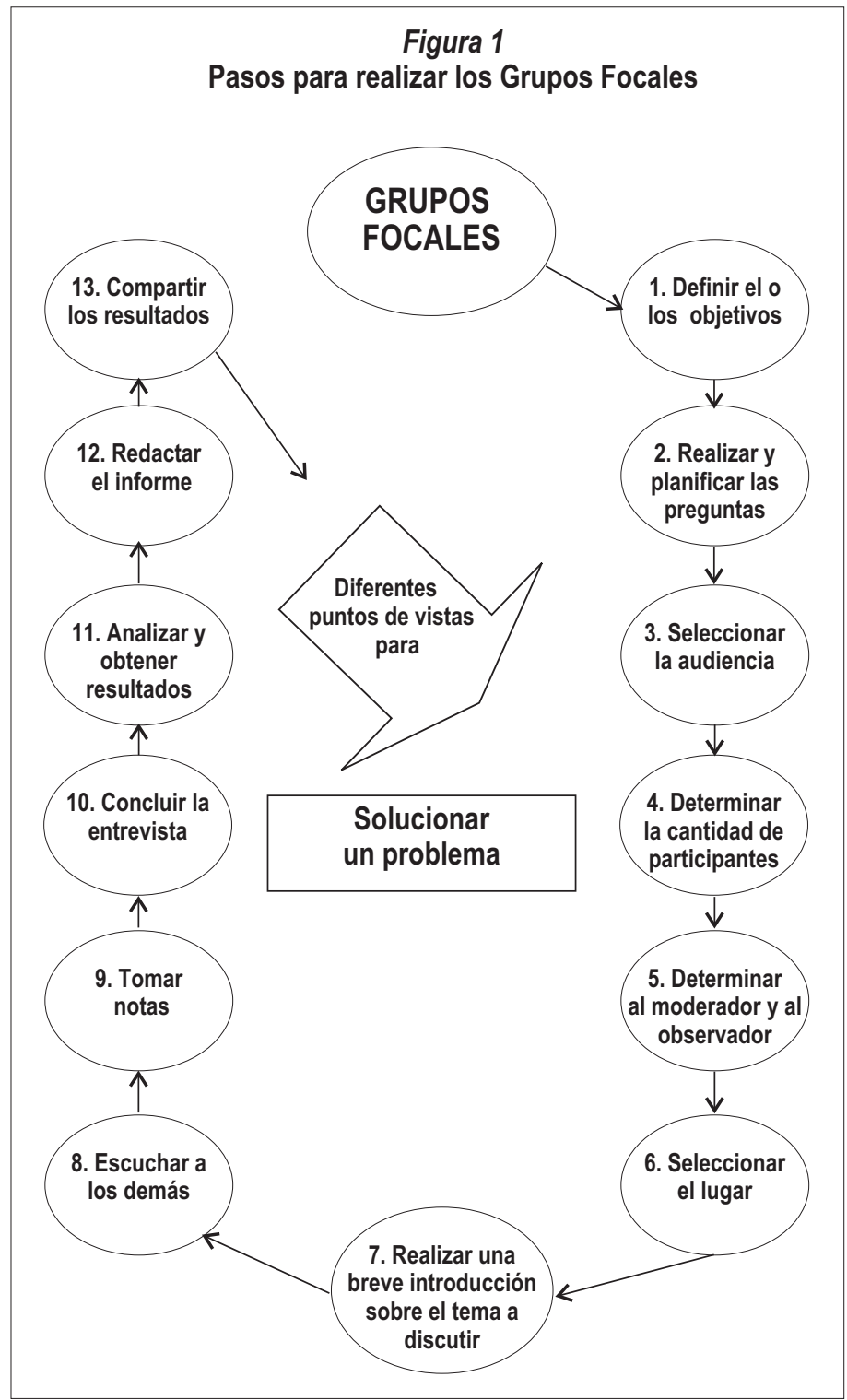


La técnica del Focus Group para determinar el diseño de ...

La Figura 1 muestra de manera esquemática los pasos para realizar una investigación mediante la técnica del grupo focal (Cortés, 2005, p. 68).

El motivo que originó este estudio fue que la UTA cambió su modelo educativo a partir del año 2002, y a que en el modelo anterior el aprendizaje estaba centrado en el profesor y en el actual se centra en el alumno. Este nuevo proyecto universitario señala la disminución de las clases lectivas e intenta generar una nueva promoción de educandos que adquieran un conjunto de habilidades que les permita autonomía a lo largo de la vida (UTA, 2005).

A raíz de lo mencionado en el párrafo anterior, las unidades que integran la universidad reflexionaron acerca de los mecanismos que serían necesarios para ajustarse a este nuevo modelo. Por supuesto, la biblioteca no fue ajena a esta situación y realizó el análisis correspondiente sobre cómo vincular la formación de usuarios al nuevo paradigma universitario.

Se realizaron diversas estrategias para abordar el problema. Una de ellas fue estudiar a los usuarios mediante la técnica del Focus Group. La técnica se aplicó en la comunidad de estudiantes del nivel superior de la UTA.

En una primera instancia se reflexionó sobre el tema investigado con el fin de realizar el diagnóstico sobre la forma en que la biblioteca enseñaba el 
Métodos cualitativos para estudiar a los usuarios de ...

uso de la información a los estudiantes. Para obtener la información requerida se elaboró un guión que contenía las siguientes preguntas:

1 ¿Conocen el modelo actual que tiene la biblioteca para enseñar los servicios que ofrece?

2 ¿Han participado en las charlas que dicta la biblioteca?

3 ¿Qué piensan del modelo actual de charlas?

4 ¿Conocen los recursos de información de la biblioteca?

5 ¿Les gustaría tener parte en un programa de formación de usuarios que desarrolle habilidades informativas?

6 ¿Les gustaría que los programas de habilidades informativas estuvieran relacionados con sus asignaturas?

7 ¿Los profesores fomentan el uso de la biblioteca?

8 ¿Cómo les gustaría que fuera un curso para enseñar el uso de la información?

9 ¿Les gustaría que se los tomara en cuenta para diseñar un programa de formación de usuarios?

Una vez redactado el guión de las preguntas, se seleccionó y definió a los entrevistados y se decidió que el grupo estuviera formado por un total de 10 alumnos de diferentes carreras.

La invitación a participar en el grupo focal se les hizo mediante un oficio formal en el que se mencionaba el objetivo de la investigación. Lamenta- 
La técnica del Focus Group para determinar el diseño de ...

blemente no pudieron acudir a esta cita 3 de los 10 estudiantes invitados debido a que ya tenían otro compromiso. Los alumnos que participaron pertenecían a las siguientes carreras:

1) Tres estudiantes a la carrera de Educación General Básica.

2) Uno a Pedagogía en Historia y Geografía.

3) Uno a Pedagogía en Castellano.

4) Uno a Kinesiología y Rehabilitación, y

5) Uno a Ingeniería Eléctrica.

La reunión programada duró dos horas aproximadamente. Se determinó aplicar esta técnica en un lugar conocido por todos los entrevistados, así que se fijó como lugar de encuentro una sala de la antigua biblioteca que cumplía con los requisitos de comodidad y aislamiento.

Por otro lado, se seleccionó a una bibliotecaria de servicio de la UTA como moderadora. La elección de esta persona se debió a que no estaba involucrada con el tema en estudio, sin embargo había trabajado anteriormente en la obtención de información a través de encuestas sobre otros temas relacionados con usuarios en las bibliotecas públicas. La moderadora recibió instrucciones generales sobre cómo hacerles las preguntas a los entrevistados. Las recomendaciones más importantes fueron:

- Saber escuchar las respuestas de los entrevistados.

- Atender sus preguntas. 
Métodos cualitativos para estudiar a los usuarios de ...

- Guardar silencio cuando los entrevistados estuvieran contestando.

- Evitar hacer comentarios sobre el tema investigado.

- No interferir cuando los entrevistados estuvieran dando las respuestas.

- Evitar gesticular durante la entrevista.

El observador ayudante que tomó las notas correspondientes fue el Jefe de Atención al Público, ${ }^{2}$ este observador siguió las instrucciones que aparecen a continuación:

- Registrar las respuestas de los entrevistados.

- Anotar los gestos de los entrevistados.

- Ubicarse en un lugar secundario.

- No intervenir en las preguntas del moderador

- Guardar silencio durante la sesión.

Antes de aplicar el grupo focal, la moderadora y el observador se reunieron para tratar asuntos relacionados con la planificación de la actividad.

Se tomaron medidas preventivas para que la entrevista se realizara adecuadamente, tales como supervisar el aseo de la sala, la disposición de las sillas y las mesas conforme a la cantidad de integrantes. Además se realizaron llamadas telefónicas previas

2 El autor de este capítulo tuvo la responsabilidad de ser el ayudante que tomó las notas de la investigación. 
La técnica del Focus Group para determinar el diseño de ...

para recordarles por teléfono a los participantes la fecha y lugar de la entrevista

Durante la entrevista se notó cierto nerviosismo en los entrevistados, porque era la primera vez que tomaban parte en una investigación al interior de la universidad. Al inicio de la actividad todos los integrantes se miraban sin articular palabra alguna entre ellos.

La moderadora hizo la presentación formal y les dio una bienvenida cordial y amena, se presentó y le preguntó su nombre a cada integrante, además de su carrera y el semestre al que pertenecían. Los integrantes paulatinamente fueron sintiendo confianza lo que se percibió en la voz segura con la que contestaron las preguntas; incluso aparecieron sonrisas en las caras de algunos de los participantes.

Enseguida se explicó el motivo del Grupo focal y se les solicitó que respondieran las preguntas que les haría. Les pidió que respondieran sin miedo y sin vergüenza admitiéndoles que todo lo que mencionaran era confidencial, y que sus respuestas podrían solucionar problemas reales acerca del servicio de la biblioteca.

Al plantearles la primera pregunta ¿Conocen el modelo actual que tiene la biblioteca para enseñar los servicios que ofrece? los participantes se miraron entre sí con cara de desconcierto, pues reconocieron desconocer el sistema de educación de usua- 
Métodos cualitativos para estudiar a los usuarios de ...

rios de la biblioteca. Una respuesta que refleja fielmente este desconocimiento es la siguiente:

- En realidad no tenía idea que dan charlas a los primeros años sobre los servicios que tiene la biblioteca, yo me enteré por los compañeros de los cursos superiores, ellos fueron los que me enseñaron los servicios de la biblioteca y a llenar la papeleta.

Incluso varios de ellos señalaron algunas sugerencias de difusión para que los estudiantes y los académicos de la universidad conocieran este servicio. He aquí algunas de ellas:

Luego de las primeras respuestas, no se consideró pertinente plantear la pregunta 2 ¿Han participado en las charlas que dicta la biblioteca?

- "Falta hacer un folleto motivando a los alumnos a participar de las charlas que hacen".

- "Sí, motivarlos con carteles llamativos y colocarlos en todas las salas de clases, en los quioscos de diarios, en el casino, porque ahí los ven todos los alumnos".

A la pregunta número 3 ¿Qué piensan del modelo actual de charlas? respondieron con más propuestas para mejorar el sistema de charlas a los usuarios. Por ejemplo:

- "Una bienvenida sirve para que los mechones tengan un panorama general de las características que tiene la biblioteca, pero es también nece- 
La técnica del Focus Group para determinar el diseño de ...

sario que se profundice sobre lo que tiene la biblioteca".

- "Se puede modificar para que sea mejor. Entregarle un folleto donde estén los servicios que tiene la biblioteca y a la vez darles un curso especial según el año que curse el alumno y su carrera, eso sería bueno".

En relación con la pregunta número 4 ¿Conocen los recursos de información de la biblioteca? la mayoría de los alumnos hicieron una pausa y mencionaron desconocer algunos de los recursos de información que la biblioteca pone a disposición de los usuarios.

Para que los participantes fueran más específicos la moderadora les preguntó si conocían las bases de datos que la biblioteca ofrece, y si habían utilizado las revistas, diarios, o el material audiovisual, y si habían consultado la Internet en la biblioteca. Los alumnos fueron contestando poco a poco e insistieron en la difusión de los servicios y/o recursos mediante diversos mecanismos.

Esto queda reflejado en las siguientes respuestas:

- "Yo no sabía que existían las bases de datos y sería bueno que se nos informara y también a los profesores porque ellos tampoco tienen idea de eso". 
Métodos cualitativos para estudiar a los usuarios de ...

- "Yo voy a leer el diario y las revistas, sé que ahí se encuentran pero no sé cómo se llama esa sección. Estoy seguro que mis compañeros casi nunca lo hacen porque nunca los veo por ahí o porque lo desconocen".

- "Yo los conozco pero no conozco todos, no sabía que se podía pedir libros o artículos a otras bibliotecas fuera de Arica. La biblioteca debería informar sobre todo esto y enseñar a todos los compañeros sobre todo; también es necesario para los funcionarios de la biblioteca porque a veces no saben o no tienen idea sobre éstos, uno le pregunta algo y no dan una respuesta inmediata".

En la pregunta 5 ¿Les gustaría formar parte de un programa de formación de usuarios que desarrolle habilidades informativas? la moderadora tuvo que explicar qué eran las habilidades informativas.

Las respuestas a esta pregunta fueron muy específicas y detalladas. He quí algunas de las más interesantes:

- "Es necesario que se capacite a los alumnos porque a veces no tienen idea dónde pueden encontrar un libro o una revista".

- "Yo veo que los alumnos de primer año van de un lado para otro buscando información. Los funcionarios creen que los alumnos conocen todas las secciones y no las conocen, por ejemplo 
La técnica del Focus Group para determinar el diseño de ...

los mandan a la hemeroteca y no tienen idea qué significa eso".

- "También es importante que se enseñe el uso de los computadores porque muchos de mis compañeros no tienen idea o le tienen miedo y no saben buscar los libros de la biblioteca".

- "Cuando yo busco información en el computador de la biblioteca nunca sale información y tengo que estar un buen rato esperando que salga $y$ si no, me voy y le digo al funcionario que me diga donde está el libro".

- "Como dije anteriormente yo no tenía idea que la biblioteca tenía bases de datos es necesario que se sepa y que además enseñen a usarlas”.

- "A mí, por ejemplo, cuando busco información en Internet, si sirve, la bajo, pero me demoro bastante, además hay mucha información que no se sabe quién la escribió y no se si está bien o está mal. También existe mucha basura en Internet y deberían enseñar a usarla”.

- "Yo pienso que es importante que nos enseñen cómo utilizar los computadores, a buscar información en la biblioteca y en otras. También para que uno no pierda tiempo es importante que nos informen qué información existe en cada sección porque a veces uno anda apurado y tiene que ir de sección en sección buscando la información y eso no me gusta". 
Métodos cualitativos para estudiar a los usuarios de ...

La moderadora leyó la pregunta número 6 ¿Les gustaría que los programas de habilidades informativas estuvieran relacionados con sus asignaturas? Los alumnos se quedaron callados y no emitieron respuesta alguna; en ese momento la moderadora tuvo que explicar en forma detallada lo que significaba la pregunta y paulatinamente los participantes fueron respondiendo.

Todos encontraron que la relación entre "habilidades informativas y asignatura" sería beneficiosa para los estudiantes de la universidad, esto queda reflejado en las siguientes respuestas:

- "Sería fantástico que la biblioteca apoye con estos cursos porque los alumnos lo necesitan y se le debe dar prioridad a éstos".

- Se tendría que conversar con los profesores para que se integren, pero primero se debe informar a los profesores porque no saben sobre lo que se está haciendo en la biblioteca".

- "A mí me gustaría que se realizará esto pero es importante que se vaya realizando a medida que fueran ingresando los alumnos a la universidad".

- "Yo considero que sería motivador para el alumno y más significativo para él y se aprendería mejor".

- “A mí también me gustaría que los cursos estuvieran relacionados con lo que yo estudio, sería más fácil encontrar información”. 
La técnica del Focus Group para determinar el diseño de ...

- "Es importante que la biblioteca nos apoye en los trabajos, a veces no sabemos a quién recurrir y una buena opción sería la que se propone, conocer los libros de nuestra área y hacer mejores trabajos".

- "Estoy de acuerdo con todo lo que se ha dicho pero las clases deben ser bien didácticas".

En relación con la pregunta 7 ¿Los profesores fomentan el uso de la biblioteca? los alumnos también se demoraron en contestar; se miraron a los ojos y sonrieron. Estaban dudosos en responder, al final señalaron lo siguiente:

- "No todos los profesores fomentan el uso, ya que algunos profesores nos pasan los apuntes para que nosotros los fotocopiemos".

- "Algunos nos dicen que revisemos lo nuevo que está llegando a la biblioteca, incluso algunos profesores lo hacen".

- "Por ejemplo en nuestra carrera es importante estar actualizado y la mayoría de los profesores nos hacen usar diferentes revistas o libros para realizar los trabajos".

- "Yo he visto que los profesores fomentan el uso de la biblioteca cuando los alumnos están realizando su actividad de titulación, el profesor da las instrucciones, orienta y ayuda”. 
Métodos cualitativos para estudiar a los usuarios de ...

¿Cómo les gustaría que fuera un curso para enseñar el uso de la información? Fue la pregunta $\mathrm{n}^{\circ} 8$, aquí los participantes mostraron gestos menos rígidos y cada uno de ellos dio algunas sugerencias para mejorar la educación de los usuarios en cuanto al uso de la información. Dentro de las sugerencias mencionadas estuvieron:

- "A mi me gustaría que los bibliotecarios nos ayudaran u orientaran o que nos apoyen cuando estemos realizando la tesis".

- "Podría ser más personalizado y consecutivo".

- "Me gustaría que nos ayudaran a identificar el material que se encuentra en las distintas secciones que tiene la biblioteca, también es importante enseñar qué significa la ubicación de libros para que los alumnos no se pierdan con tantos libros. No tiene que ser repetitivo y es necesario que se enseñe cómo buscar información".

- "Yo pienso que debería ser muy atractivo. A mí como me gusta la música me gustaría que hicieran un video con música e información de la biblioteca y que estuviera en la biblioteca y en otros lugares como el hall de la universidad o en el casino".

- Debe ser teórico y práctico. La persona que dé el curso debe tener paciencia porque no todos aprenden por igual y debe ser muy didáctico. También deberían obligar al alumno a que asista 
La técnica del Focus Group para determinar el diseño de ...

al curso, pero que éste fuera no solo de 15 minutos sino que debería durar más tiempo".

- "También debe ser exclusivo por curso y por carrera”.

- "Debe ser entretenido para que los alumnos no se aburran y así quieran acudir".

Para este momento los participantes ya se tenían confianza y esbozaban sonrisas y hasta algunas carcajadas cuando terminaban de mencionar algunas sugerencias.

A la última pregunta, la no 9 ¿Les gustaría que se los tomara en cuenta para diseñar un programa de formación de usuarios?, todos los participantes contestaron al unísono y fuerte que "s's" les gustaría participar. A todos ellos les gustaría estar involucrados en el diseño.

Una participante señaló que era importante la participación de los alumnos y que era necesario crear formularios para que los estudiantes pudieran dar sugerencias sobre este tema. Con este último comentario la moderadora puso término a la entrevista.

La moderadora agradeció a todos los participantes por el tiempo invertido en este grupo focal, y por la activa participación que tuvieron. Los despidió y los invitó a participar en futuros estudios con grupo focal. Por último, les señaló que se realizaría 
Métodos cualitativos para estudiar a los usuarios de ...

una reunión para informales sobre los resultados de la investigación.

Por su parte los participantes estuvieron contentos y parecían satisfechos de haber participado en esta investigación; se sentían agradecidos por haber sido invitados a contribuir con sus respuestas en el desarrollo de la investigación.

Cuando los participantes se retiraron de la sala, la moderadora y el observador evaluaron la sesión al intercambiar opiniones y registrar la información que por alguna razón había quedado pendiente. Luego se realizó el análisis de datos para obtener los resultados del estudio.

\section{Resultados y conclusiones}

De acuerdo con los objetivos planteados podemos mencionar que mediante el grupo focal aplicado a los estudiantes de nivel superior se conocieron las percepciones que realizaba la biblioteca sobre las actividades de formación de usuarios.

Cada año la biblioteca ofrece charlas sobre sus servicios a los alumnos que ingresan por primera vez a estudiar pero lamentablemente no todos los estudiantes asistieron a ellas. Para solucionar este problema el estudio permitió establecer que es imprescindible difundir estas pláticas a través de:

- Trípticos.

- Folletos. 
La técnica del Focus Group para determinar el diseño de ...

- Carteles llamativos.

- Eventos informativos.

- Coordinación con los académicos para darles las charlas a todos los estudiantes.

En lo sucesivo los contenidos de las charlas que eran meramente informativos sobre las secciones, los horarios y el reglamento, deberán modificarse e impartir clases especiales sobre el uso de la información para todos los estudiantes de la universidad; es decir, deberá haber cursos para alumnos de primer año y cursos diferentes para los estudiantes de niveles más avanzados.

La biblioteca deberá crear los mecanismos necesarios para que los estudiantes universitarios puedan conocer todos los recursos de información, tanto impresos como electrónicos. Para ello será necesario difundir también cuáles son los recursos con que cuenta la biblioteca; la inversión necesaria para adquirir estos recursos deberá recuperarse con el uso óptimo que hagan de ellos los alumnos.

Es importante desarrollar las habilidades informativas de los estudiantes de la universidad. Los alumnos deben aprender cómo buscar, localizar, evaluar, organizar, sintetizar y comunicar la información con el fin de realizar adecuadamente sus actividades académicas.

El personal de la biblioteca deberá involucrase con la planta académica y realizar actividades con- 
Métodos cualitativos para estudiar a los usuarios de ...

juntamente con ella para fomentar el uso de los recursos bibliográficos y electrónicos que posee la biblioteca.

Los participantes en los grupos focales expresaron diversas ideas para diseñar un curso sobre el uso de la información, dentro de las que podemos destacar las siguientes:

- Que los cursos sean personalizados.

- Que sean consecutivos.

- Que apoyen a los alumnos en la elaboración de sus tesis.

- Que el curso esté apoyado con materiales audiovisuales.

- Que sea didáctico.

- Que sea especializado por carreras.

- Que los cursos contengan conocimientos teóricos y prácticos.

El uso de la técnica del grupo focal permitió detectar que el punto de vista de los estudiantes es fundamental, debido a que son los usuarios finales y quienes utilizarán los recursos y los servicios; por ello es imprescindible involucrarlos en el diseño de un curso sobre el uso de la información.

Los entrevistados mencionaron que esta actividad o experiencia fue positiva porque ahora están comprometidos a conocer y utilizar la biblioteca.

Los alumnos sienten que algunos compañeros sí saben cómo localizar información, pero que hay 
La técnica del Focus Group para determinar el diseño de ...

otros que no dominan esa habilidad, lo cual hace imprescindible promover la enseñanza de las habilidades informativas en la universidad.

Gracias al estudio realizado se pudo detectar también que la técnica del grupo focal es muy efectiva para recopilar información directamente de los sujetos para los que fue diseñada la educación, acerca de la manera en que la biblioteca educa a sus usuarios en el uso de la información.

\section{Obras consultadas}

Cortés, C. (2005), Formación de usuarios y modelo educativo: propuesta metodológica para su integración vinculación en instituciones de educación superior, Tesis de Maestría en Bibliotecología y Estudios de la Información, México : Universidad Nacional Autónoma de México.

Matus, G. \& Molina, F. (2006), Metodología cualitativa: un aporte de la Sociología para investigar Bibliotecología, Valparaíso, Universidad de Playa Ancha.

Rodríguez, G., Gil, J., \& García, E. (1999), Metodología de la investigación cualititativa, Málaga, Aljibe.

Romo M., \& Catillo, C.(2002), "Metodología de las Ciencias Sociales aplicadas al estudio de la nutrición, en Revista Chilena de Nutrición, 29 (1), consultada el 03 de marzo de 2007 en http://www.scielo.cl/scielo. php?pid $=$ S0717 $-5182002000100003 \&$ script $=$ sci arttext 
Métodos cualitativos para estudiar a los usuarios de ...

Universidad de Tarapacá (2002), Transformación de la biblioteca en un espacio de educación e interacción social como parte del proceso aprendizaje/enseñanza y de formación integral, Arica, UTA.

Valles, M. (1997), Técnicas cualitativas de investigación social de investigación social : reflexión metodológica y práctica profesional, Madrid, Síntesis.

Young, R. \& Harmony, S. (1998), Working with faculty to design undergraduate information literacy programs : a bow - to - do - it manual for librarians, London, Neal- Achuman Publishers. 


\title{
El incidente crítico como técnica para recolectar datos
}

\author{
Ana Cecilia BALboa
}

\section{Introducción}

\begin{abstract}
- ste capítulo explica en qué consiste la técnica del incidente crítico y cuáles fueron sus antecedentes; se describe el desarrollo de esta técnica, sus principios fundamentales y sus aplicaciones. Se revisan brevemente los hallazgos de un considerable número de estudios que hacen uso de esta técnica en el área de la bibliotecología, se indica el estatus actual y los posibles usos futuros que se le pueden dar. Se describe además la aplicación de la técnica en un estudio que se realizó en cinco bibliotecas académicas de universidades privadas, con el fin de evaluar la comunicación interpersonal entre el bibliotecario y el usuario durante la entrevista de referencia, y se presentan los resultados obtenidos.
\end{abstract}


Métodos cualitativos para estudiar a los usuarios de ...

La técnica del incidente crítico consiste en un conjunto de procedimientos para recolectar observaciones sobre el comportamiento humano que tienen un significado especial y que cubren criterios que han sido sistemáticamente definidos para facilitar así su utilidad potencial en la resolución de problemas prácticos y para desarrollar principios psicológicos.

Por incidente se entiende cualquier actividad humana observable que sea suficientemente completa por sí misma para permitir que se hagan inferencias y predicciones acerca de la persona que realiza el acto. Para ser crítico, un incidente debe ocurrir en una situación en la que el propósito o intención del acto sea lo suficientemente claro para el observador, y cuyas consecuencias sean suficientemente definitivas como para dejar poca duda acerca de sus efectos.

Ciertamente las personas hemos estado haciendo observaciones de otras personas durante siglos. El trabajo de muchos grandes escritores del pasado indica claramente que había aficionados observadores de sus prójimos.

Algunos de estos escritores probablemente habrán confiado en las detalladas notas que hicieron sobre sus observaciones. Otros quizá habrán tenido inusuales habilidades para reconstruir las imágenes de su memoria con detalles vívidos. E incluso otros habrán hecho una serie de observaciones rela- 
El incidente crítico como técnica para recolectar datos

tivamente sistemáticas de muchas instancias de un tipo particular de comportamiento. Tal vez lo que se necesitaba para complementar estas actividades era una serie de procedimientos para analizar y sintetizar tales observaciones dentro de un número de relaciones que pudieran ser probadas por medio de observaciones adicionales sometidas a condiciones más cuidadosamente controladas.

\section{Definición del incidente crítico}

Según su inventor John C. Flanagan (1954), la Técnica del Incidente Crítico (TIC) es:

[...]un conjunto de procedimientos para recolectar observaciones directas del comportamiento humano de tal manera que facilite su utilidad potencial para resolver problemas prácticos y desarrollar principios psicológicos amplios.

Y se trata

[...] esencialmente de un procedimiento para recolectar ciertos hechos importantes concernientes al comportamiento en situaciones definidas [...] No consiste en un conjunto rígido único de reglas que dirigen o controlan tal recolección de datos. Más bien se la debe ver como un conjunto flexible de principios que deben ser modificados y adaptados para satisfacer la situación específica que se tiene a la mano. 
Métodos cualitativos para estudiar a los usuarios de ...

Es esencial que un incidente contenga suficientes detalles de modo que pueda ser analizado posteriormente y ofrecer resultados justos e imparciales. $\mathrm{El}$ incidente debe proporcionar una indicación clara de la percepción ejercida por el observador acerca del desempeño de la persona involucrada.

Más que recolectar opiniones, fragmentos y estimaciones, se pretende obtener un registro de comportamientos específicos de aquellos que están en la mejor posición para hacer las observaciones y evaluaciones necesarias. La recolección y tabulación de estas observaciones hará posible formular los requerimientos críticos para desempeñar una actividad. Una lista de comportamientos críticos proporciona las bases para hacer inferencias en cuanto a los requerimientos necesarios por lo que toca a aptitudes, entrenamiento y otras características.

Flanagan dice también que tales comportamientos son analizados en el contexto de los incidentes o situaciones observadas, las cuales tienen un significado especial y concuerdan con criterios sistemáticamente definidos.

Wilson, Starr-Schneidkraut y Cooper (1989) sintetizan la idea de Flanagan y definen al incidente crítico como un conjunto de metodologías relacionadas, que involucra la recolección de reportes de instancias u ocasiones ("incidentes") detallados, en los cuales un individuo hizo algo que fue especial- 
El incidente crítico como técnica para recolectar datos

mente efectivo o especialmente inefectivo para lograr el propósito de una actividad.

Ovretveit (1992) sugiere que la técnica del incidente crítico le permite a quien responde, expresar necesidades y expectativas especiales y que esto no depende del análisis de un número limitado de componentes, como sería el caso de un cuestionario previamente elaborado. Los usuarios experimentan y recuerdan un servicio dado como una secuencia de incidentes, y no como atributos individuales como, por ejemplo, bueno, regular o malo.

Edvardsson (1992) escribe que:

[...]para que un incidente sea "crítico", el requerimiento es que se desvíe significativamente, ya sea positiva o negativamente, de lo que es normal o de lo que se espera.

Por su parte, Chell (1998) la define como:

[...]un procedimiento cualitativo de entrevista que facilita la investigación de sucesos o acontecimientos significativos (eventos, incidentes, procesos o asuntos) que han sido identificados por el entrevistado, más la forma en que éstos han sido manejados y los resultados que han sido obtenidos en función de los efectos percibidos. El objetivo es obtener un entendimiento del incidente desde la perspectiva del individuo, tomando en cuenta tanto los elementos cognitivos, como los afectivos y los del comportamiento. 
Métodos cualitativos para estudiar a los usuarios de ...

Roger J. Callan (1998) manifiesta que es un procedimiento que registra comportamientos observados que llevan hacia el éxito o el fracaso en el logro de una tarea específica. Finalmente Fisher (1999) propone que el incidente crítico es un conjunto flexible de principios que se proponen facilitar la solución de problemas prácticos por medio de la identificación de comportamientos efectivos, incluyendo los factores relacionados con el comportamiento, tales como el diseño ergonómico (comunicación personal).

En conclusión, la técnica del incidente crítico es un procedimiento que permite la aplicación de diversas teorías para estudiar un comportamiento determinado; en este caso nos referimos tanto a la teoría relacional del campo de la comunicación como a otras áreas del conocimiento y también al campo de la bibliotecología.

\section{Antecedentes}

La llamada "Reported Significant Observation" (RSO), fue usada por la Fuerza Aérea de los Estados Unidos en su programa de psicología de la aviación y más tarde desarrollada por John C. Flanagan (1954); la RSO es más conocida como la "Técnica del Incidente Crítico". Sin embargo, las palabras "crítico" e "incidente" tienen otras connotaciones en el campo de la seguridad nuclear, por lo que sus 
El incidente crítico como técnica para recolectar datos

primeros usuarios dentro de la Compañía Nuclear Aerojet le dieron el nombre más apropiado de "Reported Significant Observation” (Observación significativa divulgada).

La técnica del incidente crítico (TIC) surgió como un resultado de varios estudios conducidos durante la Segunda Guerra Mundial por el Programa de Psicología de la Aviación de la Armada de los Estados Unidos. Este programa estaba bajo la dirección del doctor John Flanagan y fue creado para intentar mejorar el entrenamiento de los aviadores militares. La TIC se usó ampliamente para mejorar la selección de la tripulación de vuelo, el entrenamiento y el desempeño en el combate. Los estudios querían obtener información acerca de las causas por las que fallaban tanto pilotos como entrenadores. Esta técnica de contar "historias de guerra" es la parte medular del proceso del incidente crítico.

Después de que terminó la Segunda Guerra Mundial, Flanagan y otros psicólogos del Programa de Psicología de Aviación, fundaron el American Institute for Research (AIR), organización educativa y científica no lucrativa. Los estudios que esta institución llevó a cabo ayudaron mucho para desarrollar la TIC. Otros estudios llevados a cabo en la Universidad de Pittsburg bajo la dirección de Flanagan proporcionaron más bases y comprensión acerca de esta técnica. Finalmente, en 1954, 
Métodos cualitativos para estudiar a los usuarios de ...

Flanagan publicó una descripción completa de la técnica junto con una revisión de más de 60 estudios (Flanagan, 1954; Roman y Latham, 1974; Zemke, 1979).

Esta técnica ha sido utilizada en más de 700 estudios publicados desde ese momento, incluyendo el realizado en 1960 llevado a cabo por AIR para el National Board of Medical Examiners, en el cual se usó la TIC para recolectar ejemplos de prácticas clínicas efectivas e inefectivas de los internos y residentes con el propósito de definir las dimensiones críticas o su competencia, lo que dio por primera vez una definición concreta de los requerimientos para tener un desempeño efectivo como médico, específicamente como médico residente.

La TIC de Flanagan ha sido utilizada en una amplia variedad de investigaciones, pero se sabe poco de su uso en la Ciencias de la Información y la Bibliotecología.

En 1987, la National Library of Medicine (NLM) ${ }^{1}$ de los Estados Unidos condujo una encuesta nacional entre cerca de tres mil profesionales de la salud que usaban la base de datos Medline. Esta encuesta sin embargo, no sirvió para conocer con detalle las respuestas a preguntas tales como: ¿cuál era el im-

1 http://ftp.nlm.nih/gov/od/ope/cit.html 
pacto que la información recuperada por Medline estaba teniendo en sus actividades profesionales?, ¿cuál era la razón por la cual buscaba usted información a través de Medline?, ¿para qué estaba siendo usada esa información?, o ¿cuál era el impacto final sobre la situación que motivó su búsqueda?

Por eso, en agosto de 1988, la Oficina de Planeamiento y Evaluación de la NLM, con apoyo del American Institute for Research (AIR), iniciaron una investigación para saber si la técnica del incidente crítico podría proporcionar las respuestas a tales preguntas, ya que la metodología tradicional de encuesta, con categorías de respuestas pre-definidas, no era la adecuada para entender la motivación y el comportamiento del usuario, ni tampoco sus consecuencias.

\section{Proceso para obtener incidentes críticos}

Flanagan presenta el procedimiento en cinco pasos:

1. Propósitos generales. Ésta es una condición básica. Involucra una orientación fundamental en términos de los objetivos últimos que persigue el estudio, los cuales deben ser comprendidos y aceptados por la mayoría de los participantes. También debe incluir una breve declaración escrita que se haya obtenido de autoridades en el campo. 
Métodos cualitativos para estudiar a los usuarios de ...

2. Planes y especificaciones. Se proporcionarán instrucciones precisas a los observadores, quienes deberán estar familiarizados con la actividad de los observados. Se especificará el grupo cuyo comportamiento será estudiado y tales comportamientos serán categorizados; las instrucciones serán consistentes con respecto a los estándares que se usarán en la evaluación y clasificación. Se debe poner mucha atención en aquellos aspectos del comportamiento que sean cruciales para formular una descripción funcional de la actividad. Sólo se podrá obtener objetividad si los observadores siguen el mismo conjunto de reglas. En este sentido, se establecerán las especificaciones y se harán explícitas antes de hacer la recolección de los datos. Dichas especificaciones incluirán: las situaciones observadas, su relevancia con respecto al objetivo general, la extensión del efecto sobre el objetivo general, y el personal que haga las observaciones.

3. Recolección de datos. Es preferible hacer la recolección de datos a partir de una observación directa, pero también es aceptable la recolección de datos retrospectivos que estén frescos en la mente de los sujetos que se van a estudiar, efectuada por medio de entrevistas individuales, entrevistas de grupo y cuestionarios.

Es aconsejable llevar a cabo un estudio piloto 
El incidente crítico como técnica para recolectar datos

para verificar la interpretación de las preguntas y las instrucciones. La pregunta debe incluir una breve especificación acerca del tipo de comportamiento relevante y se les debe pedir a los sujetos que recuerden ciertos incidentes, como por ejemplo los más recientes. En el momento de la entrevista, deberán ser los entrevistados y no los entrevistadores los que hablen más.

4. Análisis de los datos. El propósito es resumir y describir los datos de manera eficiente para poder formular categorías, lo cual es un proceso subjetivo. Una vez que se ha desarrollado el sistema de clasificación se puede obtener un grado de objetividad bastante satisfactorio, y se pueden formular hipótesis a través del estudio de los incidentes.

5. Interpretación de los reportes. En muchos casos, los errores verdaderos no se cometen durante la recolección y el análisis de los datos, sino que se falla en hacer una interpretación adecuada de éstos.

Yasar Tonta (1992), de la universidad de Berkeley en California, resume los procedimientos de la TIC en dos grandes pasos:

a) Recolección y clasificación detallada de los reportes de incidentes, $y$

b) Elaboración de inferencias basadas en los incidentes observados. 
Métodos cualitativos para estudiar a los usuarios de ...

\section{El procedimiento de la entrevista y la reco- lección de los datos}

La recolección de datos se puede hacer de diferentes maneras: entrevista personal, entrevista de grupo, o cuestionario (Flanagan, 1954; Callan, 1998).

Al seleccionar el instrumento de recolección hay que tener en cuenta el tipo de personal disponible en la biblioteca. Puede ser que ya existan expertos dentro de la organización, ya sea entrevistadores o diseñadores de cuestionarios. A falta de estos expertos, se pueden contratar consultores en el área.

Al escoger entre la entrevista y el cuestionario, la principal consideración, aparte del problema del personal que va a llevar a cabo la recolección de datos, es la validación de los resultados del estudio. Esta consideración incluye dos aspectos: la predisposición y el anonimato.

\section{Predisposición}

Flanagan (1954) sugiere que el entrevistador sea alguien familiarizado con el área que va a ser estudiada, pero también hay que tener cuidado al seleccionar y entrenar a las personas que van a recoger los datos, porque se pueden obtener resultados no apropiados de un ingeniero eléctrico empleado como entrevistador si el ingeniero está predispuesto a descubrir problemas de seguridad en cuanto a electricidad. El entrevistador será capaz de detectar 
y corregir las falsas interpretaciones de la pregunta sin inducir al participante a una respuesta predeterminada.

Si se emplea la entrevista será menos probable que se predisponga al participante. Esto es debido a que el entrevistador puede percibir las opiniones que causan que los individuos reaccionen de manera diferente a la misma pregunta. Si el participante ha malinterpretado la pregunta o está tratando de mencionar algún problema personal, el entrevistador tiene la libertad de cambiar la pregunta para re-direccionar al participante de vuelta a la trayectoria.

Si se elige el cuestionario, desafortunadamente no se podrá variar una vez que haya sido distribuido, y siempre habrá un cierto número de resultados inválidos en cada estudio. Esto se puede minimizar sólo a través de una redacción cuidadosa de las preguntas escritas y con el uso de un ejemplo o comentario introductorios incluidos en el paquete del cuestionario.

\section{Anonimato}

El anonimato es importante para los individuos quienes podrían recibir una acción punitiva como resultado de la información que revelen.

La entrevista se basa en la premisa de que los individuos estarán menos inhibidos debido a que usualmente estarán describiendo incidentes o situa- 
Métodos cualitativos para estudiar a los usuarios de ...

ciones "casi fallidas" en las que no hubo daños. Pero el entrevistador sólo puede ofrecer promesas orales de que el material de los participantes permanecerá en el anonimato.

El cuestionario asegura más el anonimato porque no pregunta los nombres. Los resultados se pueden regresar incluso en sobres sellados. La apertura que permite el anonimato puede ayudar a revelar la actitud del empleado y la información moral, las cuales son difíciles de obtener por otros métodos.

Flanagan cree que el método más apropiado para la recolección de datos es la entrevista individual, debido a su eficiencia, lo inmediato del proceso y las demandas mínimas para que la gente coopere. Afirma que: "la recolección y la tabulación de estas observaciones permiten formular los requerimientos críticos de una actividad (ej. calidad del servicio)”.

La entrevista no se propone preguntarle al entrevistado que identifique las causas que contribuyeron a su experiencia satisfactoria o no satisfactoria, sino sólo que describa aquellos incidentes en los que tuvo lugar una interacción de servicio buena o mala.

Repetir los eventos o historias de esta manera es algo que la mayoría de la gente hace con facilidad. Es el investigador quien se hace responsable de la abstracción y las inferencias. Flanagan sugiere que 
El incidente crítico como técnica para recolectar datos

para que el proceso de la entrevista sea más efectivo, será necesario:

- Indicarle al entrevistado la autoridad sobre la cual se está llevando a cabo la entrevista.

- Hacer una declaración por escrito acerca del propósito del estudio.

- Explicarle por qué él ha sido elegido para comentar.

- Convencer al entrevistado de que se guardará el anonimato.

- La principal "pregunta" debe manifestar que se desea un incidente o un comportamiento reciente.

- Permitirle al entrevistado que él sea el que hable $\mathrm{y}$ evitar hacerle preguntas inducidas

- Hacer preguntas de seguimiento para asegurarse de que se ha dado una narración o relación comprensible y detallada.

Anderson y Nilsson (1964) y Edvardsson (1992), están de acuerdo en que el mejor método para la recolección de datos es la entrevista personal, debido a la profundidad y riqueza de los datos recolectados. Los datos no adquieren su riqueza fácilmente, se requiere de una preparación cuidadosa para la entrevista en sí. 
Métodos cualitativos para estudiar a los usuarios de ...

\section{Análisis y validación de los datos}

Conforme se recolectan los incidentes, se van clasificando y gradualmente debe surgir un esquema de clasificación. La forma en que se clasifican los incidentes es subjetiva puesto que el investigador elige los encabezamientos o etiquetas bajo los cuales se categorizarán los incidentes. Las categorías deben estar abiertas al cambio y desarrollo conforme se recolecten más incidentes.

Una vez que se ha establecido el esquema de clasificación se puede alcanzar una cierta objetividad para colocar los incidentes en las categorías definidas. La clasificación de los incidentes será únicamente de valor si éstos se analizan cuidadosamente y se colocan en la categoría correcta, con lo cual se optimizará la confiabilidad de los resultados.

El análisis consiste en hacer una lectura cuidadosa, en separar y volver a leer, y en volver a separar en grupos y subgrupos, al mismo tiempo que se mantiene la máxima cantidad de detalles al leer los incidentes, se reconocen las similitudes, y se mejora la clasificación. Dos investigadores deben trabajar independientemente en la categorización, el absoluto acuerdo entre ellos proporcionará una categorización más objetiva. Ahí donde se identifiquen diferencias se debe volver a leer el material y reacomodarlo hasta que se logre un total acuerdo, ya sea en una subcategoría ya existente o desarrollando 
El incidente crítico como técnica para recolectar datos

una nueva. Una vez que se complete la categorización de los incidentes, se deberá determinar la importancia de cada atributo y cada subcategoría. La medida más simple para determinar la importancia es el número de incidentes identificados bajo cada subcategoría o atributo.

\section{Aplicaciones}

Flanagan describió los siguientes usos para la técnica de incidentes críticos (1954):

- Medición de desempeños típicos. Es la aplicación más simple y natural, se refiere a preparar por escrito la declaración del requerimiento crítico y a evaluar el desempeño del personal involucrado en una actividad.

- Medición de la destreza o habilidad.- Se evalúa el desempeño contra las muestras de comportamiento estándar.

- Entrenamiento.- Se establecen los requerimientos del entrenamiento.

- Selección y clasificación.- Se trata de identificar con precisión los elementos de trabajo importantes para una tarea específica.

- Diseño de trabajo.- Equipara las tareas y el entrenamiento con cada miembro del equipo.

- Procedimientos de operación.- Se detallan los datos reales sobre los éxitos o fracasos que pueden 
Métodos cualitativos para estudiar a los usuarios de ...

ser analizados sistemáticamente para mejorar la efectividad y la eficiencia.

- Diseño del equipo.- Se implementan las ideas de retroalimentación para modificar el equipo.

- Motivación y liderazgo.- Se estudian las actitudes que proporcionan las bases para analizar la motivación y el liderazgo.

- Consultoría y psicoterapia.-Se desarrollan medidas objetivas para el mejoramiento. Se analizan los tipos de mejoría que resulten del uso de procedimientos específicos por parte del terapeuta. La TIC se ha usado como un método clave en las industrias hoteleras y de los restaurantes para registrar el éxito o fracaso en situaciones de servicio (Bitner, Booms y Stanfield Tetrecuilt, 1990). En este último caso la técnica se utilizó con el propósito de reducir mucha información cualitativa y facilitar la evaluación de los aspectos positivos y negativos del servicio, y para analizar las fuentes de satisfacción o insatisfacción por parte de los usuarios.

Roger J. Callan (1998) dice que es una técnica útil y apropiada para estudiar cuestiones de calidad en el servicio y para evaluar las percepciones de los usuarios, ya que proporciona información significativa acerca de las necesidades de los clientes. En estudios futuros podría ser valioso incluir una muestra de los proveedores del servicio para comparar y contrastar las percepciones de las tres partes 
El incidente crítico como técnica para recolectar datos

involucradas en la provisión y obtención del servicio ofrecido. En muchos casos, lo que puede ser la crítica fundamental es la actitud y el comportamiento del proveedor del servicio, más que el servicio en sí mismo.

Los incidentes identificados le permiten al investigador situarse más allá de las descripciones del atributo, tales como empleados amigables o empleados eficientes, para proporcionar razones que expliquen el comportamiento de éstos y subsecuentemente dar soluciones que puedan ser aplicadas a una unidad operacional en particular o a un grupo de unidades similares.

La técnica ha sido utilizada en varias disciplinas, como en la administración, los recursos humanos, la hotelería, el turismo, la educación y en especial para medir la hospitalidad. Bitner et al. (1990) recolectaron incidentes en tres industrias: hoteles, restaurantes y líneas aéreas, considerándolas como representativas de los servicios de alto contacto en donde las habilidades de comunicación oral son particularmente importantes.

Owen $(1976,1977)$ sugiere que la TIC podría ser útil para el desempeño y determinar los requerimientos críticos en los empleos. De manera similar, Berkner (1979) sugiere su uso como un elemento para evaluar el desempeño. Cabe hacer notar que a un nivel más general, Pearn y Kandola (1993) 
Métodos cualitativos para estudiar a los usuarios de ...

la incluyeron como una de las diez técnicas más útiles para el análisis de empleos, de los papeles a desempeñar y de las tareas a realizar.

\section{El uso de la técnica del incidente crítico en bibliotecas}

La técnica del incidente crítico ha sido usada en algunas bibliotecas en particular en las décadas del 60 y 70, después del artículo de Flanagan de 1954, e incluso logró una entrada en los principales volúmenes de la Encyclopaedia of Library and Information Science (Shirey, 1971).

Slater y Fisher (1962) usaron el concepto de "incidente crítico" en estudios acerca del uso de la biblioteca como una forma de "enfocar la mente de la persona que responde y de proporcionar datos sobre una ocurrencia específica”. Este es un enfoque mucho más útil que el de buscar narraciones generalizadas sobre el uso de la biblioteca. En 1966, Menzel citó los estudios de la TIC como un factor significativo en el desarrollo de investigaciones empíricas en el área de la información. Por su parte Chamberlain (1982) y Smith (1988), la utilizaron para identificar las diferencias perceptuales que existían entre los estudiantes y académicos en cuanto a la efectividad de los bibliotecarios. Collins (1985) la empleó para analizar el comportamiento de los bibliotecarios de referencia en las bibliotecas 
El incidente crítico como técnica para recolectar datos

académicas de la Universidad de Boston, Massachussets.

La TIC ha sido aplicada en dos estudios de servicio de referencia "avanzados". En ambos casos los autores dan buenas narraciones de sus métodos. Carr (1980) obtuvo 113 ejemplos de incidentes críticos de 39 respondientes, cuando examinó el papel que desempeña el personal bibliotecario al ayudar a adultos aprendices independientes. Siegel (1991) hizo un estudio para conocer el uso que hacen los médicos del MEDLINE y Radford (1996) uno sobre el servicio de referencia en tres bibliotecas académicas.

Más recientemente Wilkins y Leckie (1997) usaron esta técnica como procedimiento clave para estudiar las necesidades de información y el comportamiento durante la búsqueda de información sobre el personal profesional y gerencial de la Universidad de Western Ontario.

Shelag Fisher y Tony Oulton (1999) se interesaron en la TIC en 1980 cuando la escuela de bibliotecología de la Universidad de Manchester, en el Reino Unido, estaba desarrollando el currículo para una maestría en part-time, post-qualification, post-experience que evolucionó hasta convertirse en la maestría en "Strategic Library Management" (Gerencia Estratégica de Bibliotecas). La técnica del incidente crítico parecía ser la apropiada para enseñarles métodos de investigación a los gerentes de 
Métodos cualitativos para estudiar a los usuarios de ...

bibliotecas; algunos de los estudiantes de esta maestría que utilizaron la TIC en su investigación fueron Andrews (1991) y Harrington (1992), quienes participaron en tres estudios que se estaban llevando a cabo en la mencionada universidad: uno era sobre las necesidades de desarrollo de los empleados como elemento clave para el cambio en la Educación superior del Reino Unido; otro sobre las prácticas de toma de decisiones en bibliotecas de pequeñas a medianas en Europa, el proyecto DECIMAL; y el último sobre el desarrollo de herramientas de apoyo para el aprendizaje el proyecto LISTEN: (Library and Information Services Training and Education Network), que se debía usar para ayudar a los trabajadores de las bibliotecas a que ascendieran hacia la gerencia.

El Learning Support Tool o herramienta para el apoyo en el aprendizaje consistió de 14 actividades, dos de las cuales adoptaron la forma de un estudio de incidente crítico. Se les pidió a los participantes considerar cinco incidentes críticos relacionados con su vida laboral reciente y responder a tres de ellos como mínimo para hacer un auto-análisis. Después de completar la actividad, se les pidió que analizaran sus relatos considerando qué habilidades habían usado o deberían haber usado; si podían identificar patrones ya fueran positivos o negativos; $y$ cómo se re- 
El incidente crítico como técnica para recolectar datos

lacionaba la evidencia obtenida de esta actividad con otros compañeros de trabajo.

La mayoría de estos estudios no explota los beneficios de la técnica por completo porque sólo toma en cuenta el punto de vista del bibliotecario, o se enfoca en el usuario individual como un agente libre que tiene la opción de usar, o no, un servicio de información. Unicamente los estudios de Radford (1996) y Balboa (2005) consideraron la interacción entre el usuario y el bibliotecario.

Para llevar a cabo la entrevista usando la TIC de forma correcta se debe hacer previamente un trabajo de investigación y compilar la muestra y las entrevistas telefónicas; sin embargo la entrevista en sí no es muy estructurada, lo que quiere decir que el entrevistador debe ser capaz de adaptar las preguntas al entrevistado en particular. A pesar que esta técnica ha sido usada como una metodología de investigación subjetiva, una de sus ventajas es su versatilidad.

Usada cualitativamente la TIC proporciona datos discursivos que pueden ser objeto de análisis narrativo, y pueden ser codificados y categorizados de acuerdo con los principios de la teoría fundamentada en los datos (Grounded Theory) ${ }^{2}$ (Strauss

2 Se refiere a la teoría que es desarrollada inductivamente a partir de un cuerpo de datos. 
Métodos cualitativos para estudiar a los usuarios de ...

y Corbin, 1990). Según los principios de esta teoría, a partir de los datos se pueden derivar seis tipos de incidentes:

1. Incidentes proactivos; en donde el actor actuó siguiendo los objetivos de la organización o personales.

2. Incidentes reactivos; en donde el actor actuó en respuesta a presiones de dentro o de fuera de la organización.

3. Incidentes tangibles; los cuales involucraron un cambio en la organización, que podía ser observado o medido por ejemplo, la construcción de una segunda sala de lectura.

4. Incidentes intangibles; que involucraron situaciones que no podían ser observadas o medidas y estaban abiertas a la percepción de diferentes participantes, por ejemplo cambios en el proceso gerencial o problemas de relaciones humanas.

5. Incidentes positivos; en los que el actor consideró el evento de manera positiva.

6. Incidentes negativos; en donde el actor consideró el evento en forma negativa.

\section{Descripción de la aplicación}

La Técnica del Incidente Crítico se aplicó en un estudio realizado en bibliotecas académicas de instituciones de educación superior en México con el fin de evaluar la comunicación interpersonal entre 
El incidente crítico como técnica para recolectar datos

el bibliotecario y el usuario durante la entrevista de referencia. Se tomó como base el tercer axioma propuesto por Watzlawick et al. (1967) que se explica a continuación.

En su libro La Pragmática de la Comunicación Humana, Watzlawick et al. (1967) estudiaron el comportamiento o la psicología de la comunicación como un proceso interactivo. Estos investigadores querían descubrir e identificar patrones significativos y afirmaban que la búsqueda de patrones es la base de toda investigación científica, y que en donde hay un patrón hay significado.

Esta búsqueda de patrones es la base de un cálculo hipotético propuesto por Watzlawick (1967), que va acompañado por la identificación de cinco propiedades simples o "axiomas" acerca de la comunicación humana:

- Primer axioma: Uno no puede no comunicarse. Esto es, todo comportamiento o conducta humana tiene valor de mensaje; es decir, de comunicación. Las palabras o el silencio, la actividad o inactividad, siempre influyen sobre los demás.

- Segundo axioma: Los seres bumanos se comunican tanto digital como analógicamente.

Las palabras pertenecen al código digital y son el vehículo del contenido, mientras que la comunicación analógica es la comunicación no verbal, la cual es el vehículo de la relación. 
Métodos cualitativos para estudiar a los usuarios de ...

- Tercer axioma: Toda comunicación bumana tiene un aspecto de contenido y uno de relación. $\mathrm{El}$ aspecto de contenido de un mensaje transmite la información, mientras que el aspecto de relación transmite el tipo de relación que se quiere lograr con el interlocutor.

- Cuarto axioma: La naturaleza de la relación depende de cómo ambas partes pautan las secuencias de comunicación.

Es decir, en una interacción uno de los participantes siempre toma la iniciativa o es el líder, mientras que el otro tiende a la dependencia, y es difícil decir cuál surge primero o qué sería del uno sin el otro.

- Quinto axioma: La comunicación puede ser ya sea complementaria o simétrica.

La comunicación simétrica se base en la igualdad de poderes, mientras que la complementaria en la complementariedad de la conducta de uno en relación con la conducta del otro.

El tercer axioma clave del que parte Watzlawick (1967), y el que se propuso para este estudio, es que cada mensaje tiene un aspecto de contenido y uno de relación. El contenido es qué se dice, y la relación es cómo se dice.

Los aspectos de contenido tienen que ver con el intercambio de información, y los aspectos de relación con los sentimientos y actitudes que tienen los 
El incidente crítico como técnica para recolectar datos

interactuantes durante el encuentro, lo cual resultó relevante y útil para comprender la interacción entre bibliotecario y usuario.

El estudio piloto que Flanagan sugiere dentro de la sección de "recolección de datos" para verificar la interpretación de las preguntas aplicadas en la entrevista, se llevó a cabo en las bibliotecas de la Universidad Nacional Autónoma de México y proporcionó la base para diseñar el estudio principal.

Para aplicar la técnica se siguió el proceso descrito por Flanagan (1954) que, como se explicó con anterioridad, consiste en realizar cinco etapas: 1 ) Propósitos generales, 2) Planes y especificaciones, 3) Recolección de datos, 4) Análisis de los datos y 5) Interpretación de reportes. Se utilizó la entrevista personal como instrumento de medida y se siguieron los siguientes cuatro pasos.

\section{Propósitos Generales}

Los objetivos del estudio fueron entender y mejorar la relación bibliotecario-usuario dentro del contexto de bibliotecas académicas, desde la perspectiva de la comunicación interpersonal; se trataba de identificar y describir los factores críticos de esta relación, que, tanto bibliotecarios como usuarios, percibieron como importantes para el éxito o fracaso de la interacción en el servicio de referencia. 
Métodos cualitativos para estudiar a los usuarios de ...

Como resultado del estudio piloto, se determinaron las cuatro preguntas de investigación que se presentan a continuación:

1. ¿Se perciben como importantes los aspectos de relación en la comunicación interpersonal para que tenga éxito el encuentro entre el bibliotecario y el usuario en el servicio de referencia?

2.¿Qué aspectos de relación se pueden identificar en la comunicación interpersonal en cuanto al éxito que se tenga en la entrevista de referencia, según lo perciben bibliotecarios y usuarios?

3. ¿Qué aspectos de relación se pueden identificar en la comunicación interpersonal con respecto a los encuentros no exitosos, según lo perciben los bibliotecarios y los usuarios?

4. ¿Difieren los aspectos de relación de importancia para los usuarios, de aquellos que tienen importancia para los bibliotecarios?, y de ser así, ¿cómo?

\section{Planes y Especificaciones}

Se asistió durante varios meses a un cierto número de sesiones realizadas por empresas que se dedican a los estudios psico-industriales, con la finalidad de aprender las diferentes técnicas de entrevista. El uso de la TIC requiere de entrevistas relativamente largas (en este proyecto se promediaron de 1.5 a 2 horas) y, por lo tanto, una muestra limitada de entrevistados. 
$\mathrm{El}$ incidente crítico como técnica para recolectar datos

\section{Selección de bibliotecas}

Se eligieron 5 bibliotecas académicas privadas para realizar esta investigación:

- Universidad Iberoamericana.

- Universidad Anáhuac.

- Instituto Tecnológico Autónomo de México.

- Tecnológico de Monterrey campus Estado de México.

- Universidad la Salle.

La elección de estas cinco instituciones se debió a que cuentan con un servicio de referencia en el que las preguntas de referencia académica son por lo general más profundas y requieren interacciones de comunicación interpersonal más complejas que las que se hacen en las bibliotecas públicas o escolares, y son más diversas que aquéllas que se dan en una biblioteca especializada. Estas universidades se distinguen por tener diversidad en cuanto al número y niveles de grados que ofrecen, en cuanto al nivel de sofisticación de los estudiantes, y en cuanto a la misión de cada biblioteca. Se eligieron estas instituciones para proporcionar una amplia gama tanto de bibliotecarios como de usuarios.

Cada tipo de biblioteca ya sea académica, pública o especializada, tiene funciones distintas que se pueden ver reflejadas en los objetivos, los procedimientos y el contenido de las interacciones, por lo que no es conveniente mezclarlas. 
Métodos cualitativos para estudiar a los usuarios de ...

\section{Selección de la muestra}

Las personas seleccionadas para este estudio se eligieron de tal manera que se asegurara el reporte de todos los posibles resultados, pero no necesariamente con base en su representación proporcional en la población.

\section{Bibliotecarios}

En el caso de los bibliotecarios, una vez identificados los sujetos que serían entrevistados se les enviaron cartas de invitación para participar en el estudio, las cuales estaban firmadas por el Director de sus respectivas bibliotecas. Posteriormente se llamó por teléfono a cada invitado para concertar una cita para la entrevista, y si el bibliotecario aceptaba se le proporcionaban los detalles, como el lugar y la hora en que ésta se llevaría a cabo.

De esta manera se reclutaron dos bibliotecarios por cada biblioteca quienes al solicitarles participar como voluntarios se les dijo también que el estudio tenía relación con la entrevista de referencia. También se les informó que el propósito de la investigación no era evaluar su desempeño profesional o sus habilidades, sino entender la dinámica que se da durante la entrevista. Por lo tanto los participantes se eligieron ellos mismos; sin embargo no se les informó la naturaleza del estudio para que el sesgo se mantuviera al mínimo. Todos ellos leyeron y fir- 
El incidente crítico como técnica para recolectar datos

maron una hoja informativa y de consentimiento, y llenaron la hoja de recolección de datos.

Cuatro bibliotecarios eran hombres y seis mujeres; todos ellos referencistas de tiempo completo con un promedio de edad de 44 años; y 10 años de experiencia en el servicio de referencia en diferentes bibliotecas académicas. Dos de ellos contaban con el grado de maestría y ocho con el de licenciatura, todos en Bibliotecología.

\section{Usuarios}

En el caso de los usuarios, éstos se eligieron al azar dentro de las bibliotecas. Después de que se observaba que habían tenido un encuentro con el bibliotecario encargado del servicio de referencia se los abordaba e invitaba a participar en el estudio; se les preguntaba si estaban dispuestos a contestar unas cuantas preguntas, y si estaban de acuerdo en que la entrevista fuera grabada. Si el usuario aceptaba se lo llevaba a un lugar aparte para la entrevista, o se concertaba una cita para una entrevista posterior. Se entrevistó así a un total de diez usuarios y se siguió con ellos el mismo procedimiento que con los bibliotecarios: se les dio a leer y a firmar una hoja informativa y de consentimiento, se les aseguró su anonimato y se les pídió que llenaran la hoja de recolección de datos. De los diez usuarios, dos eran hombres y ocho mujeres; la edad promedio era de 
Métodos cualitativos para estudiar a los usuarios de ...

31 años; dos de ellos tenían estudios de postgrado. Todos manifestaron asistir un promedio de 2.4 veces por semana a la biblioteca para hacer alguna investigación.

\section{Recolección de Datos}

Las entrevistas se llevaron a cabo en las diferentes bibliotecas académicas a distintas horas del día, entre semana y los fines de semana, pues el tipo de usuarios varía entre la mañana y la tarde, y también entre quienes asisten entre semana o los fines de semana. Un ejemplo: los alumnos (usuarios) que asisten por la tarde a la universidad son generalmente los que trabajan medio tiempo, y los que asisten los fines de semana los que trabajan tiempo completo.

Hubo algunas variaciones debidas a la altura de tiempo en que se encontraba el semestre, lo cual impactó el nivel de actividad en el servicio de referencia y el tiempo del que el bibliotecario dispusiera para cada usuario. El nivel de actividad puede elevarse sustancialmente hacia el final del semestre.

Se abría cada sesión de la entrevista con una presentación estándar. Se le entregaba al participante una hoja informativa y de consentimiento, se le pedía que llenara una hoja de recolección de datos (dependiendo de si era usuario o bibliotecario) y se le pedía permiso para grabar la entrevista. Muchos de los participantes mostraron su preocupación por la 
El incidente crítico como técnica para recolectar datos

confidencialidad de la información pese a que la entrevistadora les aseguró que todos los datos serían tratados con la más estricta confidencialidad.

Cumplido lo anterior se procedía con las preguntas. En una hoja separada se registraba cualquier ademán o gesto que hiciera el entrevistado y que pudiera aportar aspectos no verbales durante la interacción de referencia. Se requería que los incidentes hubieran tenido lugar en las últimas dos semanas.

Antes de las entrevistas se alentó a los participantes a ser lo más explícitos posible en sus respuestas, recordándoles que: (a) sus respuestas serían totalmente confidenciales, (b) que el estudio era de carácter exploratorio y no estaba diseñado para juzgar su efectividad; y a los bibliotecarios se les informó expresamente que no se haría una evaluación de su desempeño ni se le comunicarían los resultados a su jefe o supervisor, y (c) que el estudio se llevaría a cabo únicamente con propósitos de investigación y que bajo ninguna circunstancia se incluiría su nombre o características que lo identificaran en este estudio. También se les aseguró que no había respuestas "correctas", y que únicamente se intentaba descubrir cuáles eran sus perspectivas acerca de estos temas.

Las interacciones se llevaron a cabo de manera individual y las preguntas de la entrevista se centra- 
Métodos cualitativos para estudiar a los usuarios de ...

ron en las percepciones tanto de los bibliotecarios como de los usuarios: acerca de entrevistas de referencia exitosas y no exitosas, acerca de las características tanto de los buenos como de los malos bibliotecarios y usuarios, y acerca del propósito de la entrevista de referencia. Las preguntas fueron abiertas y se basaron en las preguntas de investigación. Se recolectaron datos demográficos y la entrevista fue grabada. Todas las cintas fueron inmediatamente numeradas y codificadas para su posterior identificación.

Si el usuario se negaba a participar se seleccionaba otro. Por lo general los usuarios fueron muy cooperativos y sólo unos cuantos se rehusaron a ser entrevistados. Las causas por las que se rehusaron se debieron principalmente a presiones de tiempo. Sin embargo en las raras ocasiones en que un usuario se rehusó, el siguiente accedió a ser entrevistado y nunca hubo necesidad de volver a visitar una biblioteca.

En el caso de los bibliotecarios las visitas fueron programadas de modo que éste tuviera tiempo para responder tranquilamente a la entrevista sin ser interrumpido. El plan original era entrevistar al bibliotecario inmediatamente después de la interacción pero esto hubiese sido casi imposible debido a que los participantes deben cumplir con un horario asignado en el servicio de referencia, y podrían ha- 
El incidente crítico como técnica para recolectar datos

ber tenido mas usuarios que atender, $u$ otras responsabilidades, como responder el teléfono.

Las entrevistas fueron grabadas para su posterior trascripción y codificadas para su identificación.

\section{Análisis de los Datos}

Esta sección describe los procedimientos empleados en el análisis de la entrevista y los datos observados. Se analizaron las transcripciones y los datos complementarios de todas las entrevistas con los bibliotecarios y con los usuarios para a) desarrollar un esquema de categorías que reflejara las dimensiones del contenido y de la relación entre el encuentro usuario-bibliotecario, b) examinar los incidentes particulares, y c) comparar las percepciones que tenían los usuarios acerca de los bibliotecarios, y viceversa.

La principal forma de registro de datos usada en el análisis fue la transcripción de las entrevistas, en las cuales se omitieron las porciones que no estaban relacionadas con la pregunta de investigación (como discusiones acerca del tiempo) o aquellas que daban demasiados detalles (tales como la estrategia de búsqueda).

Cada una de las transcripciones de las entrevistas fue colocada en una carpeta junto con la hoja de consentimiento firmada, la hoja de recolección de datos y las notas manuscritas que contenían infor- 
Métodos cualitativos para estudiar a los usuarios de ...

mación acerca del comportamiento no-verbal observado en los participantes.

\section{Desarrollo de un esquema de categorías}

El esquema de categorías se desarrolló por medio de la cuidadosa lectura de las transcripciones y utilizando un esquema de codificación derivado del Esquema de Categorías que se utilizó en el Estudio Piloto.

Al seleccionar las etiquetas para las categorías se usaron las propias palabras de los participantes cuando esto fue posible. Algunas etiquetas fueron desarrolladas para formar categorías más grandes con el propósito de agrupar a aquellas que eran similares.

A partir del estudio piloto se identificaron las palabras y frases que sugerían temas, y fueron codificadas utilizando marcadores y clips de colores para facilitar el análisis. Al analizar las transcripciones, palabras y frases que sugerían temas identificados en las categorías del estudio piloto, se marcaban con un color y la hoja se marcaba con un clip de igual color y lo mismo se hacía con aquellas que se iban adicionando. De esta manera todas las afirmaciones que pertenecían a una categoría podían ser rápidamente identificadas, interpretadas y categorizadas en relación con el contexto de su ocurrencia. Cuando era necesario hacer un cambio de cate- 
El incidente crítico como técnica para recolectar datos

goría, se cambiaba el color del clip y el texto se marcaba con el nuevo color. Como había más categorías que colores, tanto de los marcadores como de los clips disponibles, se utilizaron combinaciones, por ejemplo, la categoría de "Barreras-de relación" se marcaba con un clip azul (para "barrera") y con un clip amarillo (para "de relación"). Esto permitió la organización y el acceso a grandes cantidades de datos cualitativos.

Las categorías fueron marcadas con la letra de $\mathrm{Bi}$ bliotecario (B) o de Usuario (U) que mencionó dicho factor. Las subcategorías también fueron listadas siguiendo el orden de la más frecuentemente mencionada al principio, de modo que los factores más críticos pudieran ser fácilmente identificados.

Se recolectaron los incidentes críticos tanto de bibliotecarios como de usuarios pidiéndoles que: a) identificaran el propósito o meta de la interacción, b) recordaran y describieran una interacción exitosa, y c) recordaran y describieran una interacción no exitosa.

La colocación de los incidentes en categorías se logró al leer con cuidado y repetidamente las transcripciones de las entrevistas. Los incidentes ya estaban clasificados como "positivos" o "negativos" según los habían percibido y reportado los informantes. 
Métodos cualitativos para estudiar a los usuarios de ...

La primera tarea fue determinar si el éxito o fracaso de la interacción estaba asociado con las dimensiones de "Contenido" y de "Relación" o bien con una combinación de ambas. Se subrayaron las palabras y frases que daban alguna indicación sobre estos aspectos.

Al clasificar los incidentes se consideró el énfasis del informante y se anotó. Se puso particular atención a la pregunta ¿"Qué hizo a la interacción exitosa o no exitosa"? ya que muchas veces el informante discutía tanto cuestiones de contenido como de relación, pero casi siempre describía una con mayor detalle que la otra.

Los incidentes se clasificaron como "Combinación" sólo si discutían de manera equitativa los aspectos tanto de relación como de contenido en cuanto a las percepciones de éxito o fracaso en la interacción. Si un incidente tenía ambos aspectos pero se inclinaba más hacia una dirección, era colocado en la que más peso tenía.

Después que los incidentes fueron colocados en las categorías de temas de "Contenido", de "Relación", o de "Combinación", se analizaban de nuevo, esta vez con la finalidad de identificar sub-temas.

Se desarrolló un esquema de categorías que fue utilizado para identificar y clasificar los temas de incidente crítico. El esquema se fue modificando 
El incidente crítico como técnica para recolectar datos

durante el curso del análisis conforme surgían nuevas categorías y se eliminaban, cambiaban o se combinaban algunas otras. El esquema final contiene los temas principales relacionados con el "Contenido", y los temas principales con temas de "Relación".

La técnica del incidente crítico (Flanagan, 1954) permitió que el análisis se enfocara precisamente sobre las preguntas de investigación números $2 \mathrm{y}$ 3 , que abordaban los aspectos de relación de la comunicación y cómo influyen éstos sobre la percepción de éxito o fracaso tanto de los bibliotecarios como de los usuarios.

\section{Interpretación de reportes o resultados}

\section{Metas y objetivos de la interacción}

Las metas, tanto para los usuarios como para los bibliotecarios, se centraron en los aspectos de contenido. Unos y otros hablaron sobre el conocimiento como un tema importante y las dos categorías más altas de los bibliotecarios estuvieron también relacionadas "con el conocimiento".

Facilitadores. Son las cualidades o características que tienen un impacto positivo sobre las percepciones de los participantes en la interacción bibliotecario-usuario. 
Métodos cualitativos para estudiar a los usuarios de ...

Facilitadores de relación según los bibliotecarios. Son las percepciones de los bibliotecarios acerca de las características positivas de los usuarios que facilitan el logro de las metas.

a. Actitud positiva

a) Hacia el bibliotecario (2B)
a) "Educado" (2B)
b) "Humilde" (1B)
c) "Respetuoso" (1B)

b) Hacia el trabajo (4B)
a) "Responsable" (4B)
b) "Motivado" (2B)
c) "Persistente" (2B)
d) "Paciente" (2B)
e) "Serio" (1B)

b. Calidad de la relación (5B)
a) "Entusiasta, interesado en aprender" (5B)
b) "Buenas habilidades de comunicación" (4B)
c) "Acepta ayuda del bibliotecario" (4B)
d) "Abierto" (3B)
e) "Dispuesto a invertir tiempo en su búsque- da" (3B)
f) "Reconoce que el bibliotecario está ahí para ayudarlo" (2B)
g) "Que sepa escuchar" (1B)
h) "No defensivo" (1B)
i) "Confía en el bibliotecario" (1B)
j) "Dispuesto a lograr su objetivo" (1B) 
El incidente crítico como técnica para recolectar datos

k) "Acepta diferentes opciones de búsqueda" (1B)

Facilitadores de relación según los usuarios. Percepciones de los usuarios acerca de las características que deben tener los bibliotecarios para lograr el objetivo.

a. Actitud positiva

A. Del bibliotecario hacia el usuario (10U)
a) "Agradable" (10U)
b) "Que me atienda bien" (9U)
c) "Dispuesto a ayudar" (8U)
d) "Amable" (7U)
e) "Atento" (7U)
f) "Amigable" (4U)

g) "Le importan las necesidades del usuario" $(3 \mathrm{U})$

h) "Respetuoso" (3U)

i) "Cortés" (2U)

j) "Comprensivo" (1U)

k) "Cooperativo" (1U))

B. Hacia el trabajo (8U)
a) "Buena disposición" (8U)
b) "Interesado en ayudar al usuario" (8U)
c) "Se toma su tiempo para explicar los siste- mas y fuentes" (8U)
d) "Disfruta de su trabajo" (5U)
e) "Le gusta investigar" (1U)
f) "Persistente" (1U) 
Métodos cualitativos para estudiar a los usuarios de ...

g) "Profesional" (1U)

h) "Hace un esfuerzo extra para ayudar al usuario" (1U)

i) "Dispuesto a trabajar junto con el usuario" $(1 \mathrm{U})$

j) "Se asegura de que el usuario entienda qué hacer" (1U)

k) "Se preocupa por aprender y saber un poco más” (1U)

b. Calidad de la relación $(8 \mathrm{U})$

a) "Buenas habilidades de comunicación" (8U)

b) "Agradable" (8U)

c) "Te trata bien" (7U)

d) "Te motiva" (6U)

e) "Es atento" (5U)

f) "Hace que el usuario se sienta a gusto" (2U)

g) "Entusiasta" (2U)

h) "Receptivo" (1U)

i) "Buen sentido del humor" (1U)

j) "Que se entienda bien con el usuario" (1U)

$\mathrm{k})$ "Hace contacto visual” (1U)

\section{Barreras}

Son las características que impiden el logro de los objetivos y la comunicación.

Barreras de relación según los bibliotecarios. 
El incidente crítico como técnica para recolectar datos

Percepciones de los bibliotecarios sobre las características negativas de los usuarios que impiden lograr el objetivo.

a. Actitud negativa hacia el bibliotecario (4B)
a) "Usuario impaciente" (4B)
b) "Inseguro, dependiente" (4B)
c) "Tímido, con miedo" (3B)
d) "Enojado, actitud hostil" (3B)
e) "Grosero" (2B)
f) "Miedo de parecer estúpido" (2B)
g) "Arrogante" (2B)
h) "Agresivos" (2B)
i) "Prepotentes" (2B)
j) "No cree que el bibliotecario sea un profesio- nal" (1B)
k) "Frustrado" (1B)
1) "No saluda" (1B)

m) "Escribe recaditos quejándose del bibliotecario" (1B)

n) "Miedo de molestar al bibliotecario" (1B)

n) "Ve al bibliotecario como una figura de autoridad" (1B)

b. Actitud negativa hacia el trabajo (5B)

a) "Espera hasta el último momento para hacer su tarea" (5B)

b) "No quiere invertir el tiempo suficiente" (3B) 
Métodos cualitativos para estudiar a los usuarios de ...

c) "Más preocupado por el resultado final que por aprender el proceso" (2B)

d) "No interesado en su tarea" (1B)

e) "No tiene seriedad con sus estudios" (1B)

f) "Espera que se le dé todo en la mano" (1B)

g) "No quiere aprender" (1B)

h) "Busca la forma más fácil de cumplir con su tarea” (1B)

c. Calidad de la relación (5B)

a) "No tiene habilidad verbal" (4B)

b) "No permite que el bibliotecario lo ayude" (1B)

c) "No presta atención" (1B)

Barreras de relación según los usuarios.

Percepciones de los usuarios acerca de las características negativas de los bibliotecarios que impiden el logro del objetivo.

a. Actitud negativa del bibliotecario hacia el usuario $(5 \mathrm{U})$
a) "Mal humorados" (5U)
b) "Hace esperar al usuario"(4U)
c) "Evade al usuario" (4U)
d) "Se molesta con el usuario" (4U)
e) "Está estresado" (2U)
f) "Impacientes" (2U)
g) "Sarcástico" (1U)
h) "Amargados" (1U) 
El incidente crítico como técnica para recolectar datos

i) "Antipáticos" (1U)

j) “Gruñones" (1U)

k) "Grosero" (1U)

1) "Se resiste a la interacción porque ha tenido un mal día" (1U)

b. Actitud negativa hacia el trabajo (5U)
a) "Poca habilidad de comunicación" (4U)
b) "Le molesta que le pregunten" (2U)
c) "No le gusta su trabajo" (2U)
d) "No muestra interés por el usuario" (2U)
e) "Flojo" (1U)
f) "No toma en serio la solicitud del usuario" (1U)

c. Calidad de la relación (5U)
a) "Responde superficialmente a la pregunta" $(4 \mathrm{U})$
b) "No se quiere involucrar" (2U)
c) "No está dispuesto a invertir tiempo para ayudar al usuario" (1U)
d) "Minimiza al usuario" (2U)
e) "Cuestiona la necesidad de ayuda que tiene el usuario" (1U)
f) "Se rehúsa a hacer el trabajo del usuario" (1U)
g) "Habla con alguien más mientras te atien- de" (1U)
d. Comunicación no verbal negativa (8U) 
Métodos cualitativos para estudiar a los usuarios de ...

a) "Señala en lugar de mostrarle al usuario la fuente" (4U)

b) "Actitud despreocupada" (4U)

c) "No se levanta de su escritorio" (3U)

d) "Paralenguaje negativo: suspira, resopla, gruñe, mal tono de voz" (3U)

e) "Expresión facial negativa, te mira como si no estuvieras ahí" (3U)

f) "Parece enojado" (2U)

g) "No hace contacto visual” (2U)

h) "Come o bebe mientras te atiende" (1U)

i) "No sonríe" (1U)

j) "Mira su reloj constantemente" (1U)

k) "Mal aliento" (1U)

1) "Se la pasa comiendo o masticando chicle" $(1 \mathrm{U})$

m) "Su postura corporal te dice que estás loco"

Como se puede observar, tanto bibliotecarios como usuarios consideraron importante la actitud durante la interacción, pero la "calidad de la relación“ fue comentada más por los usuarios que por los bibliotecarios. Además, dentro del esquema de los usuarios y en relación con las barreras que impiden el objetivo, surgió la subcategoría de "Comunicación no verbal", la cual no estuvo presente en el esquema de las percepciones que tuvieron los bibliotecarios acerca de los usuarios. 
El incidente crítico como técnica para recolectar datos

La evidencia sugirió que los bibliotecarios tuvieron una marcada tendencia a evaluar el encuentro en el servicio de referencia desde el punto de vista del contenido, que involucra la transferencia de información; mientras que los usuarios le dieron una gran importancia a la relación, que es la actitud y cualidades personales del bibliotecario que les proporciona el servicio de referencia.

Los bibliotecarios percibieron la interacción como no exitosa cuando la información no estaba disponible, y los usuarios la percibieron como exitosa si el bibliotecario era agradable y trataba de ayudarlos, aún si no obtenían la información que querían.

En conclusión se puede decir que los aspectos de relación de la comunicación son muy importantes para determinar la percepción que se tiene de éxito o fracaso en la interacción durante la entrevista de referencia.

\section{Obras consultadas}

Andersson, B. \& Nilsson, S. (1964), "Studies of the reliability and validity of the Critical Incident Technique", en Journal of Applied Psychology, 48 (6), 398-403.

Andrews, J. (1991), "The use of Critical Incident research technique in an academic library", en Library and Information Research Neres, 14 (50), 22-27. 
Métodos cualitativos para estudiar a los usuarios de ...

Berkner, D.S. (1979), "Library staff development through performance appraisal", en College and Research Libraries, 40 (July), 335-344.

Balboa, A.C. (2005), La comunicación interpersonal entre el bibliotecario y el usuario en la entrevista de referencia: El proceso de mediación, Tesis de Maestría en Bibliotecología. UNAM.

Bitner, M. J.; Booms, B. H. \& Tetreault, S. (1990), “The service encounter: diagnosing favorable and unfavorable incidents", en Journal of Marketing, 54 , 71-84.

Callan, R. J. (1998), “The Critical Incident Technique in hospitality research: an illustration from the UK lodge sector”, en Tourism Management, 19 (1), 93-98.

Carr, D. (1980), “The Agent and the Learner: Interactions in assisted adult library learning", en Public Library Quarterly, 2 (2): 3-19.

Chamberlain, E.K. (1982). Critical Incidents of service functions of libraries/learning resources centers in four campuses of an urban, multi-campus community college district, EDD Dissertation, East Texas State University.

Chell, E. \& Pittaway, L. (1998), “A study of entrepreneurship in the restaurant and café industry: exploratory work using the critical incident technique as a methodology", en Hospitality Management, 17, 23-32. 
El incidente crítico como técnica para recolectar datos

Collins, J. W. III (1985), A Critical Incident analysis of the behavior of Academic Reference Librarians: Implications for inservice training, EDD Dissertation, Boston University, 150 pages.

Edvardsson, B. (1992), "Service breakdowns: a study of critical incidents in an airline", en International Journal of Service Industry Management, 3 (4), 17-29.

Fisher, Sh. \& Outlton, T. (1999), “The Critical Incident Technique in Library and Information Management Research", en Education for Information 17, 113-125.

Flanagan, J.C. (1954), “The Critical Incident Technique", en Psychological Bulletin, 51 (4), 327-358.

Harrington, C. (1992), Managing change in the Learning Resources Department of Liverpool Institute of Higher Education, Department of Information and Communications, Manchester Metropolitan University.

Menzel, H. (1966), "Information needs and uses in science and technology”, en C. Cuadra, ed. Annual Review of Information Science and Technology, Vol. 1 New York, Interscience, 41-69.

Ovretveit, J. A. (1992), “Towards market focused measures of customer purchaser perceptions of service", en Quality Forums, 18 (1), 21-24.

Owen, J.C. (1976), “Workshop session I: work control and review", 2nd Special Libraries Section Conference, Library Association of Australia, Adelaide, October, 1976, Australian Special Libraries News, 10 (1), 22-29. 
Métodos cualitativos para estudiar a los usuarios de ...

Owen, J.C. (1977), "Workshop session III: description, measurement and evaluation of the work process", 2nd Special Libraries Section Conference, Library Association of Australia, Adelaide, October, 1976, Australian Special Libraries News, 10 (1), 41-45.

Pearn, M. \& Kandola, P. (1993), Job analysis: a manager's guide. 2nd, ed. London, Institute of Personnel Management, 1993.

Radford, L. M. (1996), "Communication theory applied to the reference encounter: an analysis of critical incidents”, en Library Quarterly, 66 (2): 123-137.

Roethlisberg, F. \& Dickson, W. (1939), Management and the worker, Cambridge, MA, Harvard University Press.

Roman, W.\& Latham, G. (1974), “The reliability and validity of the Critical Incident Technique. A closer look", en Studies in Personnel Psychology, 6 (1), 53-64.

Shirey, D. (1971), "Critical Incident Technique”, en A. Kent and H. Lancour eds., Encyclopedia of Library and Information Science, 6, New York, Marcel, Dekker, 286-291.

Siegel, E. R. \& others (1991), Evaluating the impact of MEDLINE using the Critical Incident Technique, Proceedings of the Annual Symposium of Computer Applications in Medical Care, 83-87.

Slater, M. \& Fisher, P. (1962), Use made of technical libraries, London, ASLIB. 
El incidente crítico como técnica para recolectar datos

Smith, C. E. (1988), Critical Incidents of Library Media Services in an Urban, Multicampus School District, EDD Dissertation, East Texas State University, 126 pages.

Strauss, A. L. \& Corbin, J. (1990), Basics of Qualitative Research: Grounded Theory Procedures and Techniques, Sage, London.

Tonta, Y. (1992), "Analysis of search failures in document retrieval systems: A review", en The $P u$ blic-Access Computer Systems Review 3 (1), 4-53, online version.

Watzlawick, P.; Beavin, J. H. \& Jackson, D. D. (1967), Pragmatics of human communication: a study of patterns, pathologies, and paradoxes, New York, Norton.

Wilkins, J. L. H. \& Leckie, G. J. (1997), "University professional and managerial staff: information needs and seeking”, en College and research libraries, 58, 287-305.

Wilson, S.; Starr-Schneidkraut, N. \& Cooper, M. (1989), Use of the critical incident technique to evaluate the impact of MEDLINE, 2, online version.

Zemke, R. (1979), "Still trying to figure things out? Try using the Critical Incident Method", en Training 16 (4), 68, 70,73. 


\title{
La biblioteca como sistema autorreferente
}

\author{
RICARDO MONTES GÓMEZ
}

\section{Introducción}

Q abemos que actualmente impera la idea de lo - global, según nuestra percepción se trata de un enfoque que modela sistemas y relaciones considerando la totalidad como unidad, también hemos podido observar que la tendencia más visible es que quien investiga se sitúe como observador para percibir, aprehender, concebir y construir conocimiento con las herramientas que el propio entorno sociocultural proporciona. En esta ocasión como recurso metódico consideraremos la teoría de sistemas Luhmanniana desarrollada para analizar el funcionamiento de sistemas sociales y su entorno (Luhmann, 1991). Así, podemos utilizar la teoría de sistemas auto-referentes, ubicándonos como observadores de la complejidad que exista en la biblioteca, un sistema inmerso en una multiplicidad de 
Métodos cualitativos para estudiar a los usuarios de ...

relaciones de todo tipo; de interacciones que esencialmente se circunscriben a lo social.

El enfoque de sistemas, que puede considerarse complementario del reduccionismo tradicional de la ciencia, nos ha sido útil aquí para abordar el problema de la complejidad a través de una forma de pensamiento sistémico, basado en la totalidad y en sus propiedades. De esta forma el pensamiento complejo y el sistémico se integran en un esquema amplio: el problema, cada vez mayor, de la interdisciplinariedad y la transdisciplinariedad de conocimientos.

Coincidimos en que todo hecho importante debe ser analizado en sus contextos social, político, humano y ecológico; es decir, se tiene que tomar en cuenta todo para tener la posibilidad de articular y organizar la información y el conocimiento, ya que esto permite establecer el sentido; y lo complejo conlleva la relación de inseparabilidad y de inter-retro-acción entre todo objeto de estudio y su entorno, y de todo entorno con el contexto que lo rodea.

En consecuencia, teniendo como marco ambos pensamientos, el sistémico y el complejo, hemos decidido encontrar los rasgos más característicos que denoten a la biblioteca como un subsistema a fin de poder modelarla identificando sus relaciones estructurales al interior de un sistema mayor, la institución a la que pertenece; $y$ como unidad hacia el exterior con el entorno en el que se desenvuelve. 
Tomamos como ejemplo a la biblioteca parlamentaria, unidad de información que también se identifica como legislativa y, a partir de su modelación, planteamos la posibilidad de prever las necesidades de información de los usuarios.

Antes de avanzar es importante determinar el significado del término sistema, proveniente del vocablo griego systema, el cual evoca las nociones que significan reunir, juntar, colocar juntos; generalmente se trata de un "[...]conjunto de reglas o principios enlazados entre sí. $\mathrm{O}$ un Conjunto de cosas que ordenadamente relacionadas entre sí concurren a un mismo fin o constituyen en cierto modo una unidad "(Lexipedia, 1996, p. 421).

Se ve pues que el concepto hace referencia a una unidad, a un todo integrado, a un conjunto cuyas propiedades y características surgen de la interrelación, del enlace y de las conexiones entre los elementos que lo configuran, y de ese todo con el entorno en el cual se ubica. De esta forma podemos afirmar que la biblioteca es un sistema; en el mismo sentido, si colocamos juntos, unimos, e identificamos a los usuarios de los servicios de información de una biblioteca situándolos en su entorno podríamos también considerarlos como un sistema.

Si entendemos que el hecho de tratar de conocer los intereses de información que mueven individualmente a las personas es una tarea ardua, y que 
Métodos cualitativos para estudiar a los usuarios de ...

la división elemental de los componentes estructurales de un grupo social, considerado como siste$\mathrm{ma}$, permite conocer las necesidades que tiene tal grupo para poder preverlas; por ejemplo, separándola por grupos de edad, por afinidades, por formación académica, por actividad económica, o por líneas de investigación. Entonces, para analizar cualquier división estratificada, dejamos por sentado que, al ser un sistema social un objeto de estudio como sistema colectivo, el estudio muestral de las voluntades y creencias de los individuos y la complejidad de las relaciones concretas que median entre ellos permitirá deducir con cierto grado de confiabilidad la diversidad de voluntades, creencias colectivas y requerimientos de información.

Basándonos en el párrafo anterior, nos ubicamos en un nivel de análisis en el que los sistemas parciales de la sociedad global, como son los de una organización, una institución educativa, una empresa, un instituto de investigaciones, una comunidad, los usuarios de una biblioteca, o la biblioteca misma, se pueden tratar como si fueran una unidad sistémica colectiva cuyo comportamiento es directamente observable. De acuerdo con Gurvitch:

[...] ]este nivel constituye el campo privilegiado del análisis de las organizaciones, es decir, del conjunto de fenómenos de poder, de conflictos, de apremios burocráticos, de crisis de adaptación a cambios tecnológicos, etc., que es posible 
observar en el seno de las organizaciones, y también del análisis de las instituciones, es decir del análisis de los conjuntos dotados de cierta estabilidad (citado por Lugan, 1990, p. 8).

Si, como diría Luhmann (1991), podemos hablar en general del concepto de sistema cuando se observan características tales que, si no existieran, se cuestionaría el carácter de objeto de tal sistema; entonces, se llama sistema al conjunto de dichas características. Por ello también cuando se dice hay sistemas sólo se quiere afirmar que hay objetos de investigación con características tales que justifican el empleo del concepto de sistema.

Consecuentemente un sistema marca una diferencia respecto de su entorno, cuya forma tiene propiedades que lo distinguen como unidad de estudio de una complejidad; una forma que, según Jokisch (2002, pp. 51-53), consiste en la distinción de algo (el sistema) respecto del resto (el entorno); para nosotros entonces es la distinción entre algo respecto del contexto ambiental, como la biblioteca respecto de la universidad, de la empresa, del instituto, del parlamento.

Así, la sociedad se diferencia dinámicamente en distintos subsistemas sociales: cultura, academia, religión, justicia, etcétera; y también, cada uno de estos subsistemas tiene como entorno a los otros subsistemas, los cuales se encuentran clausurados en sí mismos; de suerte tal que cada uno de ellos es 
Métodos cualitativos para estudiar a los usuarios de ...

independiente de los otros y posee su propio código, su medio de comunicación; son pues subsistemas autorreferentes. El diferenciamiento sistémico se presenta cuando se da la autorreferencia; es decir, por medio de la posibilidad que existe de que los sistemas hagan referencia de sí mismos, cuando constituyen sus propios elementos y las operaciones elementales de éstos. Por ello el sistema debe hacer posible una descripción de sí mismo, debe ser hábil para hacer un uso interno de la diferencia entre él y el ambiente a fin de orientar sus propósitos con información sobre sí y el entorno (Jokisch, 2002, p. 323).

Es decir, lo que veremos en lo sucesivo es la aplicación de una teoría que plantea la necesidad de identificar a la biblioteca como un sistema social, que se desenvuelve en un entorno al cual se debe, $y$ que procura, a través de la autorreferencia, conformar su estructura para dirigir sus actividades y productos hacia el logro de los objetivos que el contexto ambiental propone y requiere para alcanzar objetivos específicos.

Así, formalmente, un sistema social es distinto de su entorno, y sus operaciones se circunscriben a lo cerrado de los límites propios respecto al entorno; es decir, el sistema observado es capaz de producir por sí mismo elementos y estructuras adecuadas que lo hacen distinto de otros subsistemas de su entorno 
La biblioteca como sistema autorreferente

con los cuales, indudablemente, mantiene comunicación e intercambio de información.

El esquema general que se adoptó para el desarrollo de este capítulo fue el siguiente:

I. Identificación del sistema y de su función en el entorno.

II. Autorreferencia del sistema de estudio.

III. Modelación sistémica.

\section{Identificación del sistema y su función en el entorno}

De acuerdo con Robinson una biblioteca parlamentaria o legislativa es aquella que se dedica a:

[...]buscar la información precisa, integrarla con otros materiales, sintetizarla a un tamaño que se pueda digerir, traducirla a términos que puedan comprender los no-expertos, y entonces diseminarla ampliamente en el Parlamento, en una forma que no sea partidista y tan objetiva como sea posible, con el fin de que todos puedan usarla con un alto grado de confianza, [y además] contribuir con algún valor adicional ofreciendo opciones no expuestas en ningún otro lado del siste$\mathrm{ma}$, basadas en su propio entendimiento y conocimiento del campo (1999, p. 8).

El autor propone un modelo de los servicios de información parlamentaria, en el que se muestra un filtro (dos embudos que aparecen unidos por la par- 
Métodos cualitativos para estudiar a los usuarios de ...

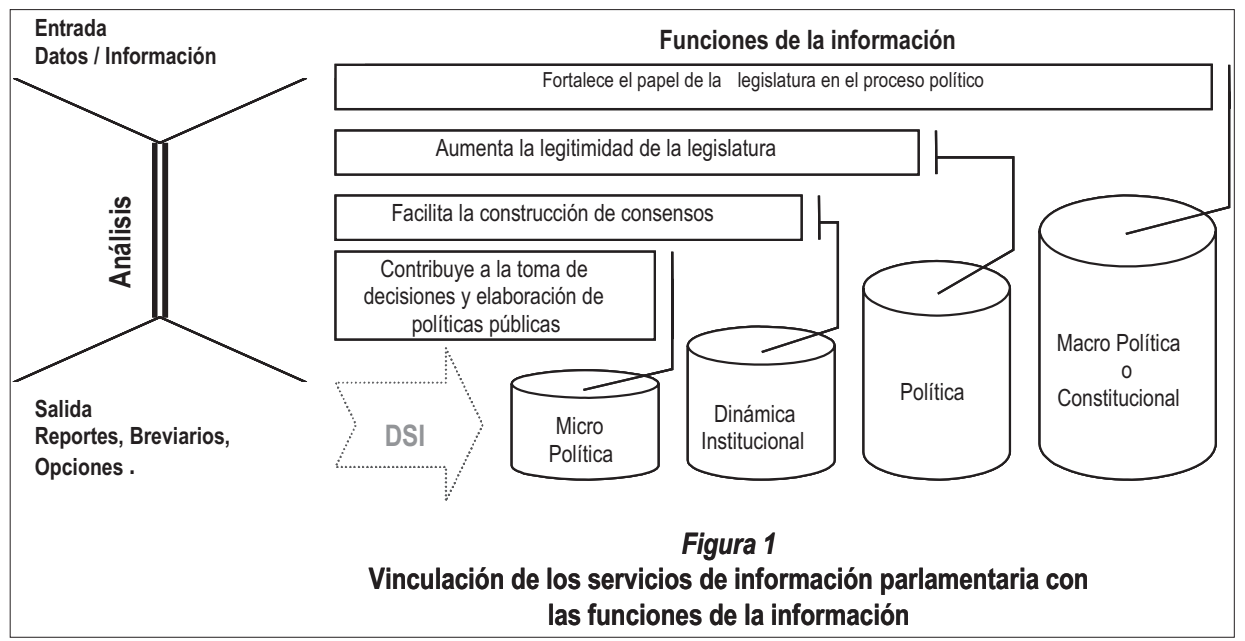

te más angosta que reproducimos en la Figura 1), que resulta de interés para nuestra modelación:

Se observa que los datos, el conocimiento y los servicios referentes son indispensables en el Parlamento desde el punto de vista de las funciones propias de la información, y se considera que en el nivel básico, de la 'micro política', la información tiene como finalidad la creación de bases para tomar decisiones y elaborar políticas públicas sobre temas específicos.

En el nivel de análisis correspondiente a la 'dinámica institucional' se indica que la biblioteca parlamentaria, o un servicio de investigación, cuando proporcionan servicios de información aceptables 
pueden facilitar el acuerdo político al reducir el rango del debate sólo a las diferencias axiológicas del caso.

Tratándose de un nivel político, utilizar información de alta calidad producirá un incremento en la legitimidad de las acciones parlamentarias, y esto llevará a un nivel más amplio de apoyo tanto para las políticas adoptadas cuanto para el Parlamento.

Finalmente, en el nivel macro político o constitucional, la información objetiva sobre el espectro estructural y orgánico político nacional, capacitará al Parlamento para actuar más independientemente al promover reformas o nuevas opciones completas para ser consideradas en el debate político (Robinson, 1990).

De esta forma se puede identificar a la biblioteca parlamentaria porque, aun sin visualizarla físicamente, podemos afirmar que un sistema como la biblioteca, que funciona en un entorno como el Parlamento, requiere información y el tratamiento de ella; es decir, buscarla, integrarla, sintetizarla, traducirla y diseminarla como conocimiento registrado en recursos de información, y así atender las demandas propias de su ambiente.

Para realizar tales actividades de tratamiento de información se percibe la necesidad de un staff o plantilla de personal diferente a los parlamentarios o legisladores, pues éstos fundamentalmente hacen 
Métodos cualitativos para estudiar a los usuarios de ...

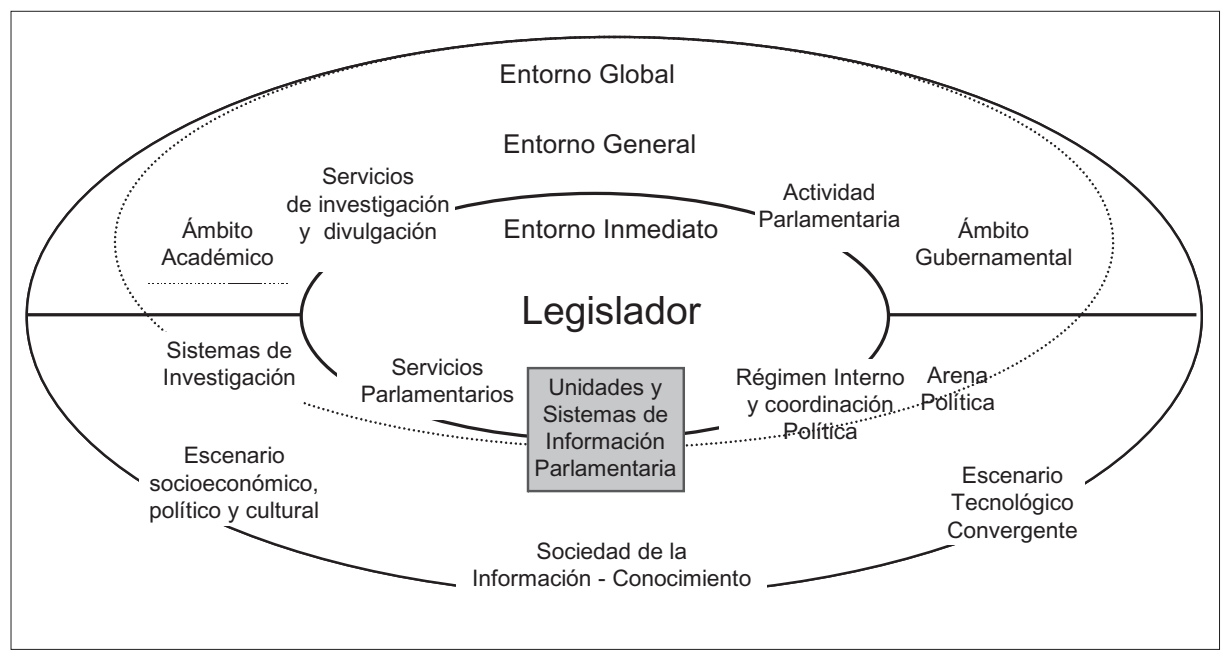

Figura 2

Centralidad del legislador y entornos de actuación de su función parlamentaria

labores políticas, de gestación legislativa, y de representación y control. Así, encontramos que el trabajo de suministro de información parlamentario es aquel que se realiza con la finalidad de darle cumplimiento a las facultades de las cámaras, y por tanto deberá apoyarse en personal conocedor o experto en las necesidades técnicas y los procedimientos que le importan a la institución a la que pertenece la biblioteca.

En la Figura 2, se descubren diversos escenarios de competencia informativa en donde interviene el legislador interactuando con diferentes sistemas. 
En la Figura 2 se nota la posibilidad de establecer un modelo de autorreferencia centrado en la interrelación de información legislador-unidad, que propicie el adecuado entendimiento de la problemática referida a ciertas necesidades y el uso de información pertinente; en todo caso, podemos abordar la situación problemática como dirigida a explorar y describir la complejidad de las relaciones entre usuarios de información, y plantear un modelo que posibilite un eficiente servicio bibliotecario parlamentario, teniendo como base la previsión de satisfacer esas necesidades de información.

La biblioteca, considerada como un todo y como una unidad, se constituye de diversas áreas o secciones enlazadas o conectadas, que permiten la adquisición de materiales bibliográficos, la organización técnica y la divulgación de información en diversos formatos. El entorno que la rodea, en este caso, es el Poder Legislativo, como se puede observar en la Figura 3.

Al tener intercambio con el entorno, los sistemas también tienen la calidad de autorreferentes. La teoría de sistemas autorreferenciales sostiene que la diferenciación sistémica sólo se efectúa mediante autorreferencias; es decir, los sistemas sólo pueden referirse a sí mismos al constituir de sus elementos y operaciones elementales. Para hacer posible esto, los sistemas tienen que producir y utilizar 
Métodos cualitativos para estudiar a los usuarios de ...

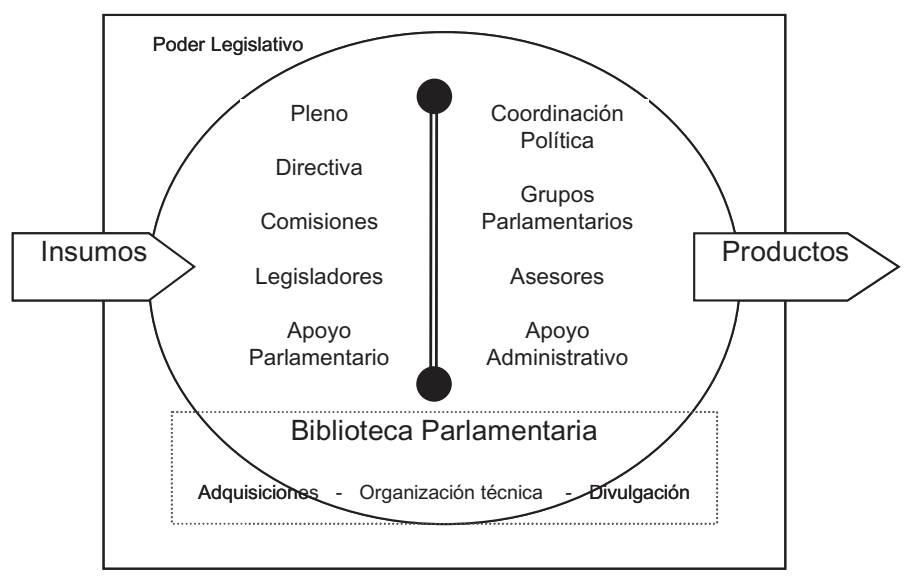

Figura 3

La biblioteca parlamentaria como sistema

descripciones sobre sí mismos; tienen que ser capaces de utilizar, al interior del sistema, la diferencia entre sistema y entorno como orientación y principio del procesamiento de información (Luhmann, 1991, p. 32).

El autor indica que los sistemas están estructuralmente orientados al entorno y que sin él no podrían existir, de tal forma que se constituyen y se mantienen mediante la creación y la conservación de sus diferencias con el entorno utilizando sus límites para regular dicha diferencia, ya que sin sus diferencias no habría autorreferencia, pues ésta es la premisa para hacer funcionar todas las operacio- 
nes sistémicas; lo que significa que pueden observarse a sí mismos y de este modo enfatizar su estructura mediante sus diferencias con el medio.

Así, se entiende como sistema a un conjunto de elementos interrelacionados, pero cuya unidad está determinada o referida por los rasgos característicos que adopte esa interrelación, y no por el número de partes que constituyan su estructura para lograr un objetivo; por tanto, tales características de interacción son diferentes a las de la suma de las propiedades de los elementos de la unidad.

En la Figura 4 se puede observar al sistema y a su unidad de información inmersos en la complejidad inherente a las interacciones de sus órganos, a las de éstos entre sí y a las de su unidad con otros sistemas sociales; se ve también la interconexión entre sistemas parciales con subsistemas o con super sistemas, y estas conexiones de elementos en relación compleja.

Se muestra también en la Figura 4, que el sistema hace una importación energética, insumo que puede o debe ser captado del entorno que rodea al Parlamento o Congreso.

Ya que el tipo de relación que nos interesa destacar entre los órganos del Parlamento o Congreso es comunicativo, podemos identificar ciertas necesidades de información al saber que ellos tratan de mantenerse al día sobre los asuntos de su propia competencia o de otros sistemas, subsistemas y supersiste- 
Métodos cualitativos para estudiar a los usuarios de ...

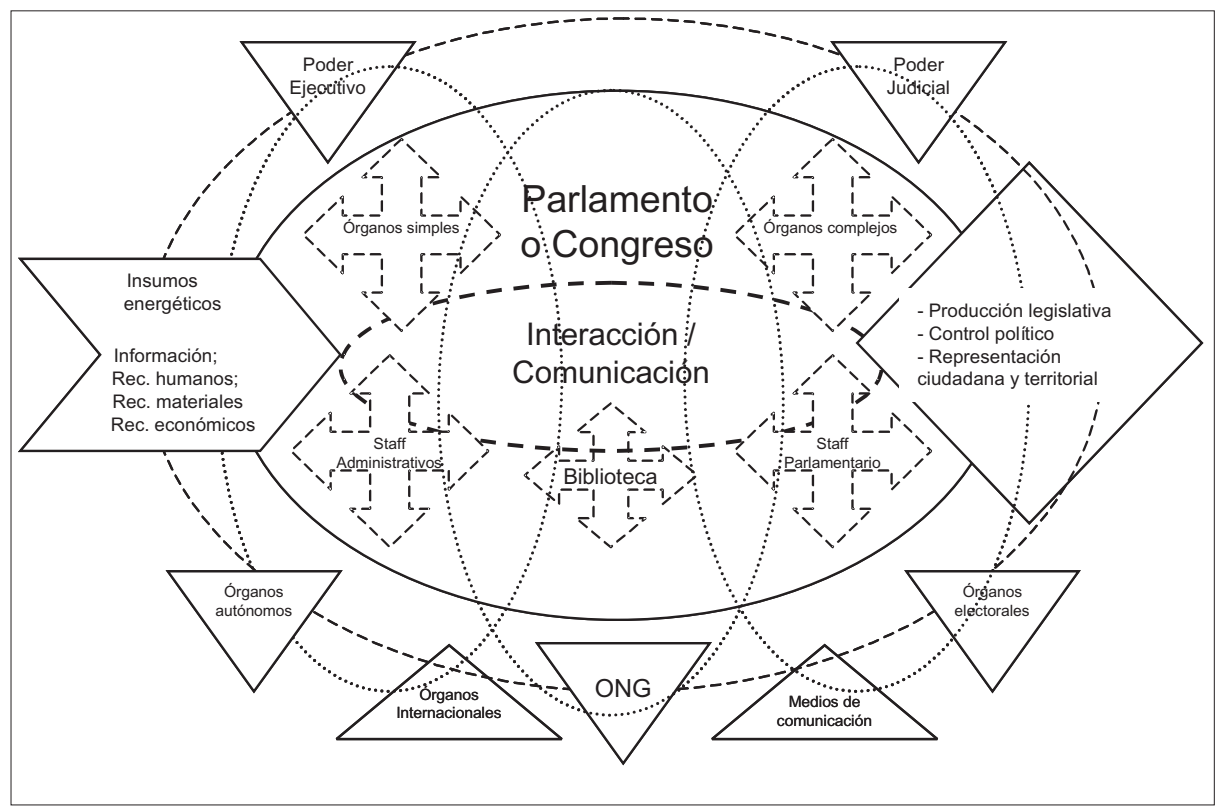

Figura 4

Complejidad intra y extra sistémica del Parlamento y su biblioteca

mas conexos; que realizan sus actividades cotidianas de legislación, control, y representación, para el cual necesitan alguna información de cifras, de legislación, de técnicas, de políticas, de planes, de presupuestos; o que cuando tienen en la mira el desarrollo, la creación, la modificación, la reforma, o la derogación de algún ordenamiento jurídico en particular; debaten y argumentan, y fijan un posicionamiento político. En fin, la información es indispensable para el Parlamento y sus órganos, para poder tomar decisiones sobre políticas en temas complejos 
y para tener un mejor control en los procesos de creación normativa y aplicación ejecutiva.

Se entiende también que en el ámbito bibliotecario, los servicios de referencia, de investigación documental y de análisis bibliográfico deben considerarse como una función de identificación y compilación documental sobre las causas y efectos que subyacen a los problemas inherentes a la técnica legislativa, a la función de control parlamentaria y a la representación ciudadana y territorial, en forma tal que le permitan al legislador concentrarse en soluciones de política pública. Se trata de que la biblioteca pueda ofrecer opciones y alternativas a las necesidades de información propias del entorno y trazar líneas bibliográficas o documentales que muestren los probables impactos o efectos de las diferentes posibilidades de acción antes de que éstas sean llevadas a cabo por el tomador de decisiones, así, el parlamentario informado, podrá tomar una decisión verdaderamente razonada $\mathrm{y}$, sobre todo, bien documentada.

De acuerdo con Ashby, citado por Johansen (1993), la recuperación de información requiere la especialización de una parte del sistema a fin de obtener sólo aquélla que es necesaria o requerida por la unidad sistémica en relación con la variedad existente en el entorno. Por supuesto que nosotros nos acogemos a tal aseveración pensando en referencia 
Métodos cualitativos para estudiar a los usuarios de ...

a la biblioteca, ya que de acuerdo con los principios bibliotecológicos, el sistema puede seleccionar de la variedad informativa generada en el medio, aquella información registrada, útil o que tenga sentido para el sistema, pensamiento que nos lleva a la autorreferencia bibliotecaria como un subsistema reductor de la variedad informativa, capaz de controlar el alud de fuentes de información y que cuenta con la indispensable organización para difundirla y aprovecharla hacia el interior del sistema total, en nuestro caso, el Congreso o el Parlamento.

Para Maturana y Varela (1990) las relaciones, las interacciones, y la selección conectiva que tienen efecto dentro del sistema, y de éste con el entorno, ocurren de acuerdo con su finalidad estructural u objetivo sistémico. Es decir, el sistema determina lo que le debe ocurrir a éste y por tanto el entorno y los sistemas en él sólo impactan al sistema, no lo determinan.

Teniendo esencialmente en consideración lo anterior, diríamos, que el Parlamento o Congreso determina la necesidad de información y requiere de una parte especializada de ésta para su tratamiento documental; refiriéndonos a la biblioteca parlamentaria, en relación con sus recursos, la adquisición documental debe tener efecto en razón de las actividades de selección, organización y divulgación documental correspondiente, y la interrela- 
ción intraparlamento impacta a la biblioteca en función de la conexión que otros subsistemas parlamentarios tienen con ésta y ésta con aquellos.

Si los elementos de un sistema establecen diversos tipos de relaciones y conexiones al interior de la estructura (intrasistémicas), podemos observarlos a partir de los niveles en que se realizan, y estas relaciones pueden ser físicas, biológicas, sociales, energéticas, comunicacionales, informáticas, etcétera; por tanto no será lo mismo la relación o conexión entre órganos, ya sean éstos simples o complejos, con la biblioteca; más bien la propia función de los órganos determinará el grado o tipo de conexión que habrá de tener ésta con aquellos. Lo cual dependerá de las características mismas del Parlamento o Congreso y del grado de importancia que la biblioteca tenga dentro de la estructura.

Al respecto de la disposición de información, donde la biblioteca tiene un papel primordial, Estela Morales (2001) indica que "la disponibilidad de información debe ser la suficiente para garantizar al usuario la satisfacción de sus necesidades, independientemente del lugar en que se encuentre, coordinando con efectividad los aspectos técnicos y los factores sociales y políticos" lo cual trasciende los límites mismos del sistema reductor de incertidumbre. Llevando lo anterior a una representación gráfica, según nuestra percepción, tenemos: 
Métodos cualitativos para estudiar a los usuarios de ...

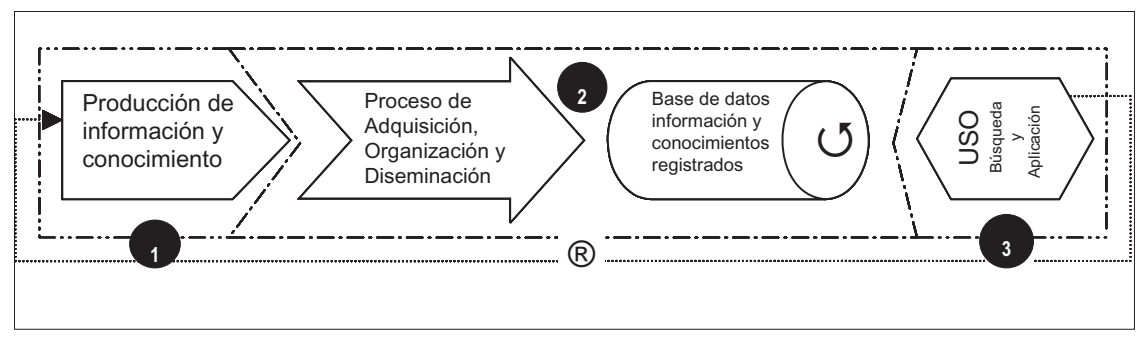

Figura 5

Concatenación de la información y el conocimiento registrados hasta su uso, previa organización.

La Figura 5 muestra cómo pensamos la complejidad sistémica respecto a la concatenación segmentada de producción de información y conocimiento, la función bibliotecológica y la conjugación del usufructo correspondiente. Suponemos, así, la existencia del sistema 1 , referido a la producción intelectual y artística, en el que se identifica a creadores, investigadores, editores y demás autores personales y corporativos que, de una $\mathrm{u}$ otra forma plasman conocimientos que se registran en diversos formatos documentales.

El sistema 2 se refiere a la bibliotecología aplica$\mathrm{da}$, cuyo sentido se justifica en la medida que clasifi$\mathrm{ca}$, cataloga e indiza los contenidos intelectuales para crear una base de conocimientos que permita dar referencia y pueda localizar los productos intelectuales a través del segmento sistémico 3, correspondiente al uso de la información, el cual inquiere al sistema bibliotecológico. 
Finalmente, aparece una línea de retroalimentación $\left({ }^{\circledR}\right)$, que no es otra cosa que las diferencias generadas por el receptor usufructuario de la comunicación informativa, línea que transfiere mensajes de contenido y se reconecta con el sistema emisor. Tal línea retroalimentativa representa el grado diferenciador de estados previos a la selección contingente de sentido (Luhmann, 2002, pp. 244-245), y mediante esa retroalimentación se podría evaluar la satisfacción de una necesidad de información.

Aquí queremos destacar dos asuntos medulares: en primer lugar, la descripción de los contenidos intelectuales (segmento sistémico 2), se limitaba, bibliotecológicamente hablando, a la clasificación, catalogación e indización, (fundamentos de la organización documental) con el propósito de crear, mantener y difundir una base de conocimientos que, mediante su conjugación con el sistema de uso (segmento sistémico 3 en la Figura 5), pueda disponer, en cualquier momento de la conexión, de la consulta, con el segmento anterior.

$\mathrm{Y}$ en segundo término, si bien es cierto que esta triada fundamental (clasificación, catalogación e indización) de la biblioteconomía es la que le da su sentido y valor social, afirmamos también que es indispensable un factor de previsión para impactar al segmento sistémico de uso. No se trata de anticipar todos los estados concretos que un sistema pue- 
Métodos cualitativos para estudiar a los usuarios de ...

da experimentar en el futuro, ni tampoco de anticipar el estado esencial del sistema colocado en el plano del tiempo futuro. Se trata únicamente de la capacidad de reducir las distancias (desviaciones, alejamientos) entre el sistema y el entorno, que pudieran poner en peligro la existencia del sistema (Luhmann. 2002, p. 66).

Respecto del párrafo anterior, se intenta excitar al segmento de organización documental para que reduzca su opacidad y reactive su funcionalismo estructural en virtud de la necesidad manifiesta de los sistemas jurídicos, psíquicos, o sociales, ubicados en el entorno. Así:

Por un lado el sistema puede responder a diferentes estímulos del entorno con la misma reacción. Escoge, a pesar de las diversidades del entorno, una forma homogénea de reacción, es decir, puede reducir la complejidad del entorno. Por otra parte, un sistema puede reaccionar de manera diversa a situaciones homogéneas o constantes; es decir, se puede condicionar a sí mismo, se puede regir según condiciones internas que no tienen ninguna correlación inmediata con el entorno (Luhmann, 2002, p. 61).

Hasta aquí hemos contemplado a la biblioteca sobre todo desde el punto de vista de su estructura sistémica y lo hemos referido al interior del entorno inmediato que la rodea; sin embargo, vale la pena decir que la biblioteca debe interactuar y rela- 
La biblioteca como sistema autorreferente

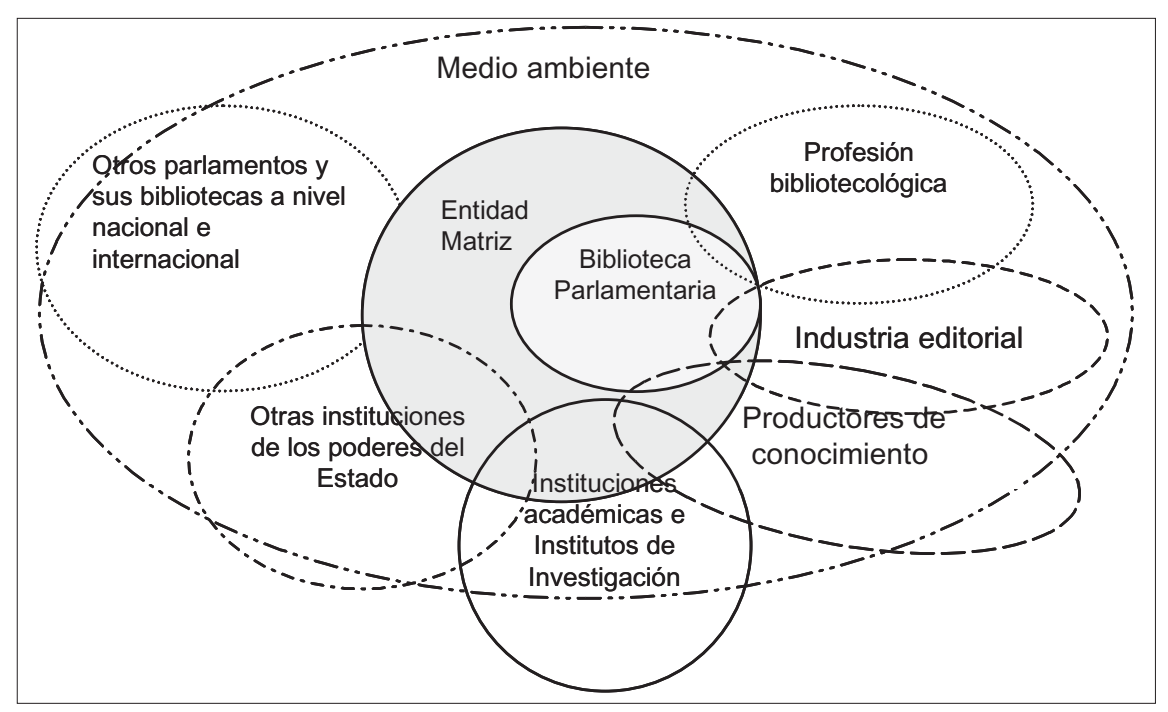

Figura 6

Complejidad sistémica referida al Parlamento o al Congreso y su biblioteca

cionarse con aquellos entornos que están más alejados del inmediato al que pertenece. Se puede referir la interacción de las bibliotecas con diversos ámbitos sistémicos más amplios: el entorno que rodea a la biblioteca o la institución a la que pertenece vista como subsistema; el ámbito natural de la industria editorial y el control bibliográfico; el contexto general de la profesión bibliotecológica; los productores de conocimiento; otros parlamentos y sus bibliotecas; y las instituciones académicas. La Figura 6 nos da una imagen de esta realidad compleja. 
Métodos cualitativos para estudiar a los usuarios de ...

Abundando sobre la complejidad reiterativa del sistema biblioteca podemos acotar que las relaciones e interrelaciones del sistema con el entorno, y de los otros sistemas con éste, tales relaciones se dan de dos maneras:

Primero, un nivel intrasistémico donde se presenta un intercambio entre los diversos componentes de la biblioteca, los cuales pueden conceptualizarse como sistemas que se hallan en constante interacción, dependencia y conexión con la adquisición y el procesamiento de los materiales documentales, y con los servicios característicos de una biblioteca.

Segundo, el nivel intersistémico entre la biblioteca y los sistemas de su entorno, ya sea éste inmediato, general o global; y las relaciones e interacciones que conectan a los sistemas complejos y simples con la unidad de información.

Las relaciones e interacciones del sistema con el entorno y los sistemas de su entorno se dan de dos formas: una, relaciones directas sistema a sistema con los sistemas que constituyen el entorno inmediato circundante a la biblioteca; $y$, dos, relaciones indirectas o mediadas entre la biblioteca y su entorno más general del cual la biblioteca obtiene sus colecciones; un ambiente donde finalmente el Parlamento o el Congreso también actúan y se conectan 
con otros sistemas con los que tienen interconexiones e influencias recursivas.

Desde esta perspectiva creemos que las bibliotecas deben experimentar un cambio y adecuar su estructura autorreferencialmente desde la perspectiva sistémica, a fin de permitirse tener claridad de miras y una interactuación con el entorno inmediato más exigente. Proponemos que como principio de actuación se prevean las necesidades de información propias del entorno ambiental en tanto que es conveniente que las bibliotecas busquen, en efecto, reconstruirse a partir de contestar a las preguntas ¿cómo poder relacionarse con el ambiente que las rodea?, y ¿qué interacciones pueden ser eficaces y eficientes con respecto a las metas u objetivos de la recursividad sistémica a la cual se pertenece?

\section{Autorreferencia del sistema}

Para Molina (1995) los sistemas, como las bibliotecas, tienen en particular tres atributos; en primer lugar, teleológicamente, su existencia se debe a un propósito del que se desprenden sus objetivos principales, en tanto que la causa final de su existir determina su proceder existencial y, diríamos nosotros, a tono con Luhmann, su estructura.

En segundo término, la estructura guarda una relación de cohesión mediante la cual los elementos sistémicos se organizan a fin de manifestarse 
Métodos cualitativos para estudiar a los usuarios de ...

integralmente y emerger, para responder de manera global al propósito final del sistema o a su causa original.

Siguiendo a Medina, los elementos estructurales pueden ser analizados en forma individual en una suerte de atomicidad descriptiva de las partes constitutivas del sistema; sin embargo, a este nivel de análisis los elementos también pueden estudiarse como constituyentes de una energía funcional que se determina en razón del valor operativo que se le adjudique al sistema de manera individual. Propone que deben contemplarse los elementos de un sistema como la biblioteca a través del análisis del funcionamiento lógico de cada una de las partes, es decir, "[...]precisando el papel de cada grupo de elementos como unidad de proceso en la totalidad de los procesos que tienen lugar en el sistema" (Molina, 1995, p. 134).

El tercer atributo de los sistemas se materializa en el ambiente; es decir, el entorno que rodea a la biblioteca y con el cual interactúa como unidad sistémica. En ese ambiente se ubican los "[...] objetos que influyen sobre el sistema y todos aquellos objetos que son modificados por el comportamiento del sistema” (Molina, 1995, p. 134).

Es evidente que un sistema, como la biblioteca no está constituido solamente de elementos; sino que puede considerarse dotado de subsistemas cua- 
La biblioteca como sistema autorreferente

litativos que intercambian información, y cuyas conexiones e interacciones originan redes de comunicación que pueden pensarse como sistemas diferentes a cada una de las otras partes o elementos de la biblioteca.

Dentro de la biblioteca se producen situaciones $\mathrm{y}$ eventos en los que uno o varios de los sistemas al actuar generan perturbaciones que tienden a modificar la organización y las acciones de otros sistemas, del mismo modo que, a nivel intrasistémico, al interior de la biblioteca, las relaciones mutuas de los subsistemas entre las partes o elementos que los constituyen, reconfiguran y transforman sistémicamente la unidad de información para responder a la emergencia requerida por el entorno.

Los subsistemas elementales que constituyen a la biblioteca y ésta misma como unidad sistémica, deben afrontar el azar y el impacto permanente del entorno ambiental y de los subsistemas que también le pertenecen a éste, y sobre todo aquéllos que, en esta óptica, perteneciendo al entorno general, entran también en contacto directo con ella. Tal complejidad está referida a una amplia variedad de posibilidades y probabilidades centradas en necesidades de información.

Para resolver con oportunidad, confiabilidad y pertinencia las posibilidades y probabilidades que se le plantean a la biblioteca, ésta debe seleccionar 
Métodos cualitativos para estudiar a los usuarios de ...

opciones, tomar decisiones y realizar sus elecciones a partir del dominio semántico inherente al medio ambiente. Es decir, a través de unidades léxicas que originan distinciones a las cuales se les atribuye un significado y un significante de sentido, y éstos generan nuevamente una red terminológica subyacente en thesauros y léxicos, taxonomías y clasificaciones que bien pueden verse como sistemas especializados que también se conjugan en un rejuego de complejidad como el que ideó Ranghanatan, o la Clasificación Colonada, que para clasificar textos se identifican con las distintas ramas del saber humano a partir de un sistema multidimensional donde cada clase se descompone en sus elementos o conceptos básicos de acuerdo con ciertas características llamadas facetas, tales como Personalidad, Materia, Energía, Espacio y Tiempo, y cuya secuencia se considera como el orden natural de nuestras representaciones mentales.

Los subsistemas de la biblioteca no se desenvuelven al unísono en una misma actividad, actúan en relación con un principio jerárquico y de especialización de las acciones que se establece al interior del sistema en términos de su organicidad, según la cual, para determinadas actividades, por ejemplo, la diseminación selectiva de información (DSI), los otros subsistemas (p.e. selección y adquisición, catalogación y clasificación, préstamo y circulación, etcéte- 
ra) permanecen en estado latente sin perder su potencial de participación que son necesarios para ésta $\mathrm{u}$ otras actividades propias de la biblioteca.

Es importante tener en cuenta que el enfoque sistémico considera que si bien el sistema no es la suma de las partes, sí es una totalidad organizada y organizadora que comporta emergencias, cualidades e interrelaciones que las partes aisladas no tienen, de ahí la diferencia entre el sistema y el entorno. La biblioteca no puede pensarse o entenderse con un estudio aislado de sus elementos, dado que éstos al integrarse $\mathrm{y}$ formar parte de ella adquieren cualidades propias. Y la situación es la misma cuando tomamos a la biblioteca como elemento del sistema mayor; en tal sentido ésta adquirirá cualidades propias referidas a su entorno o al sistema al que pertenece.

Como las bibliotecas son sistemas tienen identidad propia (siempre en función de un ambiente o suprasistema), y pueden referirse a sí mismas, realizar distinciones consigo mismas y con el entorno, $\mathrm{y}$ con los sistemas de un entorno con base en la referencia a sí, o al entorno o a los sistemas en él, de los cuales las bibliotecas se separan por medio de sus límites; guiándonos nuevamente por Luhmann recordemos que:

[...] el punto de partida de cualquier análisis teórico-sistémico debe consistir en la diferencia entre sistema y entorno. Existe sobre este punto un consenso específico. Los sistemas están estruc- 
Métodos cualitativos para estudiar a los usuarios de ...

turalmente orientados al entorno, y sin él, no podrían existir: por lo tanto, no se trata de un contacto ocasional ni tampoco de una mera adaptación. Los sistemas se constituyen y se mantienen mediante la creación y la conservación de la diferencia con el entorno, y utilizan sus límites para regular dicha diferencia. Sin diferencia con respecto al entorno no habría autorreferencia ya que la diferencia es la premisa para hacer funcionar todas las operaciones autorreferenciales (Luhmann, 1991, p. 39).

Así la biblioteca hace referencia a sí misma, se autorrefiere como parlamentaria en términos de su pertenencia al Parlamento; y al ser elemento de él le debe su funcionalidad a éste, y si lo que se requiere es información ella está obligada a proporcionarla teniendo como premisa la organización de la misma o de los soportes documentales pertinentes.

En este caso la autorreferencia implica que la biblioteca como sistema social realiza su propia organización, es decir:

[...] el sistema sólo puede disponer de sus propias operaciones, dentro del sistema no existe otra cosa que su propia operación única, que logra conformar dos acontecimientos fundamentales: la autorganización y la autopoiésis. Autorganización quiere decir construcción de estructuras propias dentro del sistema; autopoiésis, en cambio, significa determinación del estado siguiente del sistema a partir de la limita- 
ción anterior a la que llegó la operación (Luhmann, 2002, pp. 110-111).

Por ello decimos que la biblioteca tiene identidad propia, reflexiona respecto de sus observaciones y, cada vez que las lleva a cabo, se incluye en ella.

Hasta aquí, una biblioteca es autorreferencial cuando constituye, por sí misma, los subsistemas que la integran y cuando permite que coexista, en las relaciones con éstos, una referencia a esta organización, con lo cual tal organización es reproducida continuamente.

Respecto a la autorreferencia, a los límites que la diferencian como biblioteca, se observa que la parlamentaria o legislativa es distinta, en términos ontológicos y teleológicos, a otros sistemas que integran al Parlamento; a saber, por ejemplo, el archivo, las áreas de deliberación, y otras áreas administrativas y de apoyo parlamentario. En relación con los procesos que tienen efecto en un sistema, basándonos en el pensamiento luhmanniano, se sabe que existirá una autorreferencia procesal denominada reflexividad, la cual se presenta cuando la diferenciación entre el antes y el después constituye la base de la observación; es decir, si hablamos de procesos en bibliotecología, la observación diferenciada respecto a, por ejemplo, la manifestación de una necesidad de información, su atención por par- 
Métodos cualitativos para estudiar a los usuarios de ...

te de la biblioteca y la evaluación de la satisfacción por parte del usuario, todo esto en un lapso temporal (antes/después). Esto es, información acerca de la información.

Desde esta perspectiva la biblioteca del Parlamento debe reconocer en sí misma su capacidad para aprender de las reacciones, irritaciones y perturbaciones percibidas en el entorno. De esta for$\mathrm{ma}$, al representarse así, la biblioteca se permite la fabricación y recreación propias ya que la autorganización es una propiedad de los sistemas; una biblioteca autorreferente es un sistema capaz de enfrentarse a un entorno complejo, y de adaptarse dinámicamente a los cambios que tienen lugar en el propio sistema.

En nuestro caso lo importante será estudiar un modelo para adoptar un dispositivo que controle la necesidad de información del medio. La relación de previsión informativa del sistema con su entorno consistirá, en esta perspectiva teórica, en reducir la complejidad de la necesidad de información, que siempre es mayor que la de la biblioteca. La reducción de la complejidad exigiría, por tanto, previsión y selección.

Mi definición de biblioteca, considerada como sistema, será en lo sucesivo: el conjunto organizado de elementos y procesos estructurados en interdependencia, que interactúan a través de la comunica- 
ción como un todo unitario y complejo, inserto en un entorno al cual se adaptan con la finalidad de proporcionar productos y servicios de información en forma oportuna, pertinente y confiable por tiempo indefinido y en las condiciones establecidas por el ambiente de la realidad que impera y a la cual se deben.

Para nuestro propósito modélico, hemos adoptado la concepción de un arquetipo de mapeo procesal que concibe a la biblioteca parlamentaria como una interacción relacional compleja, multifacética y dinámica, que incluye grados e intensidades muy variables de asociación y disociación. Aquí la "estructura" pasa a ser una construcción abstracta que no es diferenciable del proceso interactivo en desarrollo, sino que constituye, más bien, una representación temporal y acomodaticia de este sistema en un momento dado. Estas consideraciones nos llevan a una idea fundamental: los sistemas socioculturales como la biblioteca son intrínsecamente elaboradores de su estructura y son cambiantes.

\section{Modelación sistémica}

La sociedad y sus segmentos requieren bibliotecas que se anticipen a sus demandas potenciales y necesitan unidades de información que sean proactivas en su oferta de servicios. 
Métodos cualitativos para estudiar a los usuarios de ...

Esto supone, en contraste con la imagen burocrática de biblioteca que prevalece generalmente, una mayor agilidad para gestionar la información y entregársela oportunamente al usuario. Todo esto hace necesaria una mayor capacidad de innovación en la cultura organizacional y en el uso de la infraestructura (Quijano, 2004, p. 2).

Teóricamente creemos que es posible prever la documentación (información) que será requerida por el investigador legislativo, por el parlamentario, o por los complejos órganos que se desempeñan en el entorno de la biblioteca parlamentaria; creemos que se trata de acercarse lo más posible al umbral de las necesidades de información que requerirá el usuario para tomar sus decisiones, para llevar a buen puerto su investigación y para contar con registros informativos cuya vigencia sea pertinente a lo largo de su actividad parlamentaria, de control, representativa, y legislativa.

En bibliotecología la noción de necesidad de información es "el resultado de los problemas que se le presentan a un individuo en una situación específica, que lo motiva a buscar conocimientos, ideas, hechos, datos o trabajos creativos o imaginativos producidos por la mente, los cuales son comunicados formal y/o informalmente en cualquier formato" (Calva, s.f.); es decir, individualmente o en grupo, las personas enfrentan diversas situaciones en 
su devenir temporal y tienden a buscar la información que satisfaga tal ausencia de conocimiento o de datos; así, el sustento genérico de la existencia de la biblioteca recae en la posibilidad que ésta tiene para resolver necesidades de información. En nuestro caso, la biblioteca deberá desarrollar operaciones dirigidas a organizar la información que satisfaga los requerimientos de los legisladores.

La biblioteca deberá responder al requerimiento de información del entorno en tanto ha seleccionado la información pertinente que satisfaga las necesidades propias de los legisladores o parlamentarios; si lo hace así, con anticipación a los estímulos exteriores, habrá logrado cierta estabilidad en la emergencia requerida por los estímulos del entorno.

La pregunta es si la biblioteca parlamentaria puede prevenir o prever la necesidad de información y cuál es ésta en función de la dinámica propia del entorno parlamentario que la rodea como sistema. $\mathrm{La}$ respuesta está, según nosotros, en la versión de que la operación pertenece a la biblioteca (clausura operativa) y no al entorno; así, se coloca a la observación y a la capacidad de distinción de los sistemas como algo importante a partir de su posibilidad de prever. Esto quiere decir, por tanto, que bibliotecas como la parlamentaria pueden observar y distinguir; hay que presuponer en ellas una capacidad 
Métodos cualitativos para estudiar a los usuarios de ...

de observación, lo cual designa un tipo de operación que se lleva a efecto en el sistema mismo.

La biblioteca y el Parlamento (sistemas de sentido), al ser autorreferentes, pueden ubicarse en su propio espacio (su lugar) y ser conscientes, reflexivos de sí mismos y de otras relaciones con sus entornos; pero la diferencia existente -no referida a lugares físicos sino al lugar etéreo de comportamiento, de acción y sentido, de comunicación, y por tanto de selecciones, elecciones y decisiones-le permite al sistema, ver y verse a sí mismo como una unidad con capacidad para prever, ya que es capaz de percibir, observar, computar y actuar en consecuencia; y de tomar decisiones que son acciones conductuales como, para la biblioteca, el desarrollo de sus colecciones, la organización técnica documental y los servicios de referencia, préstamo y orientación.

Pasemos entonces al asunto de la modelación. En relación con la connotación del término modelo aprovecharemos el conocimiento vertido por Hernández Salazar (2004) cuando sostiene que desde el punto de vista epistemológico la noción ha sido considerada como:

a) Modo de explicación de la realidad.

b) Forma de representación de alguna realidad o serie de realidades y de algún proceso o serie de procesos. 
c) Sistema con valor heurístico que sirve para entender otro sistema.

d) Sistema del que se presentará una teoría; esto es, la realidad que la teoría trata de explicar.

Así, podemos entender la modelación como una técnica de configuración o conformación de modelos; tal noción se fusiona aquí con la idea de sistema.

Queremos usar esta técnica para observar cómo se relacionan los distintos componentes de la biblioteca parlamentaria para producir la previsión de ciertas necesidades de información. Estos componentes conforman un sistema que comprende recursos procesados (catalogación, clasificación e indización) para describir los materiales documentales que son útiles y pueden servir para enriquecer el trabajo propio de los parlamentarios en su trabajo cotidiano, quienes a su vez pueden producir efectos como la representación ciudadana, el control gubernamental y la legislación como productos útiles para la sociedad.

Lo que haremos es diagramar las relaciones que hay entre las actividades del entorno de la biblioteca parlamentaria para justificar la necesidad de prever los requerimientos de información; la modelación nos facilitará la comprensión de las relaciones, de la estructura, y de las actividades que llegan del entorno e impactan al sistema. Principalmente intentaremos mostrar el conjunto de actividades legislativas 
Métodos cualitativos para estudiar a los usuarios de ...

con el fin de identificar, con sentido previsor, las principales necesidades de información específicas para la confección de una iniciativa, una representación y un control, todo ello al interior del poder Legislativo. Aun trayendo a colación algunos ejemplos parlamentarios de nivel mundial, nuestras aseveraciones se concretarán específicamente al caso mexicano. Sin embargo, creemos que las variantes de procedimiento y normativas tendrán que ver más con el propio marco legal de cada país; en esencia los considerandos son tan generales que pueden ser aplicados a casi cualquier caso específico

Consideramos que los modelos autorreferenciales podrán ayudar en lo sucesivo a ubicar áreas problemáticas o a analizar problemas observando las distintas partes del sistema y las relaciones que existen entre ellas, pero sobre todo, estableciendo las diferencias correspondientes con el entorno a través de la previsión de necesidades de recopilación de datos tales como indicadores, información sobre procesos, informes de gestión, control de resultados, efectos sobre la sociedad, y doctrina jurídica, veamos:

La Figura 7 muestra el Modelo de autorreferencia y previsión de necesidades de información parlamentaria; en él se puede ver que el segmento modélico " $\mathrm{A}$ " tiene a disposición un cúmulo creciente de información que se filtra a la biblioteca parla- 
La biblioteca como sistema autorreferente

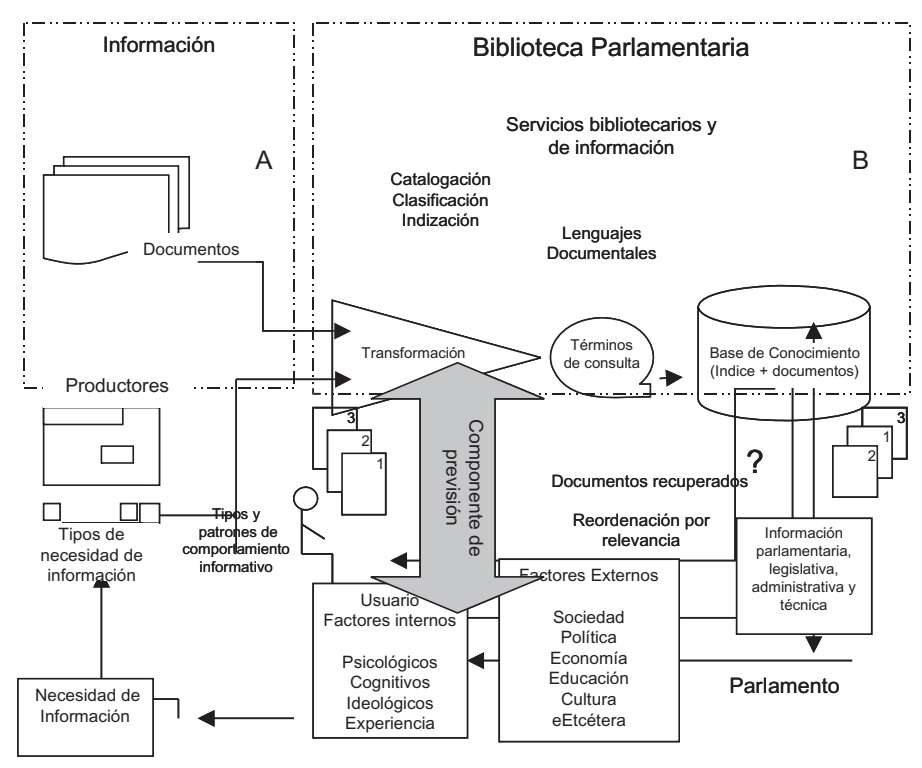

Figura 7

Modelo de auto-referencia y previsión de necesidades de información parlamentaria

mentaria por vía de documentos en su concepción más genérica, lo que incluye a los productores de información y los conocimientos registrados. El segmento sistémico "B”, biblioteca parlamentaria, representa el ingreso de soportes de información en diversos formatos, que serán representados en registros descriptivos a través de la organización técnica documental (catalogación, clasificación, indización) para ser usados por los interesados en tales 
Métodos cualitativos para estudiar a los usuarios de ...

materiales informativos; este segmento, presenta procesos de entrada y salida de información a los que se les agrega valor por vía del análisis documental y la confección de índices y resúmenes.

Los materiales o soportes documentales se refieren a las necesidades de información relativas a la política de selección y adquisición documental, y por tanto se adquieren a partir de estudios de usuarios, estudios de uso, y estudios sobre el comportamiento informativo y la demanda. Sin embargo, las necesidades de información que surgen en el usuario pueden determinarse en un espacio temporal y variar de un momento a otro, lo que supone que hay otras necesidades de información en relación con los factores externos en donde éstas se ubiquen. Es por eso que "[...] las unidades de información se enfrentan a un problema complejo cuando se habla de necesidades de información futuras o potenciales, ya que en esto es en lo que la biblioteca o el centro de documentación deben estar preparados para satisfacer las necesidades futuras de sus usuarios" (Calva, 2004, p.91).

Así, queremos destacar de manera sobresaliente el "componente de previsión" que se muestra en la Figura 7, interactuando entre la biblioteca y el entorno, el Parlamento. Tal componente es producto de la reflexividad y la autorreferencia sistémica; en tal sentido una biblioteca específica deberá valorar su disposición para implementarlo adecuadamente. 
La inserción del "componente de previsión" es consecuente con la intención de establecer un método sistemático para prever las necesidades de información, basado en las actividades desarrolladas por los individuos que componen un sistema social y que, al interior del mismo, determinan su sentido o finalidad.

Hemos decidido construir un modelo para explicar estos procesos representándolo en la Figura 8; en ella observamos que la biblioteca parlamentaria se ubica en el entorno inmediato donde interactúan, en primera instancia y por vía del insumo electoral, los congresistas o integrantes de la legislatura, quienes se organizan en grupos parlamentarios que a su vez, dependiendo de la reglamentación correspondiente, integran o forman órganos de gobierno interno para el Parlamento y las comisiones de trabajo, los cuales analizan y dictaminan las propuestas que deba decidir el Pleno en forma positiva o negativa a través de la deliberación correspondiente. Los integrantes de la legislatura, según se observa en la misma Figura 8, presentan sus necesidades de información relacionadas con las diversas formas de control que tienen sobre el Ejecutivo, y la representación y legislación que deban realizar de acuerdo con sus propios intereses o preferencias, o las del grupo parlamentario que ideológicamente suscriben, y las cuales generan investiga- 


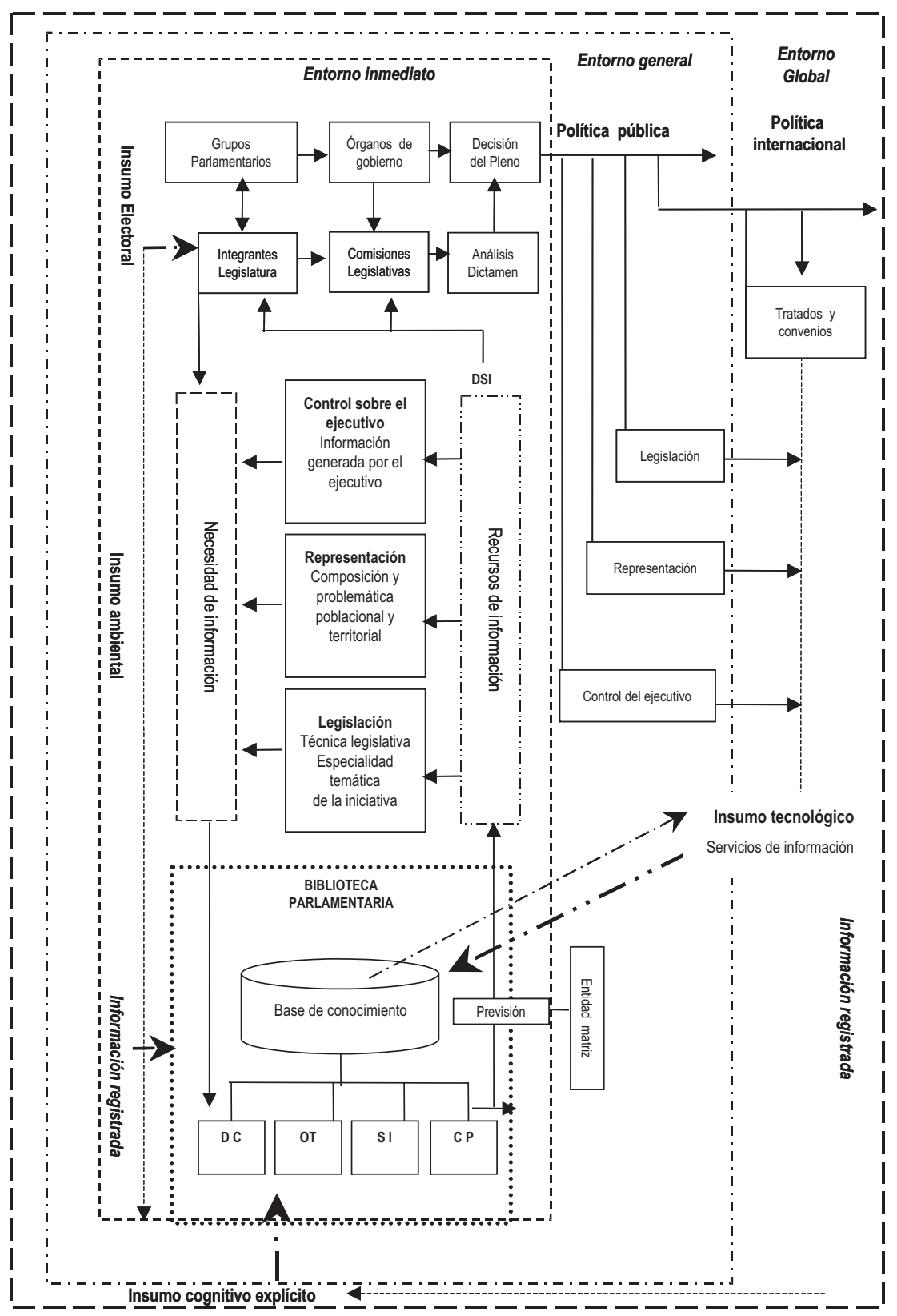

Figura 8

Modelo esquemático de la biblioteca parlamentaria enfocada al entorno 
ciones o propuestas legislativas que deberán presentarse ante el Pleno o en comisiones.

Encontramos que la necesidad de información surge, en efecto, en los individuos (factores internos), y se consolida con el insumo ambiental (política, economía, sociedad, cultura, etcétera) y debido a las actividades de control, representación y legislación (factores externos). Tanto los factores internos como los externos son variables independientes a la biblioteca parlamentaria. Acudiendo nuevamente a la Figura 8, la biblioteca parlamentaria, como sistema autorreferente, se estructura con vistas al entorno, con los componentes para el desarrollo de colecciones (DC), la organización técnica documental (OT), los servicios de información (SI), y el que hemos insertado nosotros: investigación de las necesidades de información, denominado componente de previsión ( $\mathrm{CP}$ ), que genera ésta conjuntamente con aquéllas que las anteceden y le dan basamento a la base de conocimiento.

Esta base de conocimiento, en tanto se nutre de información especializada debidamente seleccionada y organizada, apoya directamente la previsión mediante el suministro de referencias documentales provenientes del insumo cognitivo explícito (soportes de información) y del insumo tecnológico, a fin de que se canalicen como la oferta de recursos de in- 
Métodos cualitativos para estudiar a los usuarios de ...

formación útiles y necesarios para documentar el control, la representación y la legislación.

Es notable que el asunto que llama la atención se refiera a las necesidades de información; en este sentido la viabilidad de la previsión informativa depende de la habilidad de la biblioteca para observar, reconocer y adaptarse activamente a los cambiantes requerimientos del entorno. Esto exige una flexibilidad que sólo puede ser provista por una estructura modular (DC, OT, SI, CP), multidimensional, con membresía positiva, ágil en la toma de decisiones, y que cuente con redundancias semánticas que permitan crear un subsistema adaptativo y reflexivo; sinergético, que hemos denominado "componente de previsión” de información (CP).

El cambio debemos entenderlo a través de la nueva interrelación que se le da a los datos y a la información; de las diversas conexiones que se visualizan entre un nuevo conocimiento y su tratamiento bibliotecológico con sentido de previsión; y de la velocidad con la que se realizan las operaciones en el sistema para responder a las demandas del medio.

Adicionalmente, la oferta de recursos de información puede incorporarse a la diseminación selectiva de la información (DSI) por vía de la atención de necesidades de información específicas en función de los factores internos de los individuos o de los perfiles grupales de las comisiones que tienen 
que ver con la denominación y los contenidos temáticos inherentes.

Se observa también que el vínculo del Parlamento con el entorno general se da a través de la decisión del Pleno, órgano complejo que emite políticas públicas y su derivación, siendo a veces el caso políticas de carácter internacional o vinculadas con las relaciones exteriores del Estado en el entorno global. Además, de una u otra forma, el desarrollo de políticas públicas es un elemento de comunicación del órgano legislativo con la sociedad y en tal sentido queda soportado en los documentos que por vía de información registrada se suman al insumo cognitivo explícito que debe ingresar al entorno inmediato: la biblioteca parlamentaria.

Por su parte, las comisiones y los grupos parlamentarios representan, en esta misma categoría, sistemas parciales con cierto interés político, que en reuniones de trabajo colegiado analizan los proyectos e iniciativas legislativas (por ejemplo las reformas a la Constitución Política o a leyes secundarias relacionadas con asuntos como la reforma energéti$\mathrm{ca}$, fiscal, laboral y en general la del Estado, entre otros) que inciden dentro del propio sistema parlamento y en el entorno que lo rodea; lo que requiere de información especializada relacionada con las diversas áreas de conocimiento, más datos y conocimientos formales, los cuales constituyen una por- 
Métodos cualitativos para estudiar a los usuarios de ...

ción de la base de conocimiento ubicada en el entorno inmediato a la biblioteca.

Ahora bien, si el sistema total, (para nuestro enfoque Congreso o Parlamento), se utiliza a sí mismo como entorno de la formación de sus sistemas parciales, es claro que la biblioteca parlamentaria es un focus de resonancia del propio sistema total, con el cual interactúa a través de los propietarios que tienen los derechos sobre los servicios en su entorno más inmediato, de tal suerte que la biblioteca adopta, para nuestros propósitos, la connotación de un sistema parcial; y al relacionarse en el mismo entorno inmediato con las comisiones y los grupos parlamentarios debe aprender a adaptarse al cambio establecido por la propia dinámica del Parlamento o Congreso.

En concreto, los métodos y procedimientos para llegar a conocer las necesidades de información de los usuarios implican conocer las grandes líneas temáticas que el Parlamento o Congreso atiende, tales como la política social (seguridad social, derechos humanos, grupos vulnerables), la política económica (recaudación y distribución del ingreso), la política interior (gobernabilidad, seguridad pública, migración) y la política exterior (convenios y tratados, soberanía, organismos internacionales), pero la mayoría de estos temas se relacionan con los productos y servicios informativos que res- 
ponden a necesidades de considerable tipificación para grandes cantidades de personas del entorno de la biblioteca, por lo que se reduce a un nivel mínimo de tratamiento el estudio o la caracterización de los individuos que integran la legislatura, a la cual pertenece la biblioteca como un sistema parcial.

Recordemos que no se reconoce la previsión de información en virtud de las necesidades propias del usuario, sino que éstas se confunden con la satisfacción del usuario a partir de la evaluación sobre la pertinencia de los recursos o los servicios ofrecidos (Calva, 2004). Es decir, lo que necesitamos es prever en el entorno cuáles son los recursos útiles para desarrollar las actividades propias del sistema, y sumarlos al conocimiento que se tenga acerca de las características de los usuarios y de sus requerimientos (cuya satisfacción es el objetivo principal de la biblioteca) con la intención de fomentar la intuición, derivada de un verdadero estudio de previsión de las necesidades; es por esto que proponemos el rediseño a partir de la existencia de un principio que hemos denominado modelo de previsión de información (PI) (Montes, 2006) ${ }^{1}$.

1 Cfr. pp. 128 y ss. 
Métodos cualitativos para estudiar a los usuarios de ...

Por lo tanto, como queremos planear el rol de la biblioteca parlamentaria en el proceso de previsión de información en un entorno que cambia, pasaremos a esquematizar cuáles serían las medidas que deberíamos tener en cuenta para contar con un modelo de biblioteca que fuera un sistema reflexivo, autorreferente.

La Figura 9 refleja nuestra visión general sobre la aplicación modélica a la resolución de problemas de información, y muestra a la biblioteca o unidad de información en interacción con su entorno inmediato. Dentro de la biblioteca identificamos las actividades de Desarrollo de Colecciones (DC), la Organización Técnica (OT) y los Servicios de Información (SI), vinculados a una base de conocimientos y conectados al componente de previsión ( $\mathrm{CP}$ ) de necesidades de información cuyo fin es promover la indagación de éstas y su satisfacción a través de la provisión de servicios.

El modelo puede ser adaptado a cualquier biblioteca que tenga como interés prever necesidades y adelantarse a la formulación de éstas por parte del usuario.

Siguiendo a Hernández Salazar (2004) en tanto que un modelo es un sistema que tiene un valor heurístico, permítasenos considerar la Figura 9; Modelo genérico de previsión de información, para mostrar la generalidad aplicativa del modelo PI. 
La biblioteca como sistema autorreferente

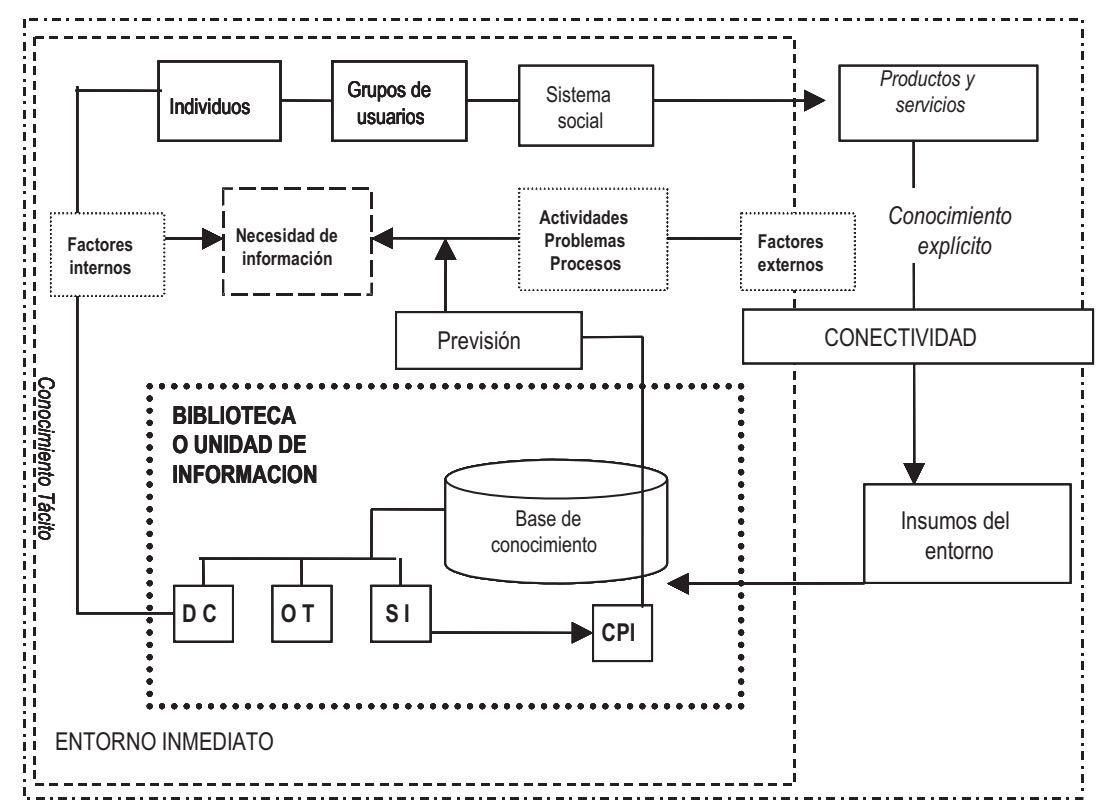

Figura 9

Modelo genérico de previsión de información

Se observa por un lado que la generalidad de los individuos o grupos de ellos ubicados en un sistema social, tienen o pueden tener, en efecto, necesidades de información que surgen a partir de factores internos; por otra parte el ambiente o entorno, donde se desenvuelve el sistema social al que estamos vinculados, determina una serie de factores externos a los individuos que inciden directamente sobre el surgimiento de sus necesidades de información. La biblioteca realiza sus actividades con el ob- 
Métodos cualitativos para estudiar a los usuarios de ...

jetivo de generar una base de conocimientos que contribuya a satisfacer las necesidades de información de los individuos o el grupo de éstos.

En tanto que la base de conocimientos es consultada y a través de ella se proporcionan servicios de información, es claro que la biblioteca o la unidad de información estará haciendo lo suyo.

El papel del tratamiento de la información es pues prevalente en este entorno, tanto como intermediación de conocimiento explícito, cuanto como diseminación que se apega a los perfiles de necesidades de información.

Planificar e implementar teóricamente el modelo de previsión de información no asegura automáticamente el éxito. Este modelo puede obtener resultados muy diversos que dependen de la reacción que tengan los Actores involucrados, el personal, y los beneficiarios de su implementación, pues la recepción de información tiende a modificar los parámetros de conocimiento tácitos individuales apoyándose, por ejemplo, en la conectividad a correos electrónicos, entre otras cosas.

En una primera etapa, la biblioteca parlamentaria deberá considerar las reacciones del entorno con el fin de mejorar los servicios al usuario, resulta muy importante que los usuarios conozcan estos servicios y obtengan una primera impresión crítica 
de su confección, a fin de justificar su implementación y asegurar su financiamiento.

La segunda etapa puede consistir en implementar una estrategia de desarrollo de la biblioteca a través de una mayor cobertura interna de servicios, estrategia que se evalúa obteniendo indicadores que muestren una mejor interacción con los beneficiarios del sistema. También hay que buscar que los legisladores hagan uso de la base de conocimiento recibiendo información que supere una modalidad "masiva" e impersonal de servicios, los cuales no deberían integrarse al contexto general sino, más bien, a las autoridades específicas y tener una cobertura temática correspondiente al ámbito de trabajo y a las necesidades particulares de información.

En consecuencia en esta etapa se deberán estimar las interacciones actuales que existan entre los usuarios y la biblioteca, para conocer el nivel directo de atención de las necesidades de conocimiento explícito; se trataría de evaluar los resultados de las entregas de información a través de la diseminación selectiva, y efectuar un seguimiento sobre el grado de satisfacción alcanzado por la gestión en periodos subsecuentes.

En forma paralela y recurrente, deberemos tener indicadores sobre la autorreferencia bibliotecaria respecto al entorno y el nivel de conocimientos con valor agregado que ésta genera; es decir, contar 
Métodos cualitativos para estudiar a los usuarios de ...

con indicadores relativos a las funciones orgánicas que se desarrollan, la posición jerárquica que se tiene dentro de la administración del congreso o parlamento; el número de usuarios y su tipificación. Y también habrá de contarse con sus perfiles de necesidades de información; el tamaño y características del acervo y los mecanismos de colaboración interbibliotecaria, así como las formas de adquisición, incluyendo el depósito legal si éste existe; la organización documental, el nivel de descripción y el análisis documental, la actualización de catálogos y la aplicación de estándares internacionales; los servicios de información que se proporcionan y el uso de recursos tecnológicos para tales fines, así como las publicaciones propias de la biblioteca.

Mención aparte deberá tener el uso de equipos y computadoras para el personal y el desarrollo de procesos técnicos; así como el edificio de la biblioteca, su cercanía con la actividad principal de su entorno, su confort, iluminación y espacio adecuados; y no estaría de más valorar la velocidad que se alcanza en la provisión de los servicios tomando en cuenta criterios de pertinencia, relevancia y confiabilidad en el cumplimiento.

Existen otros componentes que habría que incorporar en la etapa general de evaluación, como sería por ejemplo la cuestión de la complejidad técnica que implica la definición de perfiles de necesi- 
dades de información y la diseminación selectiva; cada una de las cuales exige esfuerzos de distinta naturaleza en lo que se refiere al desarrollo de procesos técnicos y al empleo de nuevas tecnologías. Adicionalmente, cada una de éstas demandará presupuesto tanto por lo que toca a recursos humanos como financieros.

\section{Conclusión}

Bajo la premisa de considerar a la biblioteca como un sistema social es posible desarrollar un modelo de autorreferencia que no sólo abarque y observe los elementos subsistémicos que la integran, según lo cual la bibliotecología clásica ha denominado desarrollo de colecciones, organización técnica y servicios de información; sino que se puede ubicar a la biblioteca observando el propio entorno en el que se desenvuelve, opera y al cual se debe, y donde ofrece sus servicios.

Tal posicionamiento sitúa a la biblioteca en la resolución de problemas complejos relacionados con su interactuar con el entorno, donde establece vínculos con otros sistemas que ahí operan y con los cuales comparte compromisos acerca de la totalidad que abarca el sistema del cual la propia biblioteca forma parte.

De tal manera y bajo tales consideraciones, la biblioteca no debe observar los problemas de las nece- 
Métodos cualitativos para estudiar a los usuarios de ...

sidades de información desde una perspectiva ajena a su entorno sino, por el contrario; el modelo que planteamos implica que la biblioteca debe considerarse como una parte del problema que implica atender las necesidades de información de los usuarios, y por lo tanto debe comprender a cabalidad el paradigma arquetípico de su entorno y reconocer en él la estructura existente para actuar en consecuencia.

La biblioteca, como subsistema autorreferente, debe admitir que es parte de la manera en que está constituido el sistema al que pertenece, y por lo tanto también comparte responsabilidad en lo que se refiere al logro de objetivos específicos; sólo así será posible redefinir sus estructuras y responder adecuadamente a un ambiente complejo.

\section{Obras consultadas}

Calva, Juan José. (2004), Las necesidades de información: fundamentos teóricos y métodos, México, UNAM, CUIB.

-- (s.f.). Calva González, Juan José, Las necesidades de información de los usuarios en la planeación bibliotecaria, en http://www.dgbiblio.unam.mx/servicios/ $\mathrm{dgb} / \mathrm{publicdgb/bole/fulltext/volVI1/necesidades.}$ $\mathrm{html}$

Hernández, Patricia. (2004), Modelo para generar programas sobre formación en uso de tecnologías de información, México, UNAM, CUIB. 
La biblioteca como sistema autorreferente

Johansen, Oscar (1993), Introducción general a la teoría general de sistemas, México, Limusa.

Jokisch, Rodrigo (2002), Metodología de las distinciones: forma, complejidad, auto-referencia, observación, construcción de teorías integrando lo macro y lo micro en las Ciencias Sociales, México, UNAM, Juan Pablos.

Lexipedia: diccionario enciclopédico (1996), México, Encyclopædia Británica.

Lugan, Jean-Claude (1990), Elementos para el análisis de los sistemas sociales, México, FCE.

Luhmann, Niklas (2002), Introducción a la teoría de sistemas, México, Universidad Iberoamericana.

-_. (1991), Sistemas sociales: lineamientos para una teoría general, México, Alianza, Universidad Iberoamericana.

Maturana, Humberto y Francisco Varela (1990), El árbol del conocimiento: las bases biológicas del conocimiento humano, Madrid: Debate.

Molina, Enrique (1995), Teoría de la biblioteconomía, Granada, Universidad de Granada.

Montes, Ricardo (2006), Modelación sistémica de bibliotecas parlamentarias: teoría de la autorreferencia en relación al entorno, Tesis de Maestría, México, UNAM. 
Métodos cualitativos para estudiar a los usuarios de ...

Morales, Estela (2001), "La Sociedad de la Información en el siglo XXI y la biblioteca universitaria", en Revista Digital Universitaria, 30 de Junio de 2001, Vol.2, No.2, en http://hfigueroabsociol.tripod.com/bibluniv.htm.

Pelufo, Marta Patricia y Edith Catalán, (2001), Introducción a la gestión del conocimiento: aplicado al sector público, Santiago, ILPES.

Quijano, Álvaro (2004), La biblioteca como organización, en http://www.uach.mx/foro/ponencias/quijano.doc.

Robinson, William (1999), El papel que juega la información en una legislatura democrática, México, Cámara de Diputados, SIID, (DG-09-99). 


\title{
La técnica del análisis de contenido y su aplicación en los planes de estudio de bibliotecología en México, para determinar la presencia de la formación de usuarios ${ }^{1}$
}

\author{
BLANCA ESTELA SOLÍS VALDESPINO
}

\section{Introducción}

G n términos generales, para resolver problemas de investigación en las disciplinas bibliotecológica y de ciencia de la información se han seguido métodos y técnicas cuantitativas, las cuales no siempre son las idóneas. Esto se hace más patente cuando se abordan fenómenos relacionados con los

1 La versión original fue publicada como artículo en coautoría con Patricia Hernández, investigadora del Centro Universitario de Investigaciones Bibliotecológicas de la UNAM, intitulado "Acercamiento al análisis de contenido como técnica para estudiar la formación”, en Hemera: revista de ciencias bibliotecológica $y$ de la información, año 4, vol. 4 número 7 de enero-junio de 2006, p. 32-63. la autora agradece a la maestra Antonia Santos, directora y editora general de esta revista su autorización para retomar algunas partes del artículo. 
Métodos cualitativos para estudiar a los usuarios de ...

usuarios de la información, concretamente el tema de la formación de éstos en el uso de información.

Este subcampo disciplinario toca aspectos que tienen que ver con comportamientos humanos de orden cualitativo, por lo que se requiere seguir técnicas de tipo cualitativo, como el análisis de contenido.

El análisis de contenido tiene sus orígenes en el uso consciente de los símbolos y del lenguaje. Y busca analizar datos, dentro de las comunicaciones, los cuales son vistos como un conjunto de fenómenos simbólicos que tienen un propósito particular. Estos símbolos contienen un gran peso: nos arrojan mensajes que producen efectos y su significado ayuda a entender las formas de pensamiento y las conductas generadas por diversos grupos humanos. El análisis de contenido se enfoca primordialmente a identificar palabras y analizarlas con objeto de descubrir su mensaje oculto.

El propósito de este capítulo es ofrecer un acercamiento a la técnica de análisis de contenido a partir de su aplicación en el análisis de los planes de estudio de las licenciaturas del área bibliotecológica, con el fin de identificar la presencia de contenidos tendientes a dotar al bibliotecólogo de conocimientos teóricos y pedagógicos sobre la planeación, elaboración y puesta en marcha de programas de formación de usuarios, con la intención de satisfacer 
La técnica del análisis de contenido y su aplicación en los ...

las nuevas demandas sociales en materia de información.

\section{La técnica del análisis de contenido}

La historia registrada por Krippendorff (1990) sobre el análisis de contenido marca tres fases históricas desarrolladas en Estados Unidos. La primera fase se dio en el área periodística e intentaba demostrar que las noticias estaban reorientándose hacia la violencia en las ciudades; ahí el método empleado fue medir los tamaños de las columnas de los diarios y anotar el tipo de información que presentaban. La segunda fase se caracterizó por la entrada de los medios electrónicos para analizar la crisis económica que estaba provocando problemas sociales y económicos, y también el papel que desempeñaban los medios de comunicación dentro de este proceso. La tercera fase fue su aparición como método empírico de estudio dentro de las ciencias sociales. Dentro de esta corriente de pensamiento aparecen términos como: "estereotipos", "actitud favorable o desfavorable", "adeptos", "objetividad", "equilibrio", todos ellos con una fuerte carga de información y con base en los cuales años más tarde aparece la teoría de las actitudes.

En ese mismo país aparece el análisis del discurso político como una corriente, y a partir de los trabajos de Lasswell en la Biblioteca del Congreso 
Métodos cualitativos para estudiar a los usuarios de ...

esos trabajos se orientaron a determinar los problemas de medición, fiabilidad y validez de las categorías de contenido establecidas previamente.

\section{El concepto del análisis de contenido}

Desde sus orígenes hasta el momento actual, la conceptuación del análisis de contenido ha evolucionado en algunos aspectos (ver Cuadro 1):

\begin{tabular}{|c|l|l|}
\hline \multicolumn{2}{|c|}{$\begin{array}{l}\text { Cuadro 1 } \\
\text { Evolución del análisis de contenido. }\end{array}$} \\
\hline AÑO & \multicolumn{1}{|c|}{ AUTOR } & \multicolumn{1}{c|}{ DEFINICIÓN } \\
\hline 1942 & ALLPORT & $\begin{array}{l}\text { Método para estudiar y analizar el contenido de las comunicaciones es- } \\
\text { crita, oral o visual, en forma sistemática, objetiva y cualitativa. }\end{array}$ \\
\hline 1952 & BERELSON & $\begin{array}{l}\text { Técnica de investigación para la descripción objetiva, sistemática y } \\
\text { cualitativa del contenido manifiesto de las comunicaciones con el fin de } \\
\text { interpretarlas. }\end{array}$ \\
\hline 1968 & HOLSTI & $\begin{array}{l}\text { Técnica para realizar inferencias mediante la identificación sistemática } \\
\text { y objetiva de características específicas de los mensajes. }\end{array}$ \\
\hline 1971 & TRAVERS & $\begin{array}{l}\text { Grupo de técnicas diseñadas para analizar las comunicaciones verba- } \\
\text { les. }\end{array}$ \\
\hline 1981 & FORDIN & $\begin{array}{l}\text { Conjunto de técnicas de análisis de las comunicaciones que apunta } \\
\text { procedimientos sistemáticos y objetivos del contenido de los mensajes. }\end{array}$ \\
\hline 1981 & KERLINGER & $\begin{array}{l}\text { Procedimiento para categorizar datos verbales y de conducta con fines } \\
\text { de clasificación, resumen y tabulación. }\end{array}$ \\
\hline 1990 & KRIPPENDORFF & $\begin{array}{l}\text { Método para analizar y estudiar las comunicaciones de una manera sis- } \\
\text { temática, objetiva y cuantitativa. Observación. }\end{array}$ \\
\hline & $\begin{array}{l}\text { Técnica de investigación destinada a formular, a partir de ciertos datos } \\
\text { dentro de un texto, inferencias reproducibles y válidas que puedan apli- } \\
\text { carse a un contexto. }\end{array}$ \\
\hline
\end{tabular}


La técnica del análisis de contenido y su aplicación en los ...

Siguiendo las definiciones presentadas en el cuadro anterior los elementos comunes son:

- Objetividad: verificación de los resultados obtenidos.

- Sistematicidad: reglas y criterios previamente establecidos.

- Contenido manifiesto: análisis de lo expresado en el mensaje.

- Capacidad de generalización: demostración de hipótesis (función heurística, descubrimiento de aspectos del discurso y de sus funciones de comprobación, verificación de la certeza o de la comunicación de las hipótesis).

Uno de los autores que más ha escrito sobre esta técnica es Klaus Krippendorff (1990, p.28), quien define al análisis de contenido como una "[...] técnica de investigación destinada a formular, a partir de ciertos datos, inferencias reproducibles y válidas que puedan aplicarse a su contexto". Lo que nos lleva a precisar que el objetivo del análisis de contenido es formular inferencias en cuanto a los efectos de la comunicación, en tanto que nos permite hacer inferencias (esto es razonamientos discursivos), con base en datos verbales, simbólicos o de tipo comunicativo; datos que pueden ser reproducidos por otros investigadores en diferentes momentos. Al aplicar la misma técnica a los mismos datos el re- 
Métodos cualitativos para estudiar a los usuarios de ...

sultado deberá ser el mismo, lo que la convierte en objetiva y reproducible.

Cabe precisar más puntualmente el concepto de inferencia, lo que en su sentido más general se concibe como la acción o efecto de inferir; es decir, sacar o extraer una o varias consecuencias. Así las inferencias son "[...]procesos intencionales y dirigidos de razonamiento que permiten al agente [un sujeto] hacerse cargo ... de la situación que considera o de las relaciones que mantiene con otros agentes [sujetos] y con el mundo que lo rodea" (Muñoz, 2000, p.332).

Más específicamente, como parte del análisis de contenido una inferencia es "[...] un proceso discursivo por el que alguien pasa de una información, una creencia o un conocimiento a otra creencia u otro (presunto) conocimiento" (Muñoz, 2000, p.332).

De acuerdo con Krippendorff el análisis de contenido pretende generar razonamientos cualitativos (inferencias) a partir de datos registrados, extraídos de los documentos.

Las principales características del análisis de contenido son:

- Buscar un significado simbólico en los mensajes.

- Considerar que los mensajes no tienen un solo significado; que tal vez no exista coincidencia acerca del significado; y que las comunicaciones 
La técnica del análisis de contenido y su aplicación en los ...

simbólicas tratan de considerar distintos fenómenos de aquellos que son observados.

- Examinar el contexto de los datos.

- Establecer las clases de inferencias y las comunicaciones simbólicas y otorgarles validez.

- Permitir ubicarse en el entorno de los datos, y conceptuarlos

Según Krippendorff (1990), el análisis de contenido requiere un marco de referencia conceptual que abarque:

- los datos, tal como se lo comunican al analista,

- el contexto de los datos,

- la forma en que el conocimiento del analista lo obliga a dividir su realidad,

- el objetivo de un análisis de contenido,

- la inferencia como tarea intelectual básica y

- la validez como criterio supremo de éxito (Krippendorff, 1990, p.36)

Las ventajas del análisis de contenido son: que no es una técnica intromisiva, que acepta materiales no estructurados y que es sensible al contexto del objeto de estudio. .

Existen varias clasificaciones sobre el análisis de contenido: 
Métodos cualitativos para estudiar a los usuarios de ...

- Análisis de contenido pragmático: procedimientos que clasifican los signos según su causa o efecto probable.

- Análisis de contenido semántico: procedimientos que clasifican los signos de acuerdo con sus significados. Incluye tres subclasificaciones: a) de designaciones, la cual proporciona la frecuencia con que se hace referencia a determinados objetos, personas, cosas, grupos o conceptos, es decir el equivalente a un análisis temático; b) de atribuciones, la cual nos dice la frecuencia con que se remite a ciertas caracterizaciones de un objeto; $y$

c) de aseveraciones, la cual nos da la frecuencia con que ciertos objetos son caracterizados de un modo particular.

- Análisis de vehículos-signos: procedimientos que clasifican el contenido de acuerdo con las propiedades psicofísicas de los signos (Krippendorff, 1990, pp.45-46).

El analista de contenido debe saber distinguir claramente los datos de naturaleza variable y los invariables; enunciar la finalidad y objetivo de las inferencias mencionadas, de acuerdo con los datos recabados y con el contexto del objeto de estudio analizado; y establecer por adelantado las pruebas que permitirán validar los resultados esperados. 
La técnica del análisis de contenido y su aplicación en los ...

\section{Etapas para realizar un análisis de contenido}

El proceso implica realizar las siguientes acciones:

- Formular los datos que incluyen la determinación de unidades, el muestreo y el registro.

- Reducir los datos.

- Sacar inferencias.

- Analizar.

- Validar directamente o bien mediante otros métodos, $\mathrm{y}$

- Verificar las hipótesis con otros datos. Estos componentes se integran en tres etapas básicas: A. proyecto; B. ejecución; y C. informe.

\section{Proyecto}

Krippendorff (1990) define al proyecto como:

La red de pasos analíticos mediante los cuales se procesa la información[...] da cuenta de la manera en que se obtienen los datos y de lo que se hace de ellos en el curso del análisis, y proporciona instrucciones a otras personas acerca de todo lo que deben hacer si pretenden reproducir los resultados. Todo informe de investigación debe contener una descripción del proyecto de investigación (pp.70-71).

Este autor considera al contexto del objeto estudiado como un elemento indispensable que determinará sustancialmente los resultados de la infor- 
Métodos cualitativos para estudiar a los usuarios de ...

mación recabada, y que además debe ser secuencial y manejarse con mucho cuidado pues estos resultados se hacen acumulativos.

Existen varios tipos de proyectos:

- Básicos. Los cuales evalúan fenómenos en el contexto de datos existentes.

- Aquellos que ponen a prueba la posibilidad de sustituir un método. Esto es aplicar dos o más métodos a los mismos datos o a diferentes métodos.

- Los que ponen a prueba la hipótesis. Este proyecto de investigación permite comprender las relaciones que pueden existir entre los fenómenos de los que se ocupa un análisis de contenido y sus condiciones circundantes (Krippendorff, 1990, p.75).

En este proceso el analista revisa los materiales existentes, juega con sus ideas y las somete a juicio buscando establecer un procedimiento que le dé lógica a su pensamiento.

Krippendorff (1990, p.259) propone los siguientes rubros para realizar un proyecto:

1.- Aplicación del marco de referencia conceptual del análisis de contenido. El analista de contenido debe encontrar puntos coincidentes de las dos realidades: la de los datos y la que se desea conocer. Debe clarificar qué desea conocer y no puede observar de manera directa, así como establecer el objetivo que persigue y marcar el universo de es- 
La técnica del análisis de contenido y su aplicación en los ...

tudio. Por ello reunirá los documentos de los que extraerá aquellos datos que le sirvan para inferir. En este proceso debe elegir cuidadosamente la información que desea conocer.

2.- Búsqueda de los datos adecuados. El analista recaba aquellos datos que deben reflejar una conexión con sus inferencias. El proceso de la búsqueda de datos puede ser posterior a lo que originalmente se concibió, porque podrían variar los datos recabados o su registro y análisis. En resumen, puede incluir cualquier dato que afecte el estudio.

3.- Búsqueda del conocimiento contextual. Es necesario contar con un soporte teórico (teorías, modelos, experiencias, datos representativos, etcétera); una conexión empírica sobre lo que se quiere inferir; situar los datos en el contexto, y convertirlos en fenómeno, para que con dicha información se establezca un puente lógico destinado a formular inferencias.

Para que cualquier inferencia a partir de los datos esté justificada, es esencial contar con algún conocimiento riguroso, alguna prueba empírica sobre las conexiones entre éstos y lo que se ha de inferir de ellos (Krippendorff, p. 259).

4.- Desarrollo de planes para determinar las unidades y el registro. El analista determinará el modo de obtener los datos, puesto que algunos de 
Métodos cualitativos para estudiar a los usuarios de ...

ellos serán más difíciles de obtener. El diseño de planes implica establecer la índole de las unidades de registro, la localización espacial o temporal de dichas unidades, el tipo de distribución de la información en el universo estudiado, y las características en materia de automuestreo acerca de las diferentes clases que hay de las unidades de información que hay que recuperar. El analista debe tomar en cuenta que algunas fuentes podrían ser de difícil acceso, que la muestra sea la apropiada, y que el tamaño representativo y los motivos no permiten que los resultados sean los esperados. En todo caso pueden retomarse las conceptuaciones y hay que revisarlas continuamente. El diseño de dicho plan tiene que ser minucioso y explícito con objeto de que posteriormente pueda ser reproducible, se requiere lo siguiente:

a) Determinar las unidades de contexto.

b) Definir las unidades de registro y los procedimientos destinados a su identificación.

c) Establecer categorías que deben cubrir ciertas características, como son: un contenido semántico que represente el marco conceptual; $\mathrm{y}$ atribuciones y designaciones que reflejen cuestiones exhaustivas y excluyentes.

d) Determinar las unidades sintácticas. Que son las representaciones lingüísticas (palabras, 
La técnica del análisis de contenido y su aplicación en los ...

símbolo, frase o párrafo), con sus unidades de enumeración (cuantificación de datos).

5.- Desarrollo de instrucciones de codificación. El analista debe cuidar que las instrucciones estén basadas en conceptuaciones declaradas y puestas a prueba; además de revisar en la literatura si existen estudios previos o similares dentro del área en la cual se esté investigando, pues algunas veces se pueden describir nuevos datos. Si es así se retomarán las instrucciones de registros ya existentes y que con alguna modificación puedan ser utilizadas. Uno de los posibles beneficios de esto sería la posibilidad de comparar resultados con objeto de establecer normas y generar instrucciones fiables para hacer investigaciones de este tipo.

6.- Búsqueda de procedimientos de análisis justificados según el contexto. Todo procedimiento analítico, por su propia naturaleza, implica ciertos supuestos acerca del contexto de los datos que deben defenderse a partir de lo que se conoce sobre este contexto. (Krippendorff, p. 260). En este punto el analista debe considerar especialmente el elemento de sensibilización acerca del contexto del fenómeno estudiado, así como los supuestos implícitos del hecho, ya que en ocasiones resulta que el tipo de análisis empleado no es el más adecuado. 
Métodos cualitativos para estudiar a los usuarios de ...

7.- Establecimiento de las normas de calidad. Es indispensable contar con altas normas de calidad, las que deberán establecerse antes de evaluar el análisis. Existen dos tipos de normas, las de validez (que se refieren a la exactitud, certidumbre o especificidad de los resultados) y las de fiabilidad (que ofrecen pruebas validantes que permiten darle seguridad al estudio).

La fiabilidad en estudios cualitativos se entiende como el grado en el que los datos que se registran son independientes de las circunstancias accidentales del estudio. Esto se refiere a la posibilidad de replicar los estudios; es decir, que alguien que realice un estudio utilizando la misma técnica (en este caso el análisis de contenido) obtenga los mismos resultados. Una manera de asegurar la fiabilidad es tener la certeza de que las categorías que se determinen incluyan el tipo de datos (términos) que corresponden al estudio (Pérez, 1994, pp.77-79).

En cuanto a la validez, ésta representa la medida en que los datos son interpretados en forma correcta; esto concierne a la exactitud, es decir, que todo sea creíble. Para lograr validez en un estudio se deben estimar dos elementos: la medida en que las conclusiones o resultados representan efectivamente la realidad; y si las ideas vertidas por los analistas representan o miden categorías 
La técnica del análisis de contenido y su aplicación en los ...

reales. En general, cualquier estudio, requiere la aplicación de ambas normas.

\section{Ejecución}

La segunda parte para llevar a cabo un análisis de contenido es ejecutar el proyecto ahí donde se encuentran generalmente problemas, muchos de los cuales no fueron considerados por el analista de contenido; como no alcanzar las normas establecidas de antemano para darle validez y fiabilidad al estudio. Lo recomendable es regresar y modificar el proyecto usando como guía el objetivo general de la investigación.

En la ejecución se desarrollan las siguientes acciones:

- Identificar y describir las unidades de registro, los cuales deben ser reproducibles y satisfacer los criterios de validez semántica ahí donde éstos se apliquen.

- Reducir y transformar los datos, dándoles la forma que exige el análisis a la vez que reteniendo toda la información relevante.

- Aplicar procedimientos analíticos sensibles al contexto (construcciones analíticas) para obtener inferencias.

- Analizar e identificar las pautas dentro de las inferencias, verificar las hipótesis concernientes a las relaciones entre éstas y los resultados obteni- 
Métodos cualitativos para estudiar a los usuarios de ...

dos mediante los métodos, y validar pragmáticamente los hallazgos (Krippendorff, 1990, p. 263).

Cuando el universo de estudio sea demasiado grande o bien algunos datos sean inaccesibles, será pertinente reorientar el universo o reducir el nivel de análisis para contar con datos relevantes que le aporten validez y fiabilidad al fenómeno estudiado.

Si existe algún problema con las categorías una posible solución es renombrarlas, ya que podría suceder que éstas no estuvieran perfectamente definidas, con lo que el estudio perdería toda fiabilidad. Para rescatar el estudio se debe optar por eliminarlas o por recodificar los datos mediante otros instrumentos.

En el momento de codificar los datos pueden presentarse una serie de problemas, como que los codificadores estén rescatando datos erróneos, o bien que las instrucciones en el registro no sean muy claras, lo que ocasionaría errores de interpretación entre un codificador y otro.

Los errores más comunes son:

- Registros ausentes. Omisión de registros que no se codificaron.

- Registros que no aparecen en la secuencia establecida previamente.

- Valores ilegítimos, que se producen cuando aparecen categorías que no fueron establecidas. 
La técnica del análisis de contenido y su aplicación en los ...

- Incongruencias originadas por ofrecer datos excluyentes.

- Improbabilidades; se trata de aquellos valores legítimos dentro del contexto estudiado, pero los que, debido al instrumento de medida, no son aplicables porque se salen de la gama de expectativas prevista.

\section{Informe}

El informe es la parte final del análisis de contenido y en la que se presenta una descripción de lo realizado, donde se plasman los motivos por los cuales se efectuó el análisis, el logro alcanzado y, sobre todo, su contribución al área de conocimiento que le corresponda.

Un informe debe cubrir los puntos siguientes:

1. Mencionar el problema general que aborda la investigación, informándole al lector la importancia del estudio.

2. Exponer los antecedentes del problema. Se sugiere incluir una reseña bibliográfica acerca de cómo fue abordado el fenómeno de investigación. Deben consignarse los motivos que llevan a creer que se están ofreciendo nuevos hallazgos.

3. Enunciar los objetivos específicos que pretendían alcanzarse por medio del análisis de contenido, mencionando la elección de los datos, mé- 
Métodos cualitativos para estudiar a los usuarios de ...

todos y diseños, en relación con el fenómeno que se estudió. Informar, en un lenguaje sencillo y resumido, el sistema examinado, los datos, el contexto y, por supuesto, los objetivos de las inferencias presentadas.

4. Justificar por qué se eligieron determinados datos y diseños.

5. Describir claramente los procedimientos adoptados que les permitan ser reproducibles. Anotar la determinación de unidades; el plan de muestreo; las instrucciones de registro en las planillas; la técnica que se debe utilizar en el manejo y análisis de los datos, y los resultados de las pruebas de fiabilidad.

6. Presentar los hallazgos encontrados y su significado en el contexto del fenómeno estudiado. Además, si fuera el caso, los métodos de análisis que no resultaron ser los más adecuados para un estudio de dicha naturaleza.

7. Incluir, a modo de resumen, una evaluación autocrítica del analista de contenido o del investigador que estuvo a cargo. La base de esto dependerá de si se alcanzó el objetivo planteado originalmente; y se describirán los elementos que no estaban contemplados y se enunciarán los resultados alcanzados en relación con la hipótesis planteada. 
La técnica del análisis de contenido y su aplicación en los ...

Ante todo el analista o investigador está obligado a dar a conocer los resultados de su estudio, los cuales pueden ser publicados en alguna revista científica, o bien presentados en algún foro académico $\mathrm{o}$ ante sus pares de forma exclusiva.

\section{Aplicación de la técnica análisis de conteni- do en los planes de estudio de bibliotecolo- gía en México}

Toda vez que se ha descrito el proceso para realizar un análisis de contenido, a continuación se presenta su utilización al examinar los planes y programas de estudio de algunas escuelas de bibliotecología en México.

De acuerdo con la clasificación de análisis de contenido presentada anteriormente, el caso que nos ocupa se basará en el análisis de contenido semántico e incluirá sus tres subclasificaciones: designaciones, atribuciones y aseveraciones. En cuanto al proyecto éste es del tipo básico, y fue utilizado para evaluar ciertos fenómenos en el contexto de los datos existentes.

\section{Proyecto}

A continuación se desarrollan los siete aspectos mencionados anteriormente. 
Métodos cualitativos para estudiar a los usuarios de ...

\section{Aplicación del marco de referencia conceptual} del análisis de contenido. Bajo este aspecto se retomarán dos realidades: la establecida por los aspectos teóricos de la formación de usuarios; y la realidad que se conoció, es decir, si en los planes y programas de estudio de las escuelas de bibliotecología aparecían contenidos relacionados con la formación de usuarios. De ahí que el objetivo del análisis fue determinar la ausencia de aprendizajes relacionados con los programas de formación de usuarios en los planes de estudio de algunas escuelas de educación superior mexicanas que imparten la licenciatura en bibliotecología y disciplinas afines. Para cubrir este objetivo se utilizaron como unidades físicas los planes de estudio de tales escuelas; el requisito que debían cubrir esos documentos fue que incluyeran: la asignatura y su objetivo explícito; el temario desglosado; las actividades de aprendizaje que realizarían; los criterios de acreditación; la bibliografía general, y la bibliografía complementaria.

En un segundo momento se consideró el perfil de egreso como indicador del nivel de involucramiento a partir de los conocimientos y habilidades adquiridos durante la licenciatura acerca de la creación de programas de formación de usuarios. 
La técnica del análisis de contenido y su aplicación en los ...

De acuerdo con estos lineamientos generales, se seleccionaron los siguientes planes curriculares:

- Licenciatura en Bibliotecología, de la Facultad de Filosofía y Letras, de la Universidad Nacional Autónoma de México.

- Licenciatura en Biblioteconomía, de la Escuela Nacional de Biblioteconomía y Archivonomía, de la Secretaría de Educación Pública.

- Licenciatura en Bibliotecología, de la Universidad Autónoma de San Luis Potosí.

2. Búsqueda de los datos adecuados. Se reunieron todos los planes y programas de estudio de las carreras de bibliotecología de las escuelas enunciadas, pues constituyeron los elementos instrumentales (Krippendorff, 1990, p.254) sobre los que se procedió a la identificación posterior de categorías y unidades sintácticas.

3. Búsqueda del conocimiento contextual. Se analizaron, las bases teóricas de la formación de usuarios de la información; y se confrontaron con la fuerte necesidad de llevar a cabo programas de formación de usuarios, pues tan sólo para la población escolarizada en el ámbito nacional se tenían registrados más de 30.2 millones de estudiantes, a los cuales se les debía dotar de habilidades que los enseñaran a desempeñarse en el manejo de la información. Además de otras co- 
Métodos cualitativos para estudiar a los usuarios de ...

munidades igualmente importantes: indígenas, amas de casa, empleados, investigadores, sujetos de la tercera edad.

4. Desarrollo de planes para determinar las unidades y el registro. Las unidades de contexto y de registro se determinaron con base en el contexto real; las categorías y las unidades sintácticas se generaron de acuerdo con el cuerpo teórico de la formación de usuarios.

a. Unidad de contexto. Escuelas que tuvieran sus planes y programas de estudio por escrito.

b. Unidades de registro. Estuvieron representadas por los planes y programas de estudio.

c. Categorías y d) Unidades sintácticas. Para desarrollar este estudio, las categorías y unidades sintácticas utilizadas se derivaron de la obra La formación de usuarios en instituciones de educación superior (Hernández, 1998, pp. 1-26), y están contenidas en el Cuadro 2. 
La técnica del análisis de contenido y su aplicación en los ...

\begin{tabular}{|c|c|}
\hline \multicolumn{2}{|r|}{$\begin{array}{l}\text { Cuadro } 2 \\
\text { Categorías y unidades sintácticas. }\end{array}$} \\
\hline CATEGORÍA & UNIDADES SINTÁCTICAS \\
\hline Usuario & $\begin{array}{l}\text { Lector, población académica, población escolar, pobla- } \\
\text { ción universitaria, investigadores, comunidades de dife- } \\
\text { rentes bibliotecas. }\end{array}$ \\
\hline Información & $\begin{array}{l}\text { Búsqueda de la información, difusión de la información, } \\
\text { uso y acceso de la información, medios de comunica- } \\
\text { ción de la información. }\end{array}$ \\
\hline $\begin{array}{l}\text { Niveles de forma- } \\
\text { ción de usuarios }\end{array}$ & $\begin{array}{l}\text { Comunicación de conceptos relacionados con la infor- } \\
\text { mación (producción, transferencia, organización, bús- } \\
\text { queda, recuperación, servicios y difusión); orientación, } \\
\text { instrucción, habilidades informativas. }\end{array}$ \\
\hline $\begin{array}{l}\text { Etapas para diseñar } \\
\text { programas de for- } \\
\text { mación de usuarios }\end{array}$ & $\begin{array}{l}\text { Definir el problema; determinar el entorno institucional; } \\
\text { determinar el perfil de necesidades de información y ne- } \\
\text { cesidades de formación del usuario meta (evaluación } \\
\text { diagnóstica); establecer los objetivos del programa; ela- } \\
\text { borar los contenidos; seleccionar las técnicas y los me- } \\
\text { dios didácticos; elaborar los medios didácticos; implan- } \\
\text { tar el programa; y evaluar el programa (evaluaciones } \\
\text { formativa y sumativa). }\end{array}$ \\
\hline $\begin{array}{l}\text { Técnicas de la for- } \\
\text { mación de usuarios }\end{array}$ & $\begin{array}{l}\text { Explicación de acuerdo con una determinada necesidad } \\
\text { dentro de la biblioteca (Point of use-Explanation); tuto- } \\
\text { rías; instrucción programada; instrucción asistida por } \\
\text { computadora; cursos formales con valor curricular; con- } \\
\text { ferencias; lectura/demostración; visitas guiadas. Aspec- } \\
\text { tos didácticos y comunicativos de la enseñanza y del } \\
\text { aprendizaje; técnicas de enseñanza y aprendizaje. }\end{array}$ \\
\hline & $\begin{array}{l}\text { Impresos, audios, videos, audiovisuales producidos por } \\
\text { computadora. }\end{array}$ \\
\hline Medios didácticos & $\begin{array}{l}\text { Diseño de medios y auxiliares didácticos, como folletos, } \\
\text { periódicos murales, trípticos, guías de ejercicios para } \\
\text { manejo de cursos o talleres, fotos, además de otros ma- } \\
\text { teriales de apoyo. }\end{array}$ \\
\hline
\end{tabular}


Métodos cualitativos para estudiar a los usuarios de ...

5.- Desarrollo de las instrucciones de codificación. Cabe señalar que un estudio como el que se realizó no tiene antecedentes en el área bibliotecológica mexicana, por lo que se carece de otros parámetros. Al momento de la captura se consignó la mención y entre paréntesis un valor asignado como norma de fiabilidad (ver Tabla 1). Es pertinente mencionar que se consideraron los documentos enunciados tanto en la bibliografía general como en la complementaria, y que en cada caso el análisis realizado se limitó al título de los documentos, no a sus contenidos.

6.- Búsqueda de procedimientos justificados según el contexto. Se estableció un apartado para cada escuela considerando los elementos perfil de egreso e identificación de las asignaturas, ambos de la Línea de Servicios.

El procedimiento general consistió en lo siguiente:

- Revisión de los planes y programas de estudio de las diferentes carreras.

- Revisión del perfil de egreso para cada plan de estudio.

- Identificación de las asignaturas relativas a la Línea de Servicios dentro de los mapas curriculares de cada escuela.

- Revisión de cada asignatura, de las que se rescató el objetivo, el temario (registrando sólo el que fue- 
La técnica del análisis de contenido y su aplicación en los ...

ra relativo a las categorías enunciadas), la revisión de las actividades de aprendizaje, la acreditación, y por último, la bibliografía que se utilizaría.

7.- Establecimiento de las normas de calidad. Como se estableció anteriormente, las normas de calidad fueron la fiabilidad y la validez. En este caso la fiabilidad se logró derivando las categorías a partir de un marco teórico consistente. Asimismo, para que hubiera una mayor objetividad, a cada unidad sintáctica se le concedió un valor numérico dependiendo de la parte en la que aparecía dentro del programa de estudio; esto con el fin de determinar el nivel de impacto causado dentro del programa de las asignaturas. La Tabla 1 nos presenta los valores asignados:

\begin{tabular}{|c|c|}
\hline \multicolumn{2}{|c|}{$\begin{array}{c}\text { Tabla } 1 \\
\text { Valores por ubicación en el programa }\end{array}$} \\
\hline Elementos analizados & $\begin{array}{c}\text { Valores } \\
\text { asignados }\end{array}$ \\
\hline Objetivo de la asignatura & 6 \\
\hline Temario: unidad o tema & 5 \\
\hline Temario: subtemas & 4 \\
\hline Actividades de aprendizaje & 3 \\
\hline Criterios de acreditación & 2 \\
\hline Bibliografía básica y/o complementaria & 1 \\
\hline
\end{tabular}


Métodos cualitativos para estudiar a los usuarios de ...

En relación con la validez o exactitud, ésta se vio reflejada al identificar los datos dentro de los mapas curriculares de cada escuela, y al analizar los programas de estudio, que fueron las fuentes directas para la recolección de datos. Para la reducción y transformación de los datos se diseñaron formas de registro de información que los mostraban.

La validez se verificó en el momento en que los datos representaron lo que a priori fue verdadero, o lo que ya se presumía como válido "Un análisis de contenido es válido en la medida en que sus inferencias se sostengan frente a otros datos obtenidos de forma independiente" (Krippendorff, 1990, p.228).

El desarrollo del proyecto permitió comprobar la factibilidad de aplicar la técnica análisis de contenido a estudios relacionados con la formación de usuarios.

\section{Ejecución}

El proceso de ejecución fue largo y minucioso, pues se analizaron cuidadosamente los planes de estudio de las licenciaturas en Bibliotecología y Estudios de la información de la UNAM, la licenciatura en Biblioteconomía de la ENBA y la licenciatura en Bibliotecología e Información de la UASLP. En un primer momento se identificaron los perfiles de egreso en los rubros de conocimientos, habilidades $\mathrm{y}$ actitudes que enunciaran la formación de usua- 
La técnica del análisis de contenido y su aplicación en los ...

rios, los cuales se retomaron al final del análisis de los datos obtenidos.

El siguiente paso consistió en consignar en los cuadros de análisis de resultados por asignaturas, las categorías y unidades sintácticas encontradas en los elementos analizados, anotando también el valor correspondiente de acuerdo con cada caso.

\section{Escuela Nacional de Biblioteconomía y Archivono- mía}

En el caso de la Licenciatura en Biblioteconomía se analizaron cuatro de las seis asignaturas de la línea de servicios; éstas fueron: Servicios al público, 1er. semestre; Uso y manejo de fuentes de información, 3er. semestre; Usuarios de la información, $4^{\circ}$ semestre; y Promoción de los servicios, $7^{\circ}$ semestre. No consideramos el elemento de bibliografía complementaria porque no fue reportado en las asignaturas analizadas.

\section{Colegio de Bibliotecología}

En el caso de la Licenciatura en Bibliotecología y Estudios de la Información se analizaron cinco de las siete asignaturas de la línea de servicios, éstas fueron: Fundamentos de los servicios de la información, 1er. semestre; Servicios bibliotecarios y de información, $4^{\circ}$ semestre; Consulta I, $5^{\circ}$ semestre; Consulta II, $6^{\circ}$ semestre; y Usuarios de la Informa- 
Métodos cualitativos para estudiar a los usuarios de ...

ción, $7^{\circ}$ semestre. Es pertinente mencionar que no fueron considerados los elementos de Actividades de aprendizaje y Criterios de acreditación, pues no enunciaban conceptos que proporcionaran una idea sobre cómo llevar a cabo determinadas actividades de aprendizaje o formas de evaluación.

\section{Escuela de Bibliotecología e Información}

En el caso de la Licenciatura en Bibliotecología e Información de la Universidad Autónoma de San Luis Potosí, se analizaron tres de las ocho asignaturas de la línea de servicios, éstas fueron: Usuarios de la Información, $5^{\circ}$ semestre; Servicios de información I, $6^{\circ}$ semestre; y Servicios de Información II, $7^{\circ}$ semestre. Cabe mencionar que el elemento de Criterios de acreditación no fue considerado debido a que sólo presentan porcentajes los aspectos tales como investigaciones, ensayos y resúmenes.

\section{Informe de resultados}

A continuación se presenta el análisis cuantitativo por categorías.

\section{Categoria: Usuarios}

La unidad sintáctica usuario obtuvo el mayor puntaje en las tres escuelas analizadas: un total de 328 puntos de valor, lo que refleja que el término fue elegido correctamente. El usuario es un elemento 
La técnica del análisis de contenido y su aplicación en los ...

constante en las asignaturas analizadas en la línea de servicios de las tres escuelas, y es considerado importante y vital para el estudiante de bibliotecología en el ámbito nacional.

La unidad sintáctica comunidades obtuvo un alto puntaje. Cliente no se consideró originalmente, así que fue una aportación a esta categoría.

La categoría usuarios consignó seis de las ocho unidades sintácticas, lo que refleja que las asignaturas analizadas presentan contenidos relativos a uno de los temas que nos ocupan y que está presente constantemente en la línea de servicios.

\section{Categoría: Información}

La unidad sintáctica Información obtuvo 482 puntos, la mayor puntuación de todas las unidades sintácticas y de todas las categorías, su importancia radica en que es la materia prima de trabajo para el estudiante de bibliotecología; naturalmente la Información se encuentra adecuadamente sustentada, en los planes de estudio de las tres escuelas analizadas.

La unidad sintáctica Búsqueda de la información tuvo presencia en dos escuelas, de lo que se infiere una preocupación por dotar a sus estudiantes de los conocimientos teóricos y prácticos que les permitan llevar a cabo esta actividad. Por su parte, la unidad sintáctica Difusión de la información sólo apareció en una escuela. 
Métodos cualitativos para estudiar a los usuarios de ...

La unidad sintáctica Uso y acceso de la información se encuentra poco representada en relación con los contenidos temáticos. La unidad sintáctica Medios de comunicación de información tuvo solamente un punto, ambas tendrán que ser reforzadas.

La categoría Información consignó el total de las cinco unidades sintácticas establecidas. Los planes y programas de estudio le han dado importancia a la Información, y coinciden en la necesidad de que el bibliotecario que está en formación sea capaz de manejar la información para poder transmitirle su uso y aprovechamiento a los usuarios y que éstos puedan resolver sus problemas en materia de información

\section{Categoría: Niveles de formación de usuarios}

La categoría Niveles de formación de usuarios alcanzó 62 puntos de valor, la mayor parte de ellos fue consignada por la ENBA en sus cuatro unidades sintácticas, lo que refleja que las otras escuelas no consideran estos aspectos como relevantes.

La unidad sintáctica Orientación obtuvo el menor valor de esta categoría. La unidad sintáctica de Comunicación de conceptos relacionados con la información obtuvo puntaje en las tres escuelas, lo que permite inferir que los estudiantes de bibliotecología en México cuentan con alguna idea sobre este primer nivel de formación de usuarios. La unidad 
La técnica del análisis de contenido y su aplicación en los ...

sintáctica Instrucción, considerada el tercer nivel de la formación de usuarios obtuvo la evaluación más alta de esta categoría, y se consignó en dos escuelas.

Es indispensable que la categoría Niveles de formación de usuarios se refuerce en contenidos, actividades de aprendizaje y bibliografía, para que el estudiante de bibliotecología en México sea capaz en los tres niveles de formación de usuarios (orientación, instrucción e importancia de la información) destinados a la comunidad que atiende su biblioteca.

Categoría: Etapas para diseñar programas de formación de usuarios

La categoría Etapas para diseñar programas de formación de usuarios obtuvo un total de 210 puntos de valor, distribuidos en cinco unidades sintácticas. Sin embargo, el total de unidades era de diez, es decir, los planes y programas de estudio carecen de contenidos relacionados con Definir el problema, Determinar el entorno institucional, Elaborar los contenidos, Elaborar los medios didácticos y Evaluar el programa. Los cuales son sustantivos para elaborar y aplicar un programa de formación de usuarios.

La unidad sintáctica Etapas para diseñar programas de formación de usuarios está adecuadamente sustentada en una escuela. La unidad sintáctica Determinar el perfil de necesidades de información y de 
Métodos cualitativos para estudiar a los usuarios de ...

formación de usuario meta (evaluación diagnóstica) fue la que obtuvo el mayor número de puntos, 168, y está presente en las tres escuelas, analizadas; es decir, existe una preocupación por dotar a sus estudiantes de los conocimientos que necesitan para identificar las necesidades de información y poder responder a la nueva orientación bibliotecológica de conocer a sus usuarios, para proporcionarles los servicios que respondan a sus demandas de información. A manera de observación, se puede decir que hubiera sido conveniente separar las necesidades de formación, de las de información para obtener otro tipo de resultados como los relacionados con el perfil de necesidades de formación de usuarios. Las necesidades de formación se refieren a las actividades que debe realizar un sujeto para buscar y localizar la información que necesita, por lo que son la base para diseñar programas de formación.

Las unidades sintácticas establecer los objetivos del programa, seleccionar las técnicas y los medios didácticos e implementar el programa, sólo fueron consignadas en una escuela.

Para diseñar programas de formación de usuarios es indispensable que el estudiante de bibliotecología en México tenga una visión completa de todas las etapas y no sólo de algunas de ellas. 
La técnica del análisis de contenido y su aplicación en los ...

\section{Categoría: Técnicas de la formación de Usuarios}

La categoría Técnicas de la formación de usuarios obtuvo sólo 58 puntos de valor en cinco unidades sintácticas de las once planteadas. En esta categoría se agregaron cinco unidades que no habían sido consideradas, y que fueron aportadas por una escuela, éstas fueron: mesa redonda, debates, taller, plática y seminario.

La unidad sintáctica que obtuvo la mayor puntuación fue la de Visitas guiadas. Técnicas de la formación de usuarios fue mencionada en dos escuelas; Explicación de acuerdo con una determinada necesidad dentro de la biblioteca (point of use explanation), $y$ Cursos formales con valor curricular, obtuvieron menciones en una sola escuela.

Traducida esta categoría en contenidos, dotaría al estudiante de bibliotecología de las diferentes técnicas que sirven en la formación de usuarios, con lo que podrían ser aplicadas de acuerdo con las características de la comunidad a la que atiende la biblioteca, implicada.

\section{Categoría: Medios didácticos}

La categoría Medios didácticos obtuvo 75 puntos, de los cuales 63 corresponden a una de las escuelas. Se consignaron siete de las ocho unidades sintácticas. La unidad sintáctica Diseño de medios obtuvo la mayor cantidad de puntos; Audiovisuales obtuvo men- 
Métodos cualitativos para estudiar a los usuarios de ...

ción en dos escuelas; Medios didácticos, auditivos, visuales, por computadora e impresos obtuvieron menciones en una sola escuela.

Es preocupante que al estudiante de bibliotecología no se le proporcionen en México, conocimientos relativos al uso y aprovechamiento de los diferentes medios didácticos en cuanto a la formación de usuarios.

El medio más utilizado es el impreso, sin embargo debido al uso cada vez más frecuente que hace el usuario de los recursos electrónicos de información, se hace indispensable dotarlo de habilidades que le permitan utilizar y aprovechar desde los catálogos electrónicos hasta las bases y bancos de datos de libre acceso para la población escolar, naturalmente de acuerdo con el nivel escolar en el que se encuentre inserto.

\section{Análisis comparativo entre las categorías}

La categoría Información fue la que tuvo mayor puntaje, el hecho puede estar relacionado con ser la materia prima con la que trabaja el bibliotecario, en comparación con el Usuario, categoría que esperábamos que tuviera el mayor puntaje. La categoría Etapas para diseñar programas de formación de usuarios obtuvo el tercer lugar de acuerdo con los puntajes. Las categorías Niveles de formación de usuarios, Técnicas de la formación de usuarios y Medios 
La técnica del análisis de contenido y su aplicación en los ...

didácticos alcanzaron puntajes menores de cien, de lo que podría inferirse que son elementos no considerados en general para formar a los profesionales en las escuelas de bibliotecología, lo que genera visiones incompletas en cuanto a la formación de usuarios. Esto ha hecho que los diferentes programas de formación de usuarios que se han implantado, no se hayan mantenido vigentes en aquellas instituciones educativas, donde en algún momento tuvieron presencia.

\section{Inferencias}

De acuerdo con el proceso de análisis de contenido, la última parte es la que se refiere a generar las inferencias, las cuales derivan del análisis cuantitativo, a continuación se presentan las inferencias por escuela y por asignatura.

\section{Escuela Nacional de Biblioteconomía y Archivonomía}

\section{Servicios al Público}

Las categorías usuario e información no están suficientemente representadas puesto que sólo se menciona un término en cada una, para el primer caso es usuario y para el segundo, información. 
Métodos cualitativos para estudiar a los usuarios de ...

Los niveles de formación están representados básicamente por el término Orientación.

De la categoría etapas para diseñar programas de formación de usuarios sólo aparece una unidad sintáctica: Determinar el perfil de necesidades de información y de formación del usuario meta (evaluación diagnóstica).

En la categoría técnicas de la formación de usuarios, con 11 unidades sintácticas desarrolladas, sólo aparece una de ellas: visitas guiadas.

No existe una categoría que sobresalga, la distribución es equilibrada.

Uso y manejo de fuentes de información.

El usuario no está aquí bien representado, pues aparece sólo en el temario.

La información aparece aquí en cuatro de las cinco unidades sintácticas planteadas originalmente y también aparece en la mayoría de los elementos analizados.

En la categoría niveles de formación fueron consignados los tres niveles Comunicación de conceptos relacionados con la información, Orientación e Instrucción.

En la categoría Etapas para diseñar programas de formación de usuarios se encontró una unidad sintáctica de diez: Determinar el perfil de necesidades de 
La técnica del análisis de contenido y su aplicación en los ...

información y de formación del usuario meta (evaluación diagnóstica).

Las visitas guiadas son consideradas en dos vertientes, la primera como una actividad de aprendizaje, y la segunda como un criterio de evaluación.

\section{Usuarios de la información}

En la categoría Usuarios se consignan por primera vez dos unidades sintácticas: población universitaria e investigador. Información se encuentra muy bien sustentada en la mayoría de los elementos analizados mediante la aparición de una sola unidad sintáctica: información.

La categoría niveles de formación de usuarios y sus unidades sintácticas: Comunicación de conceptos relacionados con la información, Orientación e Instrucción, se encuentran presentes en el elemento, temario.

Etapas para diseñar programas de formación de usuarios sólo registra dos de diez unidades sintácticas: Etapas para diseñar programas de formación de usuarios y Determinar el perfil de necesidades de información y de formación del usuario meta (evaluación diagnóstica).

En la categoría de Técnicas de formación de usuarios se mencionan cuatro unidades sintácticas de once: Explicación de acuerdo con una determinada necesidad dentro de la biblioteca (point of use explana- 
Métodos cualitativos para estudiar a los usuarios de ...

tion), Cursos formales con valor curricular, Conferencias y Visitas guiadas, se introducen cinco unidades nuevas, mesa redonda, debates, taller, plática y seminario, lo que produce un total de dieciséis unidades.

La categoría de técnicas de información consigna cuatro unidades sintácticas, Medios didácticos, impresos, visuales y Diseño de medios y auxiliares didácticos.

\section{Promoción de los servicios}

En la categoría usuarios se consigna por primera vez la unidad sintáctica: Comunidades.

La unidad sintáctica Información es incluida como una actividad de aprendizaje. En la categoría Etapas para diseñar programas de formación de usuarios se consignan por primera vez las unidades sintácticas Establecer objetivos del programa, Seleccionar las técnicas y los medios didácticos e Implementar el programa; cabe aclarar que se refieren a programas de promoción de los servicios.

La categoría medios didácticos, se encuentra bien sustentada en el temario en cuanto a tipificación o descripción de éstos.

Las actividades de aprendizaje se enfocan a establecer estrategias para la formación de usuarios. 
La técnica del análisis de contenido y su aplicación en los ...

\section{Colegio de Bibliotecología}

Fundamentos de los servicios de información

La categoría usuario consideró la unidad sintáctica Comunidades. En la categoría Información se consignaron las unidades sintácticas Información y Medios de comunicación de la información, de un total de cinco unidades sintácticas. La unidad sintáctica Información consignó el más alto puntaje. Por último, la unidad sintáctica Medios de comunicación de la información consignó un texto.

Servicios Bibliotecarios y de Información

La unidad sintáctica Usuarios se encuentra adecuadamente sustentada. Por su parte, Información no consignó ningún documento.

Las técnicas de la formación de usuarios registró un documento. El término audiovisuales aparece como un subtema; sin embargo los contenidos se orientan desde la perspectiva de tipo de colecciones y no bajo la óptica de medios didácticos.

\section{Consulta I}

Las unidades sintácticas Usuario e Información consignaron un alto número de puntos de valor. La categoría Usuario sólo considera una de ocho.

En la categoría Niveles de formación de usuarios se consignaron las unidades sintácticas de Orienta- 
Métodos cualitativos para estudiar a los usuarios de ...

ción e instrucción, pues se encontraron contenidos temáticos en el programa; sin embargo no aparecen documentos que sustenten éstos.

La categoría Etapas para diseñar programas de formación de usuarios sólo consignó la unidad sintáctica: Determinar el perfil de necesidades de información y de formación del usuario meta (evaluación diagnóstica), que aparece en el programa como un subtema.

La categoría Medios didácticos consignó la unidad sintáctica Audiovisuales, bajo la óptica de tipo de material.

\section{Consulta II}

De la categoría Información aparecieron dos unidades sintácticas de cinco, Información y Búsqueda de la información, cuyos contenidos temáticos se ven reflejados en toda la asignatura.

La unidad sintáctica Información obtuvo el valor más alto; Búsqueda de información fue la segunda que tuvo un puntaje alto.

La categoría Etapas para diseñar programas de formación de usuarios sólo registró una unidad sintáctica de diez, Determinar el perfil de necesidades de información y de formación del usuario meta (evaluación diagnóstica). 
La técnica del análisis de contenido y su aplicación en los ...

\section{Usuarios de la información}

Aparece por primera vez la unidad sintáctica Población académica, Comunidades, que consignó puntos en los elementos de Temario y Bibliografía.

Usuarios, Información, Búsqueda de la información y Determinar el perfil de necesidades de información y de formación del usuario meta (evaluación diagnóstica) se encuentran adecuadamente sustentadas.

Las categorías Usuarios e Información, consignaron un alto número de puntos; su comportamiento se mantuvo igual que en la asignatura de Consulta II.

\section{Escuela de Bibliotecología e Información}

\section{Usuarios de la información}

Las unidades sintácticas Usuario, Información y Determinar el perfil de necesidades de información y de formación del usuario meta (evaluación diagnóstica) se encuentran debidamente sustentadas.

Población universitaria es consignada por primera vez en el análisis de esta escuela.

Sobre la categoría Información aparecieron dos (información y uso y acceso de la Información) de las cinco unidades sintácticas, y de Etapas para diseñar programas de formación de usuarios, dos de diez: Etapas para diseñar programas de formación de usuarios, y Determinar el perfil de necesidades de infor- 
Métodos cualitativos para estudiar a los usuarios de ...

mación y de formación del usuario meta (evaluación diagnóstica).

La unidad sintáctica Etapas para diseñar programas de formación de usuarios es consignada en el elemento actividades de aprendizaje.

\section{Servicios de Información I}

Las unidades sintácticas Usuario, Información y Comunicación de conceptos relacionados con la información (producción, transferencia, organización, búsqueda, recuperación, servicios, difusión) están debidamente sustentadas, pues aparecen en los elementos analizados.

La categoría usuario sólo consignó la unidad sintáctica usuario de un total de ocho; niveles de formación de usuarios consignó la unidad sintáctica Comunicación de conceptos relacionados con la información de cuatro unidades sintácticas. Etapas para diseñar programas de formación de usuarios consignó dos unidades sintácticas Etapas para diseñar programas de formación de usuarios y Determinar el perfil de necesidades de información y de formación del usuario meta (evaluación diagnóstica) de un total de diez; y Medios didácticos consignó la unidad sintáctica Diseño de medios y auxiliares didácticos de ocho unidades sintácticas en esta categoría. 
La técnica del análisis de contenido y su aplicación en los ...

\section{Servicios de Información II}

Las unidades sintácticas Usuario, Información y Comunicación de conceptos relacionados con la información (producción, transferencia, organización, búsqueda, recuperación, servicios, difusión) están debidamente sustentadas, pues aparecen en los elementos: Objetivo de la asignatura, Temario y Bibliografía.

La categoría información consignó dos de cinco unidades sintácticas información y difusión de la información, y la categoría de Niveles de formación de usuarios la unidad sintáctica Comunicación de conceptos relacionados con la información consignó un total de cuatro unidades sintácticas de esta categoría.

\section{Perfiles de egreso versus valores obtenidos}

El perfil de egreso de la Licenciatura en Biblioteconomía obtuvo el valor más alto de las tres escuelas, esto se refleja de forma equilibrada en las unidades sintácticas consignadas, por lo que los conocimientos, habilidades y actitudes están reflejados en los contenidos de las asignaturas analizadas; sin embargo algunos de ellos deben ser reforzados. Sin embargo debe recordarse que el enfoque de esta escuela se orienta fuertemente hacia la línea de servicios, y que la formación de usuarios forma parte de ella.

El perfil de egreso de la Licenciatura en Bibliotecología y Estudios de la Información contó con 
Métodos cualitativos para estudiar a los usuarios de ...

más de cuatrocientos cuarenta puntos, cifra cercana a la de la ENBA; sin embargo, el perfil se inclina a otros aspectos: una tipificación más amplia del usuario y la información como materia prima del trabajo bibliotecológico, por ello resulta lógico que la formación de usuarios no sea sustentada de forma similar a como lo es en la escuela anterior. En relación a los conocimientos, habilidades y aptitudes que debe tener el egresado de esta escuela es recomendable que los contenidos que enuncian sobre la formación de usuarios sean verdaderamente incluidos, y también los que aparecen deben ser ampliados y reforzados, además de actualizar la bibliografía básica y la complementaria.

El perfil de la Licenciatura en Bibliotecología e Información de la Universidad Autónoma de San Luis Potosí obtuvo más de la mitad de puntos registrados en las otras dos escuelas. Sin embargo hay que considerar el problema desde dos vertientes; primera, los contenidos temáticos no aparecían desglosados como en las otras escuelas y, segunda, dos de las categorías no consignaron ningún punto, éstas fueron técnicas y medios didácticos. En relación con el perfil de egreso, éste enlista una serie de actividades y sólo una enuncia la formación de usuarios. 
La técnica del análisis de contenido y su aplicación en los ...

En resumen, ninguna escuela les ofrece a sus estudiantes todos los conocimientos para planear, elaborar y aplicar un programa de formación de usuarios, por ello se plantea la necesidad de insertar los contenidos faltantes y de fortalecer aquellos que se requieran, con miras a que el profesional de bibliotecología e información cuente con los elementos necesarios. Sin olvidar incluir en la bibliografía básica la obra La formación de usuarios de información en instituciones de educación superior.

\section{Obras consultadas}

Diccionario de la Lengua Española, Real Academia Española (2001), Vigésima segunda edición, España, Real Academia Española.

Hernández Salazar, P. (1998), La formación de usuarios en instituciones de educación superior, México, UNAM, Centro Universitario de Investigaciones Bibliotecológicas.

--, Solís Valdespino, B.E. (2006), “Acercamiento al análisis de contenido como técnica para estudiar la formación de usuarios", en Hemera: revista de ciencias bibliotecológica y de la información, 4; 4(7):32-63.

Krippendorff, K. (1990), Metodología de análisis de contenido: teoría y práctica, Barcelona, Ediciones Paidós. 
Métodos cualitativos para estudiar a los usuarios de ...

Martínez Rider, R. M. (1999), “Impacto de los resultados de la congruencia externa en el currículo de la Escuela de Bibliotecología e Información de la Universidad Autónoma de San Luis Potosí”, en Liber: Revista de Bibliotecología, septiembre - diciembre, 1(3), 4 - 8 .

Muñoz, J.; Velarde, J. (2000), Compendio de epistemología, Madrid, Editorial Trotta.

Pemberto, M.; Nugent, C. R. (1995), "Information studies: raising field, convergent curricula", en Journal of Education for Library and Information Science, 36(2), $126-138$.

Pérez Serrano, G. (1994). Investigación cualitativa: retos e interrogantes, Madrid, Muralla.

Plan Nacional de Desarrollo 2001-2006: Primer informe de ejecución 2001, 1.2 Educación http://www.inegi.gob.mx/difusión/espanol/fpnd. html)

Solís Valdespino, B. E. (2006) La formación de usuarios en la educación bibliotecológica mexicana (nivel licenciatura), tesis de Maestría para la obtención del Título de Maestra en bibliotecología y estudios de la información, UNAM, Facultad de Filosofía y Letras. 
Métodos cualitativos para estudiar a los usuarios de la información. La edición consta de 150 ejemplares. Coordinación editorial, Zindy E. Rodríguez Tamayo. Formación editorial, Carlos Ceballos Sosa. Revisión especializada, Francisco X. González y Ortíz. Centro Universitario de Investigaciones Bibliotecológicas/UNAM. Fue impreso en papel cultural ahuesado de 90 gr. en Producciones Editoriales Nueva Visión, ubicados en Juan A. Mateos, número 20, Col. Obrera, México D. F. Se terminó de imprimir en el mes de mayo de 2008. 